\title{
THE TELENCEPHALON OF SELACHIANS ${ }^{1}$
}

\author{
J. B. JOHNSTON
}

\author{
University of Minnesota \\ EIGHTY-FIVE FIGURES
}

\section{CONTENTS}

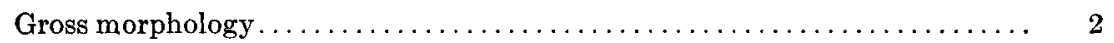

Gray masses............................................... 8

1. Bulbus olfactorius ............................. 8

2. Area olfactoria medialis ........................ 8

3. Area olfactoria lateralis......................... 9

4. Area superficialis basalis ........................ 9

5. Primordium hippocampi....................... 10

6. Primordium pallii somatici........................ 12

7. Nucleus praeopticus............................ 12

Fiber tracts and functional relations of the gray masses.............. 12

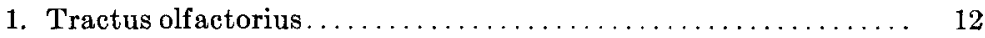

2. Tertiary olfactory fibers........................ 15

a. Intrinsic tracts in the telencephalon............... 15

b. Tracts leading to the diencephalon............... 16

3. Tracts connected with the primordium hippocampi......... 17

a. Tractus pallii............................ 18

b. Tractus cortico-habenularis.................. 18

c. Commissura hippocampi .................... 19

d. Commissura pallii posterior .................. 19

e. Fornix .................................. 20

4. Tracts connected with the primordium pallii somatici........ 23

a. Tractus thalamo-corticalis................... 24

b. An olfacto-somatic correlation tract............. 26

c. Corpus callosum......................... 26

d. Somatic projection tract..................... 27

e. Tractus taeniae.......................... 28

1 Neurological studies from the Institute of Anatomy, University of Minnesota, no. 14. This is the fourth of a series of papers on the evolution of the cerebral hemispheres, of which there have appeared:

The morphology of the forebrain vesicle in vertebrates, this journal, vol. $19,1909$.

A note on the forebrain of Chimaera, Anat. Anz., vol. 21, p. 233, 1910.

The evolution of the cerebral cortex, Anat. Rec., vol. 4, no. 4, 1910.

THE JOURNAL OF COMPARATIVE NEUROLOGY, VOL, 21, No. 1.

MARCF, 1911 . 
Summary of certain fiber complexes.......................... 33

1. Commissura pallii anterior ........................ 33

2. Basal forebrain bundle......................... 34

3. Stria medullaris .............................. 34

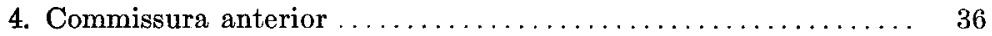

General discussion.................................. 37

Relations of gray columns in diencephalon and telencephalon..... 47

General morphology of the telencephalic fiber tracts........... 48

The pallial primordia and the anterior pallial commissure........ 50

Area superficialis basalis........................... 52

Summary of results . . . . . . . . . . . . . . . . . . . . . . . . . . . . . 54

The present study is based upon Weigert sections of the brains of Acanthias vulgaris, as identified at the Naples station, Scyllium canicula, Scyllium stellare, Raja sp.; entire brains of these and other selachians; a series of Weigert sections of the brain of Chimaera and a complete series of preparations of embryos of Squalus acanthias (see this Journal, vol. 19, 1909).

\section{GROSS MORPHOLOGY}

The first thing essential to an understanding of the telencephalonis to know its limits. This can not bedetermined from the study of the adult structures alone, but chiefly from the facts of development. This has been fully discussed in the first paper of this series. It was shown there that the line of demarcation between the diencephalon and telencephalon was indicated by the velum transversum dorsally and by the caudal border of the chiasma-ridge ventrally. In the third paper emphasis was laid on the fact that this boundary line is marked dorsally not by the point at which the velum transversum appears in a median sagittal section but by the place of attachment of the velum to the lateral nervous walls. The velum is large and easily examined in selachians so that there is not the slightest room for doubt as to the caudal limit of the telencephalon in these fishes. The velum has its point of attachment a short distance in front of the nucleus habenulae. The di-telencephalic boundary is therefore indicated by a line connecting this point with the caudal border of the chiasma-ridge as shown in the accompanying fig. 78. The exact limits of the thalamic and telencephalic gray are discussed later. 
It is entirely clear that the slender region which authors commonly call "praethalamus" lies within the telencephalon. It must therefore have a different interpretation from that heretofore given it. This interpretation will be given below on the basis of the fiber connections of this area.

The telencephalon in selachians is more or less clearly bi-lobed. In all members of this group the olfactory bulb is borne on an olfactory peduncle which may be long, as in Hexanchus, Carcharias, Squatina, or short as in Galeus, Scyllium and Pristiurus. The olfactory bulbs, it is well known, contain lateral expansions of the brain ventricle, and the length of the olfactory peduncle is a measure of the degree of evagination or of the extent to which the evaginated lateral lobes have been stretched. Although in all selachians the bi-lobed form of the telencephalon is well marked owing to the size of the olfactory bulbs and the length of the peduncles, the division of the body of the telencephalon into two lobes is much obscured by the secondary fusion of the medial apposed surfaces in all but the most primitive forms. In Scymnus, as the excellent description by Burckhardt makes clear, the two lateral lobes remain distinct and are united to one another below and in front only by a thickened lamina terminalis as is the case in most other classes of vertebrates. This is true also of the brain in early stages of development of all selachians thathave been studied. In adult Scymnus the lateral lobes extend forward and are flattened on their medial surfaces where they are in contact. In all other selachians, these apposed surfaces are fused together to a greater or less extent. In such forms as Heptanchus, Hexanchus and Acanthias the incomplete fusion leaves a deep and prominent fissure on the ventro-rostral surface between the two lobes. In such forms as Raja, Trygon, Myliobatis, Mustelus, Sphyrna and Scoliodon the fusion is more complete and the grooveis nearly or quite obliterated. These facts are illustrated in figs. 1, 2, 3, 4, 7 and 8. This secondary fusion of the lateral lobes in the selachian brain was pointed out by Wilder as early as 1875 and has recently been commented upon independently by the present writer ('06). Upon the dorsal surface of the telencephalon of most selachians is to be seen a more or less prominent pit from which 
a slender canal occupied by blood vessels leads down between the lateral lobes. This canal has been given the name of recessus neuroporicus externus by Sterzi. It meets a more or less prominent projection rostrad from the median ventricle. This is the recessus neuroporicus internus. It is very long and slender in Acanthias and is readily recognizable in the brains of all forms studied by the writer. The meeting-point of the external canal and the internal pit is believed to be the point, called recessus neuroporicus in all other vertebrates, where the brain remained longest in connection with the ectoderm. The recessus neuroporicus externus represents, or is the vestige of, the primary median sagittal fissure between the two lobes, as seen in Scymnus. It is of interest both on this account and as marking the location of the recessus neuroporicus.

In certain selachians a third vestige of the sagittal fissure is to be found in addition to the superficial groove and the recessus neuroporicus externus. In sagittal sections of the telencephalon of Scyllium stellare (fig. 5) a narrow cleft is found on the ventral surface of the forebrain through which blood vessels and the paired $\mathrm{N}$. terminalis of Locy penetrate to the tissues lateral to the lamina terminalis. This cleft meets the recessus neuroporicus externus in front of the lamina terminalis, and the dorsal canal and ventral cleft together constitute a slender sagittal fissure similar to and probably homologous with the sagittal fissure of the frog's brain. Moreover, this fissure with its dorsal and ventral openings serves to bound the area of secondary fusion mentioned above. It is only the area rostral to this fissure which has undergone secondary fusion. It will be shown later that the thick nervous roof dorsal and caudal to the recessus neuroporicus externus is due to the hypertrophy of a primary area of continuity of the lateral lobes occupied by a commissure. The lamina terminalis presents a similar thickening related to the anterior commissure (see, e.g., Scymnus).

There exist, then, in the telencephalon of selachians primary lateral lobes which have been secondarily more orless completely fused in front. These lateral lobes arise during development by the evagination of the lateral walls of the first segment of the neu- 
ral tube as do the cerebral vesicles in higher vertebrates. It is clear that the cavity of each lateral lobe is to be regarded as a lateral ventricle and its communication with the median ventricle as the foramen interventriculare.

It is now to be noticed that not all of the telencephalon enters into these lateral lobes. Brain morphologists must have a thorough understanding regarding the boundary between the telencephalon and diencephalon before any intelligent and profitable discussion of forebrain morphology is possible. I shall assume here the correctness of the conclusions already published on this subject. The more commonly accepted view regarding the telencephalon of man is that expressed in the BNA, namely, that the telencephalon consists of two lateral lobes or hemispheres whose ventricles communicate with the median ventricle by the interventricular foramina. The median or non-evaginated part of the brain surrounding this median ventricle belongs wholly to the diencephalon. The telencephalon has no median or nonevaginated portion. The view held by the writer is that the walls surrounding the anterior portion of this median ventricle and including the chiasma-ridge and the interventricular foramina belong to the telencephalon. This conclusion was based upon the study of the structure and development of the brain in nearly all classes of vertebrates and upon this question the selachians furnish the clearest evidence.

In the selachian brain the portion which must be taken from the diencep halon and assigned to the telencephalon is the somewhat slender portion which has been called by Edinger' ('08) and others the "praethalamus." This portion of the telencephalon which is not evaginated to help form the lateral lobes I have called the telencephalon medium. It consists of important masses of gray matter and is traversed by the fiber tracts connecting the telencephalon with the lower parts of the nervous system. The paired massive walls are connected with one another below by the lamina terminalis in which lies the anterior commissure as in all vertebrates. Dorsally the median ventricle is roofed by a tela telencephali which, together with the tela diencephali, makes up the tela chorioidea superior. The in-folding of the tela known as the velum 
transversum divides it into its telencephalic and diencephalic portions. The line of attachment of the tela telencephali to the massive walls is the same as the taenia fornicis in higher vertebrates. The line of attachment of the tela diencephali of course retains the name taenia thalami.

The rostral portion of the median ventricle is roofed by the massive pallium which in higher vertebrates becomes the hippocampal formation (see following pages). The taenia fornicis runs along the dorsal border of the lateral walls and continues along the caudal border of the massive pallium to meet its fellow (figs. 7, 12,45-50).

The degree of divergence of the olfactory peduncles and bulbs differs in different species. This is perhaps dependent upon the form of the head and the position of the nasal sacs with relation to the brain. In some forms the bases of the peduncles are wide apart but the bulbs lie nearly straight forward. This condition is due to the large size of the medial olfactory nuclei which occupy the medial fused walls described above. Sphyrna offers an example of widely separated and widely divergent olfactory peduncles, while Carcharias has the peduncles widely separated at the bases but not divergent. The position of the recessus neuroporicus externus is also affected by the degree of development of the fused medial walls. In primitive forms (Scymnus, Heptanchus, Hexanchus) it is situated rostrally between the lateral lobes (figs. 6, 7, 81). In Scyllium, Raja, Mustelus, Carcharias, Myliobatis and others it is pushed well up on the dorsal surface by the great growth of the medial olfactory nuclei (figs. 2,4).

The position of the external origin of the $\mathrm{N}$. terminalis of Locy is to be explained by reference to these various conditions of the secondary fusion and the sagittal fissure. Locy describes eleven genera of selachians in which the nerve has a dorsal attachment and nine genera in which it has a ventral attachment. Regarding the nerve in the ventral position he says, "there is reason to believe that, in some cases, at least, this is a secondary rather than a primary position. In observations on embryos of Mustelus canis, I have determined that it starts on the dorsal surface, and becomes carried to its ventral position through the unequalgrowth 
of the parts of the brain." This implies that in some forms the dorsal parts of the brain grow very large and push the nerve to the ventral surface. My studies show that it is necessary to explain the different positions of the nerve without implying so great differences in the position or extent of the characteristic dorsal and ventral parts of the brain. The forebrains of Acanthias and Raja are essentially like that of Scyllium in the position and relations of the various functional centers although the $\mathrm{N}$. terminalis is attached dorsally in Acanthias and Raja and ventrally in Scyllium. In all three forms the recessus neuroporicus externus is obvious and in nearly the same position. In Acanthias and Raja the nerve enters through or along the recessus neuroporicus externus from the dorsal surface; in Scyllium it enters through the ventral opening of the sagittal fissure; in both the nerve runs to a point just lateral to the recessus neuroporicus internus before plunging deeply into the brain substance (fig. 5). From this it may be concluded that the real point of origin of the nerve is neither the dorsal nor the ventral surface of the brain but is at the depth of the sagittal fissure close to the recessus neuroporicus. The difference between selachians of different species, then, lies in the peripheral course of the nerve rather than in its point of origin. In Acanthias, Heptanchus, Myliobatis, Raja and others it runs dorsal to the area of fusion of the lateral lobes; in Scyllium, Mustelus, Carcharias and others it run ventral to this area of fusion. The explanation of this seems to be simple. In Scymnus (fig. 6) the nerve lies free between the independent lateral lobes. In Heptanchus, Hexanchus and Acanthias the fusion of the medial walls is relatively small and occurs beneath the nerve which runs forward medial to the olfactory peduncles. In other forms the fused area is more extensive and greater in volume and the nerve is carried further dorsad (notably Raja and Myliobatis). If, now we suppose that in Scyllium and other forms in which the nerve has a ventral attachment, the fusion of the medial walls took place first above the nerve as it lay between the lateral lobes, it is clear that the growth of the fusion would carry the nerve down to the ventral surface. By this ventral route the nerve would reach its real origin through the sagittal fissure as it actually 
does in Scyllium (fig. 5). By this explanation of the position of the nerve we avoid any implications as to shifting of the relative position of brain centers which would lead to confusion in studying the internal anatomy.

\section{GRAY MASSES}

In a series of sections through the telencephalon of a selachian studied by low powers of the microscope the following areas occupied by neurone bodies may be readily distinguished by their structural appearances and place relations.

1. Bulbus olfactorius. Always a separate gray mass, connected with the rest of the telencephalon by a fibrous olfactory peduncle.

2. Area olfactoria medialis. This occupies the rostral and medial wall of the lateral lobe from the olfactory peduncle to the foramen interventriculare and continues caudad for a short distance above and for a longer distance beneath the foramen. Its outlines are indicated in figs. 4, 7, 8,65 and 68 . The broadest part of this center is in the free rostral wall of the lateral lobe, the greater part of which consists of diffusely scattered neurones of this center imbedded in a rather voluminous fiber mass. In the medial wall this center occupies the area below the external neuroporic recess. Here the neurone bodies are more numerous and more closely set and the center projects as a ridge into the lateral ventricle. This ridge is bounded above by a deep groove in the ventricular surface (figs. 18-20, 54-62, 75) and from this groove a zone practically free from cells extends across the fused median mass to meet the corresponding groove of the other side. The groove will be called the sulcus limitans hippocampi medialis, the cell-free zone the zona limitans medialis. The zona limitans passes slightly above the external neuroporic recess (figs. 19, $56,57)$ so that this is surrounded by the cell-bodies of the medial olfactory area. At the foramen interventriculare this part of the area extends for some distance caudad over the foramen. The greater part of the center cntinues caudad beneath the foramen to the level of the anterior commissure. This part of 
the medial olfactory area corresponds to what G. Elliot Smith has called in mammals and reptiles the paraterminal or precommissural body. Here we distinguish a small supraforaminal and a large infraforaminal portion of the precommissural body.

Throughout its whole extent the medial olfactory area belongs to the category of the central gray and its densest collections of cell bodies are adjacent to the ventricle.

The region occupied by the medial olfactory area corresponds to the region known as the septum in amphibians. The dense portion in the medial wall which projects into the lateral ventricle corresponds to the eminentia septalis of Gaupp in amphibians and to the eminentia medialis hemisphaerii of v. Kupffer in reptiles.

3. Area olfactoria lateralis. This occupies a part of the lateral wall of the lateral lobe, meeting the medial area at the olfactory peduncle and at the ventral angle of the ventricle (figs. $4,19,20,65,68)$. It extends caudad to the level of the foramen interventriculare but has no sharp boundaries. Like the medial area, this is of the nature of central gray; but a much larger volume of medullated fibers are present here than in the medial area. Its thickest part is adjacent to the olfactory peduncle.

In Acanthias the lateral wall of the ventricle shows a deep and in some places an extremely narrow and cleftlike groove (figs 51-59). which extends from the foramen interventriculare to the olfactory peduncle where this groove enters the olfactory ventricle. Opposite this groove is a cell-free zona limitans lateralis similar to that in the medial wall. Here the zona forms the dorsal boundary of the lateral olfactory area, separating it from the pallium.

4. AREa SUPERFICIALIS BASAlIS (figs. 15-20, 51-57,65, 68, $69,75)$. I give this name to the somewhat saucer-shaped gray mass which covers superficially parts of the medial and lateral olfactory nuclei. It has been called by Edinger ('08, p. 299) the cortex olfactoria, by Kappers ('06) and others the nucleus taeniae, by Houser the nucleus postolfactorius, by Catois the hypostriatum and by others the tuberculum olfactorium. I do not find any of these designations appropriate in view of the fiber connections and other relations of this area to be described below and so 
have given it a descriptive name that does not imply anything inconsistent with its functional significance. I wish to avoid any implication that this is a part of the true cortex ('09 b, p. 524).

The extreme rostral border of this gray mass is seen near the ventral surface, some distance in front of the olfactory peduncle (figs. 59,60). In following a series of transverse sections caudad from this point the mass is seen to grow rapidly broader, extending into the medial and lateral walls. Mesad it bends up rather sharply into the lower part of the septum where it meets the medial olfactory nucleus. The area basalis, however, lies ectal to the nucleus medialis septi, that is, nearer the ventral surface and the median plane in the lower part of the fused medial walls (figs. 56, 57). In the lateral wall the area basalis overlies the lateral olfactory area in the same way, forming a superficial gray mass. These relations continue caudad to the level of the anterior commissure where the area in question gradually disappears (fig. 51).

The area superficialis basalis consists of a very dense lamina of cell-bodies, irregularly crowded to a maximum thickness of ten or twelve cells, and of scattered cells both internal and external to this lamina. The dense lamina is thickest toward its medial border in the septum. At both medial and lateral borders the dense lamina gradually becomes less dense and its cells scatter into the diffuse and irregular gray of the medial and lateral olfactory nuclei (fig. 75). It appears that the superficial layer is formed by the condensation of cells belonging originally to the two olfactory areas. Except at the borders the basal lamina is everywhere separated from the central gray of the olfactory areas by a broad fiber layer containing few cells. Externally also a fiber layer covers this lamina. The deeper fiber layer contains numerous medullated fibers scattered singly or in small bundles. The outer surface of the cell lamina is covered by a dense layer of medullated fibers which run transversely or obliquely.

5. Primordium mippocampi. The roof of the telencephalon is occupied by a very thick gray mass whose fiber connections show that it is the forerunner of the hippocampal formation (see below). Over the wide foramen interventriculare (figs. 14, 15, 50-55) the 
primordium forms the whole dorsal portion of the brain and is bounded laterally by the zona limitans lateralis mentioned above. In front of the foramen, where the medial walls of the lateral lobes are fused (figs. 17-20, 56-62), the primordium hippocampi extends down in the medial wall of the lateral ventricle to the zona limitans medialis. Here it forms a prominent ridge extending into the ventricle, and is bounded below by the sulcus limitans hippocampi medialis. The zona limitans lateralis continues forward between the primordium hippocampi and the lateral olfactory nucleus to the level of the olfactory peduncle. The zona grows indistinct some distance caudal to the peduncle but its position is marked by a bundle of fibers to be described later. Forward from the peduncle a ventricular groove and the fiber bundle mentioned continue to mark the boundary of the primordium hippocampi. Following the sections forward it is seen that the primordium hippocampi becomes smaller and the ventricular groove meets the sulcus limitans medialis (figs. 60-63). In other words, the sulcus limitans medialis continues forward and bends around the rostral wall to reach the base of the olfactory peduncle. The medial and lateral sulci limitantes meet in the olfactory ventricle. In brains of the short and compact form (Scyllium and Raja) the medial wall does not project rostrad far beyond the base of the olfactory peduncle, the primordium hippocampi appears as a short broad roof and the ridge projecting into the ventricle from the medial wall becomes very much less prominent in front of the olfactory peduncle. In Acanthias and presumably in other forms with more elongated brains, the medial wall presents a very much longer rostral projection and the hippocampal ridge in the medial wall is prominent for a longer distance. A transverse section of the brain of Acanthias in front of the olfactory peduncle, or indeed anywhere in front of the foramen interventriculare presents a very close resemblance to the transverse section of the lateral lobe in the frog's brain (fig. 75). While there are great differences in size and form in selachian brains I have found no essential difference in the relations of the primordium hippocampi. The above description of the relations rostral to the peduncles follows Acanthias but the brains of Scyllium and Raja are in essential agreement. 
Caudally the primordium hippocampi does not end with the roof but continues as a strand of gray matter along the dorsal border of the wall of the telencephalon medium. The line of attachment of the membranous tela of the roof has been called the taenia fornicis and the continuation of the taenia along the telencephalon medium has been mentioned above. Along the line of the taenia but within it, abutting on the ventricle the massive pallium continues as a narrow column of gray matter which is to be reckoned with the primordium hippocampi (figs. $12,13,32$ ).

6. Primordium palli somatici. The body to which this name is given occupies the greater part of the walls of the telencephalon medium. Dorsad it reaches almost to the taenia (figs. 12, 46-50) where it bounds the primordium hippocampi externally. Rostrad it meets the lateral olfactory nucleus and the area superficialis basalis (figs. 65, 68,69). Ventrad it is bounded by the precommissural body and the nucleus praeopticus. Caudad it meets the thalamus. Throughout this area the neurone bodies are diffuse and without regular arrangement. Although it contains a considerable number of conspicuously large cells, it is only when its fiber connections are studied that the importance of this body is evident. It is more fully described below.

7. NuCleus PRAEOpticus. This consists of central gray lining the recessus praeopticus between the optic chiasma and the anterior commissure.

FIBER TRACTS AND FUNCTIONAL RELATIONS OF THE GRAY MASSES

The following description is limited for the most part to medullated fibers. A study by the Weigert method can give only the general relations but it is extremely important that these be propperly understood. The preconception which has held place in the minds of neurologists that the forebrain of fishes consists wholly of relatively simple olfactory centers has prevented an understanding of the true morphological relations.

1. Tractus olfactorius. At the base of the peduncle the olfactory tract spreads forward into the medial olfactory area and 
caudally and ventrally into the lateral olfactory nucleus. Figs. 65 and 68 show the distribution of the tract fibers in Scyllium and Acanthias. Above the olfactory peduncle, where the zona limitans is indistinct some of the olfactory tract fibers pass into the primordium hippocampi (fig. 69). These have perhaps been seen by Kappers ('06, p. 15). The medial and lateral divisions of the olfactory tract are not sharply separated from one another nor do they form compact bundles.

The medial olfactory tract contains relatively few medullated fibers and can be only imperfectly studied in Weigert preparations The medullated fibers spread diffusely into the rostral and medial wall and lose their sheaths. In Scyllium the medial tract runs mesad from the peduncle on the dorsal surface and bends down into the rostral wall (figs. 20,65). I assume that these fibers go to all parts of the medial olfactory area. In addition, some of the medullated fibers go up to the primordium hippocampi and the close relations of the area basalis to the medial olfactory nucleus suggest that the medial olfactory fibers enter the area basalis as well. In studying other fishes I have seen some evidence that the nucleus praeopticus is a continuation backward of the medial olfactory area, but no evidence on this point is to be had in the Weigert sections of selachian brains which I have studied.

The lateral olfactory tract is much more fully medullated than the medial and on that account appears much larger in Weigert sections. In Scyllium the larger part of the lateral tracts enters at once the deep gray of the lateral olfactory nucleus. The fibers spread and interlace in a confused manner and apparently reach all parts of this nucleus. As already stated, the basal superficial area along its lateral border fuses indistinguishably with the lateral olfactory nucleus and here the lateral olfactory fibers enter the basal area. At the level shown in figs. 18 and 54 it is difficult to say where the basal lamina ends laterally; there seems to be a partial arrangement of the cell-bodies in the lateral olfactory nucleus after the manner of the basal lamina up to the zona limitans. Yet this is the level at which the greatest volume of lateral olfactory fibers are entering these two gray masses. 
The smaller part of the lateral tract takes a superficial position and runs from the peduncle ventro-caudad external to the lateral border of the basal lamina (figs. 17, 18). This bundle continues as far as the basal lamina extends, gradually diminishing in size. From it fibers go ventrally in the superficial fiber layer and presumably end in relation with the dentrites of the neurones of the basal lamina. None of these fibers seem to reach the midventral line, although other fibers are seen in the same layer passing to the middle line. These I believe connect the basal area with the nucleus medialis septi. In Scyllium, then, the lateral olfactory tract ends in the whole extent of the lateral olfactory nucleus and in the lateral portion of the basal lamina.

In Acanthias the lateral tract has the same disposition as in Scyllium but has a commissural bundle in addition. The fusion of the lateral nucleus with the basal lamina is more intimate than in Scyllium and it is more clear that the superficial bundle of the lateral tract is related to the whole outer surface of the basal lamina. This superficial bundle is relatively much larger than in Scyllium and a large part of it maintains itself as a fairly compact bundle which runs ventro-caudad and bends ventrad around the caudal border of the basal lamina and finally bends forward near the mid-ventral line to decussate in the rostro-ventral part of the anterior commissure. This bundle appears in transverse section in figs. 49 to 54 and its course is shown in fig. 68 . As the bundles cross in the anterior commissure they are directed obliquely forward so that they cross at a sharp angle like a letter $X$. The appearance in transverse sections suggests that not all of the fibers cross. After the decussation a large part of the fibers pass straight forward along the mid-ventral line and eventually are distributed to the medial olfactory nucleus (figs. 54-56).

The areas into which I have traced olfactory tract fibers in selachians are the medial and lateral olfactory areas, the basal superficial area and the roof (primordium hippocampi). This agrees essentially with the work of most other authors. Kappers ('06, p. 15) denies the existence of crossed olfactory tract fibers in the pallial commissure. I have not been able to convince myself that any crossed fibers are present in my preparations. 
Edinger ('08, p. 255) states that the olfactory tract fibers cross to the opposite side through all parts of the massive forebrain. This is certainly not true of the species that I have studied. So far as medullated fibers are concerned, the anterior commissure and the pallial commissure (to be described below) are as distinct and well defined as in other vertebrates.

2. Tertiary OLFACTORY FIBERS.

a. Intrinsic tracts in the telencephalon.

1. Tractus olfacto-corticalis lateralis rectus.

2. Tractus olfacto-corticalis lateralis cruciatus.

These two tracts consist of fibers, mostly medullated, which pass up from the lateral olfactory nucleus across the zona limitans lateralis into the primordium hippocampi (figs. 19, 20). The bundle is larger and more prominent in Scyllium than in Acanthias. A large part of these fibers, usually collected in small fasciculi, enter the large roof commissure and pass to the opposite half of the primordium hippocampi.

3. Tractus olfacto-corticalis medio-dorsalis. This bundle is large and prominent in Acanthias but has not been recognized in Scyllium. It arises from the anterior part of the septum and from the rostral wall of the lateral lobe and follows the zona limitans medialis to the base of the olfactory peduncle (figs. 64 to 59). The bundle passes caudad over the peduncle and its lateral border comes into relation with the lateral olfactory tract. The bundle now diminishes but continues caudad until it meets the tractus pallii coming forward over the lateral olfactory tract. When these two tracts meet and intermingle each has decreased to a small number of fibers and both are entering the lateral border of the primordium hippocampi. That the tract here described is not a continuation of the tractus pallii is clear from the fact that over and in front of the olfactory peduncle it contains several times as many fibers as it does when it meets with the tractus pallii. The fact that it diminishes as it passes caudad along the the primordium hippocampi shows that it is either arising from or ending in that body. As it connects with the medial olfactory nucleus I assume that it is an afferent cortical tract. 
4. Tractus olfacto-corticalis septi. In the septum (figs. 16, 17, $34,56,69)$ are seen fibers forming a very diffuse bundle dorsoventral in direction. The bundle collects from the ental surface of the medial part of the basal superficial lamina and goes up into the primordium hippocampi. This is the tractus cortico-medialis of Botazzi and Kappers ('06, p. 17). I prefer to give it a name which will indicate both its origin and ending and to indicate also that its place of origin belongs to the non-pallial olfactory centers. As the tract passes up from the septum to the primordium hippocampi rostral and medial to the interventricular foramen and lateral ventricle, it corresponds in every essential to the tractus olfactocorticalis septi of amphibians. Catois describes fibers arising in his hypostriatum (my area superficialis basalis) which go up into the roof in the tractus medianus. These are doubtless the same as the fibers described here. Catois mentions only the one tract, and to this he gives the name fasciculus medianus. In Raja this fasciculus probably includes the median bundle of Edinger and the tract which Botazzi first pointed out under the name of tractus cortico-medialis (p. 20).

5. Tractus olfacto-corticalis medialis cruciatus. In the area of secondary fusion of the medial olfactory nuclei in Acanthias appear a few medullated fibers (figs. 58, 59, 69) which arise in the medial olfactory nucleus, cross to the opposite side and enter the primordium hippocampi. A similar decussation is seen in my preparations of the frog brain and has been decribed by Snessarew.

b. Tracts leading to the diencephalon.

1. Tractusolfacto-hypothalamicus. From the medialolfactory area fibers collect to enter the medial forebrain bundle (see below). They correspond to the tractus olfacto-hypothalamicus medialis of other fishes. These are joined by fibers from the lateral nucleus correspoding to the tractus olfacto-hypothalamicus lateralis. The two form a single diffuse tract in front of the anterior commissure (figs. 16-20, 53, 55).

From the septal portions of the basal superficial area many fibers collect (fig. 18) and run back to the level of the anterior commissure. From the whole outer surface of the basal lamina fibers collect into a dense layer in which the fibers run meso- 
caudad to meet with those last mentioned. All these fibers now enter into either the anterior commissure or the medial forebrain bundle (fig. 15). The forebrain bundle grows much larger at this level and farther back continues to receive fibers from the basal area. The basal bundle runs caudad over the optic chiasma and the greater part of it bends downs into the hypothalamus. It is believed that the constituents of the bundle thus far described have this destination.

A large part of the anterior commissure seems to be made up of decussating fibers of the medial forebrain bundles.

2. Tractus septo-habenularis. This tract is indistinguishable from the other bundles in the medial forebrain bundle until it enters the diencephalon. Just in front of the level of the nucleus habenulae fibers leave the medial forebrain bundle in a dorsolateral direction (fig. 44) and rise rapidly to join the stria medullaris as it enters the nucleus habenulae. It is not demonstrated that these fibers come from the medial olfactory nucleus, but there is a tract from the lateral olfactory area to the nucleus habenulae (see next paragraph), and the existence of a tract from the medial area in other fishes makes it probable that these fibers come from the medial nucleus in selachians.

3. Tractus olfacto-habenularis. When a series of transverse sections is followed from before backward there are to be seen among the fibers of the lateral olfactory tract scattered fibers which collect from the ental surface of the basal superficial area and near the dorso-caudal border of that area appear as a diffuse but individual bundle. This bundle continues caudad near the dorsal margin of the telencephalon medium and enters the nucleus habenulae, where most of its fibers decussate in the superior commissure Osborn (figs. 14, 50, 70). The exact relations of this bundle will be described below under the head of the stria medullaris. This bundle is called by Edinger the tractus taeniae and the basal area from which it arises is usually called the nucleus taeniae. My reason for not using these names must be given farther on (pp. 35-36).

3. Tracts CONNECTED WITH The PRIMORdIUM hipPoCaMPi.

In addition to the olfacto-cortical tracts mentioned above, there are to be noted the following: 
a. Tractus pallii. This is the well known tract described by Edinger, whose presence has been noted also by all later students of the selachian forebrain. The tractus pallii is connected with the whole extent of the roof, entering either by its lateral border (Scyllium) or over the whole surface (Raja, Acanthias). Kappers and Theunissen ('07, p. 502) have expressed the opinion that this tract consists of ascending fibers and that it corresponds to the tract described by the writer in Petromyzon from the hypothalamus to the "epistriatum." They refer to an experimental demonstration by Wallenberg that the tractus pallii in selachians is an ascending tract. Catois ('01, p. 83) had shown by the Golgi silver method that the tract contains descending fibers and that a part of the fibers go directly back into the lateral parts of the inferior lobes without crossing in the postoptic decussation (Raja). B. Haller ('98, p. 579, 617) had described this uncrossed portion in Scyllium catulus still earlier andI can confirm this for Scyllium canicula, Scyllium stellare, Raja, and Acanthias. In Chimaera (Johnston ' $10 \mathrm{~d}$ ) this uncrossed portion runs for its whole length as a separate bundle. In most selachians the tractus pallii runs superficial to the optic tract as both enter the diencephalon (figs. 29-31) but in Acanthias the tract is smaller than in other forms and is interlaced with the bundles of the external one-third of the optic tract. It is very probable that both ascending and descending fibers are present, but it is not known whether both are present in both the crossed and the uncrossed bundles. The ascending fibers constitute the greater part of the tract and serve to place the gustatory centers of the hypothalamus in connection with the olfactory centers of the telencephalon. This is equivalent to saying that the massive roof in selachians is an olfacto-gustatory correlation center.

$b$. Tractus cortico-habenularis. The tractus olfacto-habenularis lateralis as it rises dorsally behind the interventricular foramen is joined by a few fibers coming from the primordium hippocampi (figs. 49, 50,69-70). These fibers constitute a tractus cortico-habenularis. They have been described by Kappers ('06, pls. X and XIII, tr. olf-habenularis) for Galeus. They are more clearly seen in Scyllium than in Acanthias. 
c. Commissura hippocampi. The large commissure situated in the roof has been called by various authors the upper part of the anterior commissure, the pallial commissure or the psalterium. Catois calls it the upper part of the anterior commissure but says that it is homologous with the psalterium or commissura hippocampi. He says that the fibers connect symmetrical dorsolateral areas of the two sides. A more complete analysis of the olfacto-cortical fibers has been given by Kappers and in the above pages and it is not clear that Catois saw anything more than the decussating olfacto-cortical fibers. It is certain, however, that there are fibers which arise in the primordium hippocampi itself and cross to the opposite side. In Scyllium and Raja these fibers, are diffusely scattered among the olfactory decussations but in Acanthias part of them at least form a distinct bundle whose course is worth describing. These fibers arise in the lateral part of the primordium where the tractus pallii enters. The fibers only part of which are medullated, run caudo-mesad and gather into a bundle which runs round the caudal surface of the lateral half of the primordium hippocampi and turns forward to cross at about the level of the olfactory peduncle (figs. 49-53). The long caudal loop taken by this bundle is apparently due to the growth of the hippocampal primordium after the bundle was established along its caudal border.

The commissura hippocampi consists, then, of both decussating olfacto-cortical tracts and of true commissural fibers. The bundle is much larger in Raja than in Scyllium and more deeply placed, while in Acanthias it is smaller and more superficial.

d. Commissura pallii posterior. (Figs. 9-14, 23, 27-30, 43$50,66,69,70$.$) In addition to the gray matter described above$ as forming a caudal prolongation of the primordium hippocampi in the telencephalon medium, a large bundle of fine non-medullated fibers runs caudad along the taenia and enters into the superior commissure of Osborn. These fine fibers do not end in the nucleus habenulae, but form a commissure of the primordium hippocampi. Many authors have stated that a part of the "tractus taeniae" or the tractus olfacto-habenularis forms a true commissure in various fishes, but it has always been treated as a 
commissure of the olfactory nuclei. In selachians it is clearly a commissure of the pallial area and is evidently homologous with the posterior pallial commissure in amphibians and reptiles. It is probable that the same is true in other fishes but they will be discussed in separate papers.

e. Fornix. From the primordium hippocampi of either side fibers collect which pass forward over or through the fibers of the hippocampal commissure and beneath the corpus callosum (see below). Fig. 20 shows these fibers as they descend in front of the commissure. They pass meso-ventrad and form two dense bundles at the sides of the recessus neuroporicus externus. As they descend they gradually take a position ventral to this recessus, that is, they cross the zona limitans from the hippocampal primordium into the septum. Passing beneath the interventricularforamina they pass caudad over the anterior commissure and enter the medial forebrain bundle. Here they are lost to view, but the part of this bundle which they enter runs to the hypothalamus, the largest part of it going to the corpus mammillare.

This tract has been variously treated by other workers. Edinger ('88) first described it under the name of median bundle. Botazzi (as cited by Kappers, '06) first called the bundle fasciculus cortico-medialis and afterward adopted the term median bundle. Catois described the median bundle as consisting of fibers ascending from the hypostriatum to the roof. Kappers in his first paper described the tractus medianus as follows: "The median bundle has a fan-shaped origin of large extent in the lateral sub-cortical layer and runs towards the median line over that portion of the decussatio inter-hemispherica which has already crossed and under the part of this decussation which has not yet crossed, as clearly appears in figs. 18 and 19 , plate 1 . Then it runs obliquely downward between the two lateral ventricles to the brain floor, where a portion of it again bends laterally, thus constituting a connection between the superior and inferior parts of the forebrain, as Botazzi supposed, while another part of the fibers joins the tractus strio-thalamicus with which they go to the hypothalamus." Kappers and Theunissen ('08, p. 199) in studying the brain of Chimaera thought they found the tractus taeniae 
arising in the medio-basal region and taking a course around the rostral end of the lateral lobe. I have elsewhere ('10 d) shown that the authors were in error in the identification of this tract in Chimaera. Instead of tractus taeniae (or olfacto-habenularis) it is a part of the tractus pallii which they have traced for a part of itscourse only. In a later publication Kappers and Theunissen have revised Kappers' earlier description of Galeus and describe the tractus olfacto-habenularis as follows: "Sein Anfangsstück, welches sich durch das Septum medianum nach oben begibt, wurde früher immer als apartes Bündel, Tractus medianus, beschrieben. Wie bei Chimära sammelt er seine Fasern wie einen grossen Pinsel in dem basal gelegenen, kortikal gebauten Nucleus taeniae. Nach seiner Entstehung biegt er medialwärts in das präterminale Massiv hinein. Hierin steigt er nach oben und vorne auf und erreicht die dorsale Wand in der Nähe des Neuroporus, wo auch der dorsale Teil der Commissura anterior liegt. Ebensowenig wie jene überschreitet er dorsalwärts diese Grenze. Von hier aus geht er lateral und wieder kaudalwärts und legt sich im hinteren Teile des Vorderhirns neben der Ventrikelspalte (hier hat Wallenberg, dem sein Ursprung entging, es offenbar verletzt).

"Hier wird das Bündel erheblich verstärkt durch eine fast ebenso grosse Zahl von teilweise markhaltigen, teilweise marklosen Fasern, die in der supraventrikulären, kaudal verdickten Hirnwand entstehen. Dieser supraventrikuläre Teil des Tractus habenularis sammelt sich im hinteren Vorderhirnabschnitte aus zwei Wurzeln, wovon die eine dorsal aus der hinteren Verdickung, die andere ventral daraus kommt. (Taf. 3, Fig. 14). In der Entstehung so reichlicher Ursprungsfasern der Taenia aus der dorsalen Hirnwand liegt also ein grosser Unterschied mit Chimära vor, welcher aber in Einklang mit der grösseren Bedeutung ist, welche die dorsale Hirnwand bei Galeus hat in der Aufnahme von Riechfasern und mit der dorsalen Verlagerung des Chiasma olfactorium." I am wholly unable to see from my study of selachians how the authors have been led to such conclusions. The "tractus medianus" clearly arises in the pallium, its fibers converging from the lateral parts toward the external opening of the 
neuroporic recess. Kappers' figs. 18, 19, and 20 in his 1906 paper represent these bundles correctly and give the impression that they arise from his nucleus pallii. It must be noticed that this nucleus is dorsal to the olfactory peduncle and that the bundle runs forward from this in a superficial position to bend inward at the neuroporic recess. The tractus olfacto-habenularis (tr.taeniae) on the other hand, never reaches into the region dorsal to the olfactory peduncle and is never superficial in position. It always adjoins the ventricle, running in the central gray, and rostrally becomes diffuse and is lost beneath the foramen interventriculare. The few fibers which join the stria medullaris from the primordium hippocampi (see tr. cortico-habenularis above) come from the deep parts of the primordium immediately over the foramen. I do not know what Kappers could have seen in the brain of Galeus after his study of Chimaera which could have led him to reverse his first description. I am convinced, however, not only that the tract in Chimaera which Kappers makes a type for his later description of selachian brains is not the tractus taeniae, but also that there is no continuous tract in Scyllium or Acanthias which corresponds to Kappers' later description of the tractus taeniae in Galeus.

As to the relations of the "tractus medianus" in the ventral region, also, Kapper's earlier account seems to me nearer correct than his later one. The bundles reach the ventral region just in front of the anterior commissure and nearly at the caudal border of the basal area (the "nucleus taeniae" of Kappers). Here the small fasciculi of which the bundles are composed diverge, some of them going farther laterad than others (figs. 15, 34). The more lateral fasciculi enter the medial forebrain bundle and are lost. The more medial fasciculi are more compact and run on caudad in the superficial non-medullated fiber layer, passing by the medial border of the basal area and enter the medial forebrain bundle. The fact that some of the fibers turn somewhat laterad has led Kappers and Theunissen to state that they arise in the "nucleus taeniae." This I cannot confirm but it is entirely possible that some of the fibers do arise there as Catois has described. Two facts prevent my accepting this view without reserve. 
One is that if the tract is related to the "nucleus taeniae" it can be related only to the extreme caudal border of it. The tract inclines caudad rapidly as it goes from above downward and has almost passed caudad to the "nucleus taeniae" before it comes near it. If the tract arose in the "nucleus taeniae" we should expect to see it related to a considerable part of that nucleus. The second fact is that an entirely separate tract is present in Scyllium, Acanthias and Galeus, whose fibers run up from the "nucleus taeniae" in the medial wall. This is the tractus cortico-medialis of Kappers (tractus olfacto-corticalis septi, figs. 15-20, 34). Catois described only one bundle in this region, and I find that in Raja, which Catois figures, the "median bundle" is very large, while the tractus olfacto-corticalis is not evident. It is probable that the two bundles are united in Raja. In Scyllium it is entirely clear that the olfacto-cortical tract is independent and lies some distance laterad as in Galeus, while the median bundle passes by the basal area to go to the hypothalamus in the medial forebrain bundle.

Edinger in the last edition of his Vorlesungen follows Kappers and Theunissen, and Sterzi also in his large work on the selachian brain has adopted this description apparently without critical examination or verification.

I am convinced that Kappers by his error in identifying the tractus taeniae in Chimaera has been led into the serious mistake of reversing his earlier description of the selachian brain without basis in fact. The "tractus medianus" undoubtedly arises in the roof, descends through the septum and runs to the hypothalamus. This is the description of the fornix in reptiles and mammals and I think there can be no doubt of the homology.

4. Tracts conNected With the primordium pallit somaTICI. The gray matter of the telencephalon medium has escaped the attention of previous authors. This region has been assigned by all writers to the diencephalon under the name of "praethalamus." The nucleus praeopticus has been recognized but the main part of the gray matter of this region has been either illogically included in the "corpus striatum" or assigned to the diencephalon without careful examination. The fiber tracts running 
through this region have been fully described by many writers but the tracts which arise and end in it have been generally overlooked.

Most authors have recognized, especially in teleosts and ganoids, two parts to the basal forebrain bundle, a medial portion containing the so-called tractus strio-thalamicus and the tractus olfactohypothalamicus medialis, and a lateral portion made up of the lateral olfacto-hypothalamic tract. In selachians the tractus pallii has been compared by Kappers ('06) and the writer ('06, p. 300) with the lateral tract in teleosts. This homology is still believed to be correct although the bundle now proves to be an ascending tract in both teleosts and selachians (see discussion below).

We have now to note the presence of a third portion of the forebrain bundle which has heretofore been overlooked. This is a lateral diffuse bundle related only to the telencephalon medium and the lateral wall of the lateral ventricle. It may be known as the lateral forebrain bundle. It corresponds to what has been known as the basal forebrain bundle in amphibians (Gaupp, '97, p. 114). It is the forerunner of the capsula interna of mammals.

In parasagittal sections of the brain of Scyllium near the lateral surface of the telencephalon medium (fig. 29) a longitudinal tract is seen which ends forward in the wall of the so-called praethalamus. In the same sections are seen fibers running up from the region of the chiasma to the stria medullaris. When the longitudinal tract is traced caudad it is seen that it does not bend down into the hypothalamus as does most of the forebrain bundle (fig. 27), but goes back in the dorsal and central parts of the thallamus. This lateral bundle contains fewer fibers and is much more diffuse than the medial bundle, but owing to the wide area of its cross section it is still a bundle of considerable importance. In this and in the medial bundle run certain tracts related to the primordium of the general or somatic pallium.

a. Tractus thalamo-corticalis. This includes most or all of the lateral bundle as it appears in selachians. In transverse sections taken behind the interventricular foramina (figs. 12, 13) 
diffuse fibers, singly and in small fascicles, are found throughout the gray matter. On the lateral surface is the tractus pallii already described. Near the middle line is the medial forebrain bundle and in the dorsal region near the ventricle is the tractus olfacto-habenularis. This last gradually grows more compact and lies near the taenia. Of the remaining fibers two areas may be recognized, a dorsal and a ventral.

The fibers of the more dorsal area continue back into the diencephalon (figs. 13-9, 23, 24) and are traced to the lateral geniculate body. Some of them may be followed to the nucleus praetectalis and possibly the tectum opticum. Fibers which connect the lateral geniculate body with gray matter in the telencephalon must be regarded as optic radiations.

The fibers of the more ventral area of the lateral bundle pass back into the central part of the thalamus below the lateral geniculate and become indistinguishable among fibers ascending from the medulla oblongata (figs. 13-9, 22-25). The fibers from the oblongata belong to the lemniscus system and the bundle connecting the thalamic center of the lemniscus with the telencephalon must be regarded as the "cortical lemniscus" or general sensory radiations.

The whole system of thalamo-cortical fibers is diffuse and at the level of the optic chiasma there is no clear boundary line between the lateral and medial forebrain bundles. It is therefore not possible to say that all of the fibers in the lateral bundles are ascending, that all the ascending fibers are included in the lateral bundle or that there may not be fibers of other functions in addition to the general sensory and optic radiations. These two radiations are certainly present and I am inclined to think that all or most of the diffuse lateral bundle is ascending. It is probable that the lemniscus system includes fibers of tactile and equilibrative as well as muscle-sense functions. If so, we find in selachians all the tracts laid down by which all the forms of sensory impulses (except auditory) reach the general pallium in mammals. I have discussed elsewhere $(10 \mathrm{c}, \mathrm{p} .88)$ the general features of the problem of a somatic correlation center in the telencephalon. In such active free-swimming forms as selachians 
it is evident that the process of food-getting requires close correlation of the centers for vision and for muscle-sense and static sense with the olfactory centers. The pallial tract for gustatoryolfactory correlation is only moderately developed in selachians. The somatic tracts are larger than in most other fishes.

$b$. An olfacto-somatic correlation tract. To this tract I do not wish to give a formal name until it has been studied by the Golgi method to determine the origin and ending of the fibers. The fibers collect gradually in the rostral part of the telencephalon medium to form a broad band a little beneath the surface and ventral to the tractus pallii (figs. 15, 16). The tract runs rostrad and begins to lose itself in the lateral olfactory nucleus dorsocaudal to the peduncle. Whether the fibers end in the secondary olfactory nucleus or go on into the primordium hippocampi I cannot tell from Weigert preparations. Here over the olfactory peduncle there is no sharp boundary between the secondary olfactory centers and the primordium hippocampi. Although at its borders the bundle is diffuse and comes into contact with the latereral olfactory tract and the tractus pallii, there is no doubt that it is a distinct and individual tract.

c. Corpus callosum (figs. 14-20,67). From the whole lateral surface of the telencephalon medium, except the nucleus praeopticus, arise fine fibers which collect on the surface and pass forward ectal to the olfacto-somatic tract last described (figs. 1420). When the ental bundle enters the lateral olfactory nucleus the ectal bundle continues forward and upward over the olfactory peduncle in contact with the outer and caudal surface of the tractus pallii. The two tracts are readily distinguished because the tractus pallii is compact and consists of medium coarse fibers while the present tract consists of much finer fibers and is more diffuse (fig. 15). When the tractus pallii enters the lateral border of the primordium hippocampi (fig. 16) this tract continues rostrad and decussates with its fellow in the rostral and ectal portion of the pallial commissure. The bundle in the commissure is rather compact and is well defined. It runs independently in the superficial layer of neuropile. Beneath it is a dense median mass of cells imbedded in neuropile. Deeper, this cell mass is less 
dense and contains the hippocampal commissure and decusssating olfacto-cortical fibers. The fibers of the superficial bundle neither mingle with those of the deeper bundles nor do they dip down into the primordium hippocampi at either side. The outer bundle of fine fibers therefore seems to be a true commissure of the somatic areas in the telencephalon medium.

As these areas receive general sensory and optic radiations from the thalamus this commissure is certainly similar in function to the corpus callosum of mammals. The question whether it is the true homologue of the corpus callosum involves the question of the homology of all the other parts of the telencephalon and must be discussed later. Here I can only say that all the evidence known to me at present supports this homology. Some of this evidence $I$ have stated in a preliminary way in a recent paper ('10 c).

$d$. Somatic projection tract. This corresponds to a part of the tractus strio-thalamicus of authors. From the gray mass in the telencephalon medium fibers go caudad at first scattered singly or in small fasciculi and then forming the lateral portion of the medial forebrain bundle. This part of the medial bundle is composed of coarser fibers more diffusely arranged (fig. 13). This portion does not descend to the inferior lobes or corpora mammillaria, but goes caudad in the ventral part of the thalamus. Its fibers may be traced nearly to the tuberculum posterius. This ventral part of the thalamus contains the nucleus ventralis and the nucleus of the medial longitudinal fasciculus, and is generally considered as the chief projection or effective center of the thalamus. The tract here described is the chief projection tract for the somatic part of the telencephalon. I hesitate to give it a formal name in view of the uncertainty of its lower connections. So much of it as ends in the thalamus might be called the tractus cortico-thalamicus (instead of tr. strio-thalamicus) but it is not certain that it all ends there. In sagittal sections of Scyllium part of its fibers seems to continue toward the myelencephalon. Van Gehuchten has claimed that at least a considerable part of the forebrain basal bundle in teleosts and urodeles descends to the medulla oblongata and probably the spinal cord. This view has been confirmed by Bochenek for urodeles. Such fibers suggest the begin- 
nings of the pyramidal tract and I know no reason for rejecting this possibility. On theoretical grounds we should be disposed to expect the forerunner of pyramidal tract fibers in this basal bundle. Until these fibers are carefully investigated in selachians I shall speak of this as the somatic projection tract.

e. Tractus taeniae. This tract is included in what has been described as tractus taeniae in various vertebrates. The bundle which Edinger, Kappers and others have called the tractus taeniae in selachians has been described above as the tractus olfactohabenularis lateralis. The fibers here described have probably not been noticed before. 'These fibers arise from the telencephalon medium (somatic gray) and join the tractus olfacto-habenularis lateralis from below (figs. 11-14, 48-50, 28-30). The two systems of fibers are indistinguishable as they run through the stria medullaris and enter the nucleus habenulae. The stria medullaris and the arrangement of its several component bundles will be reviewed below.

This review of the fiber tracts shows that an important gray center or centers must be found in the telencephalon medium. The justification for calling this a somatic area lies in the entrance of ascending tracts from the visual and general sensory centers in the diencephalon. That the gray matter of this region is of considerable importance is evident even from the Weigert preparations. The cell-nuclei are stained and the cell-bodies are clearly visible in these preparations owing to the staining of non-medullated fibers and neuropile by acid fuchsin. The cell-bodies and large dentrites appear as clear spaces in the neuropile-matrix and the staining of the cell nuclei renders their identification certain.

In the telencephalon medium I have distinguished the precommissural body, the nucleus praeopticus and the somatic area. It seems probable that what other authors have called nucleus praeopticus in teleosts (e.g., Goldstein) includes a part of what is here included in the somatic area. The writer has used the name nucleus praeopticus strictly for the central gray, closely investing the preoptic recess and extending forward to the anterior commissure. In ganoids its cells are either situated in the ependymal layer or have central processes which penetrate between the epen- 
dyma cells to the membrana limitans interna. In selachians the cells of this description form a nucleus which is clearly distinct from the somatic gray. The two are separated by the medial forebrain bundle and the somatic gray is not a compact central gray but lies for the most part near the outer surface.

As a series of transverse sections of the brain of Scyllium is followed forward from the level of the optic tracts the following arrangement of gray matter is seen. The nucleus praeopticus is an almost insignificant layer of ventricular gray surrounding the small recessus praeopticus. In sections which contain the anterior border of the optic tracts in the lateral wall of the thalamus (figs. 10, 23) the central gray of the thalamus forms a rounded mass with convexity directed dorso-mesad. It is bounded dorsolaterally by a shallow ventricular groove, the sulcus Monroi, above which are the stria medullaris bundles (see below). Lateral to the sulcus Monroi is a small collection of cells which are interspersed with the diffuse fibers of the lateral forebrain bundle. This small collection of cells is quite separate from the central gray and grows larger as it is followed forward.

A few sections rostrad (figs. 11,22) the velum transversum appears attached to the dorsal border of the lateral wall. Since the di-telencephalic boundary line is marked by the velum above and the caudal surface of the chiasma-ridge below, the section drawn in fig. 23 crosses that boundaryline and that in fig. 22 lies in front of it. The central gray below the sulcus Monroi continues back into the central gray of the thalamus. The small lateral cell area is continuous caudad with the gray which lies latero-ventral to the habenular body, namely the lateral geniculate body. The diffuse fibers among which these cells lie are the optic radiations above described. There is no break in the continuity of either cell column, so that the precise boundary, if there is one, must be found by detailed studies by the Golgi method. The lateral column is most slender at a point a little behind the velum transversum and this is perhaps the point of transition from diencephalon to telencephalon in this column.

Following the convex central gray mass forward there is soon seen a decrease in size of the whole central mass and especially a 
decrease in the number of cells in its dorsal portion. Thisoccurs within the area of attachment of the velum transversum which extends through more than forty sections of 10 microns. Going on forward, the medio-basal part of this central mass, adjoining the nucleus praeopticus and not clearly delimited from it, becomes more and more rich in cells (figs. 11, 12) until the anterior commissure is reached (fig. 13) and is then clearly recognized as the pre-commissural body which forms the "bed" for the anterior commissure and is continuous forward with the medial olfactory nucleus. The dorsal part of this central gray mass which seems to fade away at the region of the velum transversum may be regarded as thalamic central gray, while the medio-basal gray and nucleus praeopticus are continuous with the medial olfactory nucleus.

While this transition from the thalamic gray to medial olfactory area is taking place the lateral or somatic gray has greatly increased and at the level of the anterior commissure occupies more than half the area of the cross section (figs. 12, 13, 48).

It should be noted that in the region between the optic chi sma and the anterior commissure the tractus pallii goes forward and upward over the lateral surface and gains a position above the somatic area (figs. 11, 12, 21-23, 30, 31, 45-48). Now the sulcus Monroi above mentioned indicates the ventral boundary of a small area adjacent to the taenia occupied by the tractus olfactohabenularis lateralis, tractus pallii, the fibers of the commissura pallii posterior and a small amount of gray which is continuous forward with the massive roof (primordium hippocampi).

At the level of the caudal part of the anterior commissure the somatic area occupies all the space lateral and ectal to the medial forebrain bundle, lateral to the precommissural body and ventral to the primordium hippocampi. It does not seem to reach the ventricle nor include any ventricular gray. Its cell-bodies are most numerous in the ectal portion (figs. 32,33 ), but there is little more than the suggestion of a cortical lamina. The deeper parts have fewer cells and contain the scattered fibers of the lateral forebrain bundle. The fibers of the tractus taeniae also have diverged from the stria medullaris and are scattered through this area. 
Passing forward through the width of the anterior commissure the following differentiations take place. The primordium hippocampi grows larger and joins the massive roof (fig. 14) whose caudal portion is seen overhanging the median ventricle in figs. 12 , 13. The tractus pallii continues up in this while the tractus olfacto-habenularis begins to incline downward. In the basal part of the precommissural body before the rostral border of the anterior commissure is reached appears the condensation of cells which leads to the area superficialis basalis (fig. 15). The medial forebrain tract gradually becomes more diffuse and is distributed to the olfactory nuclei, the anterior commissure and the somatic area (see above and below). As these tracts scatter there is a tendency for the fibers of the medial and lateral bundles to divide the somatic area into internal and external parts. The internal part is more closely related to the central gray of the lateral olfactory area. The external part meets the area basalis forward and along its dorsal border meets the lateral olfactory area. I have no doubt that from the gray of this region are differentiated the corpus striatum and somatic pallium of higher vertebrates, but the structure and relations of the pallium are more clearly foreshadowed here in selachians than are those of the corpus striatum.

In this region the sulcus Monroi separates the primordium hippocampi above from the ventricular gray which covers the somatic area internally. From this point forward the deeper gray of the somatic area merges with that of the lateral olfactory area without recognizable limit. The ectal layer seems on casual observation to fuse also with the basal superficial area and the ectal part of the lateral olfactory area. Oncloser examination, however, it is found that the somatic area has an abrupt border, marked in sagittal sections by a distinct hiatus in the compact ectal cell layer (fig. 32).

Within the area thus marked out as a somatic area there are three regions to be distinguished. First, the deeper and more diffuse gray which is most closely related to the olfactory nuclei. It is continuous rostrad with the area to which Edinger and others have given the name "corpus striatum." It certainly is not a 
true corpus striatum in selachians. Second, the ectal gray which consists of numerous small cells less compactly arranged than those of the area superficialis basalis but still suggesting a cortical lamina (figs. 32,33). This small-celled area lies ectal to the lateral basal bundle and is in turn covered ectally by a layer of fine nonmedullated fibers or neuropile. It is from this layer of small cells that arise the fibers of the olfacto-somatic correlation tract, the tractus taeniae, and the corpus callosum. Third, an intermediate region containing large cells. The caudal border of this nucleus of large cells is seen in Scyllium in transverse sections which pass through the middle of the anterior commissure and cut the caudal border of the massive roof. Such a section in shown in fig. 13. The nucleus extends rostrad some distance beyond the foramen interventriculare, and scattered cells are seen still farther rostrad. In preparations counterstained by acid fuchsin the neuropile surrounding the large cells is deeply stained and is much more dense than in any other part of the forebrain. The size of the cells and the density of the neuropile suggest that this is a center of great activity. The cell-bodies are stellate or irregular with one to several large dendrites which appear as clear spaces in the neuropile. It is from this mass of large cells that the coarse fibers of the somatic projection tract seem to arise. Among these large cells are seen numerous medium coarse fibers which in transverse sections incline slightly toward the median plane. Some of these fibers are collected into dense bundles. The remainder form a diffuse bundle the uniformity and parallel course of whose fibers make it possible to trace them. The bundle gradually approaches those which come from the olfactory centers and area basalis and all unite into the compact medial forebrain tract, of which the fibers from the large-celled nucleus form the lateral portion. These fibers cannot be distinguished farther caudad, but in the diencephalon the lateral part of the medial forebrain tract enters the thalamus and does not descend to the hypothalamus (fig. 28).

The salient features of the somatic area may be summarized as follows. It consists of a deep zone of scattered cells, an intermediate zone of large cells and dense neuropile, and a superficial zone of more numerous small cells. The second and third zones are re- 
lated to optic and general sensory radiations ascending from the diencephalon, to the corpus callosum, to the tractus taeniae and to the descending or projection tract. The homology of the large cells with the giant pyramids of higher brains msut be regarded as a possibility. The somatic area is situated in the lateral wall of the telencephalon medium, lateral and caudal to the olfactory centers, and extends rostrad somewhat in front of the interventricular foramen. Only the smaller part of it is thus involved in the evagination of the lateral lobes.

\section{SUMMARY OF CERTAIN FIBER COMPLEXES}

1. Commissura paldi anterior. I use this name to include in selachians all the fiber decussations in the roof of the telencephalon. It includes therefore: (a) true commissural fibers between the hippocampal primordia of the two sides (commissura hippocampi); (b) true commissural fibers between the somatic areas in the telencephalon (corpus callosum); and (c) decussating fibers from the medial and lateral olfactory nuclei to the primordium hippocampi.

It is of the greatest importance to see clearly the morphological relations of this commissure complex. In all the selachians studied by me it lies in the roof dorso-caudal to the external neuroporic recess. Catois figured it in this position in Raja but did not discuss the external neuroporic recess. Houser describes and figures axones of neurones lying in the "pallial eminences" in Mustelus going through this commissure to the opposite side. From his fig. 31 it is clear that the commissure lies above and behind the external neuroporic recess in Mustelus. Kappers, in 1906, did not state the position of the commissure but his fig. 18 shows it above the external neuroporic recess in a transverse section of the brain of Galeus. In a later paper the statement is made by him: "Es is auffallend, dass bei keinem einzigen Selachier, der bis jetzt von mir untersucht wurde, die Kommissur dorsal von dem sogenannten Neuroporus, in der Lamina supraneuroporica zu liegen kommt." I cannot understand this error of observation in a matter which is so perfectly clear, unless it be 
another result of Kappers' erroneous observations on Chimaera which are referred to in the same paragraph from which the above quotation is made. The writer has elsewhere described this commissure as dorsal to the neuroporic recess. Sterzi in his extensive monograph upon the selachian brain clearly states the same fact (p. 794) and shows the position of the commissure in a figure of Acanthias.

The recognition of the fact that the commissure lies in the lamina supraneuroporica separates it once for all from the anterior commissure. The same is true of Cyclostomes. Although in ganoids, teleosts and amphibians the fibers of the hippocampal commissure take an aberrant position beneath the ventricle (Johnston ' $10 \mathrm{c}$ ), the anterior commissure is never divided into two parts, one of which lies in the lamina terminalis and one in the lamina supraneuroporica.

2. Basal Forebrain BUNDLe. This is in two parts whose chief constituent bundles are the medial forebrain tract, which includes the tractus olfacto-hypothalamicus medialis, the fornix and the somatic projection tract; and the lateral forebrain tract which includes the general sensory radiations and optic radiations.

It should be noticed that the somatic projection tract which is loosely joined with the medial forebrain bundle in selachians is clearly united with the lateral bundle in higher forms. This lateral bundle comes to be known in mammals as the internal capsule and crus.

3. Stria medullaris. In the writer's first work on the brain of a fish he was impressed with the complexity of the stria medullaris even in fishes. The term tractus taeniae which Edinger and most neurologists apply to this fiber complex in fishes is very inadequate. The stria medullaris has never been fully analyzed in fishes but has recently been carefully studied by Herrick in amphibians. The bundles which I have recognized in the stria medullaris of selachians are as follows:

a. Tractus septo-habenularis, probably from the medial otlfactory nucleus by way of the medial forebrain tract. The fibers run in the basal bundle until they enter the diencephalon and then rise rapidly to the nucleus habenulae (figs. 44,70 ). 
$b$. Tractus olfacto-habenularis lateralis, from the area superficialis basalis and the lateral olfactory nucleus far forward beneath the lateral ventricles (figs. 14, 50, 70).

c. Tractus cortico-habenularis, from the primordium hippocampi, its fibers joining those of $b$, behind the foramen interventriculare (figs. 49, 50,69, 70). (It corresponds to Herrick's tractus cortico-habenularis medialis.)

d. Tractus olfacto-habenularis posterior (lateralis of Herrick). This consists of a diffuse layer of fibers arising from the preoptic region interlaced with the outermost fibers of the lateral forebrain tract (figs. 31, 70). (It thus corresponds to Herrick's tract of the same name but it is not clear in Weigert sections whether it arises from the nucleus praeopticus in the strict sense in which I use that term.)

$e$. Tractus taeniae, from the somatic area to the nucleus habenulae (figs. 11-13, 28-30, 48-50). (This probably corresponds to Herrick's tractus habenulo-striaticus, and may include his tractus cortico-habenularis lateralis.)

f. Tractus habenulo-thalamicus (Herrick). These fibers lie adjacent to those of $c$ and are directed further caudad (figs. 29, $30,70)$. Some of them go into the dorsal part of the thalamus, some enter the lateral geniculate body, others go farther ventrally near the optic chiasma. I have no means of knowing from Weigert sections the place of origin of these fibers but have used the name given by Herrick to similar fibers in amphibians, his work being based on Golgi sections.

g. Commissura pallii posterior, a true commissure of the primordium hippocampi, consisting of a very great number of fine non-medullated fibers. It forms the larger part of the commissura superior of Osborn (figs. 9-14, 23, 27-30, 43-50, 66, 69, 70).

It seems very probable that in the quotation made from Kappers, on p. 21 above, the fibers which join. his "tractus taeniae" represent the posterior pallial commissure, the tractus olfacto-habenularis lateralis and perhaps the tractus corticohabenularis.

It will be noticed that I have used the term tractus taeniae for only one of six distinct components of this fiber complex. Since 
there are so many functionally distinct bundles running to the nucleus habenulae it is necessary to have some more general name for them, and the term stria medullaris already in use for this complex in higher brains is satisfactory. Enough has been said in the above description to show that the term tractus taeniae has not been used in the same meaning by all authors or by the same author in writing of different vertebrates. Edinger ('96) defined it as a tract arising from a nucleus in the caudo-lateral part of the forebrain, the nucleus taeniae. Kappers hasfollowed this usage except that in Chimaera and selachians, as indicated above, he has been mistaken in identifying this tract and has placed its nucleus far forward in the medio-basal region. Edinger ('08) and Sterzi have followed this error. As a result, the "nucleus taeniae" means two widely different things in selachians and teleosts in the writings of these authors. Other authors have generally followed Edinger's original definition. The present writer, in his first work, through failure to understand Edinger's description, applied the name nucleus taeniae to the nucleus praeopticus, from which arises a large part of the stria medullaris. Edinger understood his nucleus taeniae to be an olfactory nucleus, but Goldstein does not find olfactory fibers going to this nucleus in teleosts and I think it extremely probable that the nucleus in question is in reality the homologue of the somatic area in selachians. If the name tractus taeniae is to be applied to the homologous structure in all vertebrates, it can not be given to any olfacto-habenular tract but must be used for a tract arising from a certain nucleus placed caudo-laterally in the telencephalon, which nucleus now appears to be somatic sensory in function.

4. Commissura anterior. Only brief mention has been made of the anterior commissure in the above description because the selachians are not favorable for the study of its constitution. The commissure is broad and diffuse and not divided into several bundles as in ganoids and teleosts. In the caudal part of the commissure its fibers are traced into the medial forebrain bundle and not beyond, so that it is reasonably certain that it consists in large part of decussating fibers of these bundles. In sections 
through the rostral part of the commissure transverse fibers are seen connected with both olfactory areas, the basal area and the somatic area. Since none of these fibers run in one section without break from their nuclei across the median plane, it is difficult or impossible in view of their diffuse arrangement to decide what ones enter the commissure. I think it probable that all three olfactory areas are involved and the part of the somatic area related to this commissure doubtless represents the corpus striatum.

\section{GENERAL DISCUSSION}

The general morphology of the selachian telencephalon has been taken up only in a descriptive way in the above pages. It is necessary to know the structure and functional connections of the parts of the brainbefore questions of generalmorphology have significance or can be intelligently discussed. The above description of the fiber tracts shows three main parts or regions in the telencephalon based on function: a secondary olfactory area occupying the lower part of the medial wall and the rostral part of the lateral wall, a primordium hippocampi in the roof and a primordium of the somatic pallium in the lateral wall of the telencephalon medium. (These regions are more concisely defined above). I have elsewhere (' $10 \mathrm{~b}$ ) discussed the significance of the existence of somatic correlating centers in the telencephalon, while the importance of the "olfactory cortex" or primordium hippocampi has been commented upon by nearly every writer on the forebrain in recent years. It remains to explain how these correlating mechanisms have come to occupy the positions that they do and to indicate how the morphological relations in the selachian brain have been modified in the course of the evolution of the telencephalon of higher forms.

The fundamental facts which determine the relations of functional columns at the anterior end of the neural tube have been stated elsewhere ('09 b, '10 c). They are: (1) the di-telencephalic boundary passing behind the chiasma-ridge; (2) the absence of motor nerves rostral to the N. III., and the consequent reduction of the ventral (motor) columns in the diencephalon and telen- 
cephalon; and (3) the prominent flexure of the telencephalon due to the hypertrophy of its dorsal columns. While the chiasmaridge certainly belongs to the telencephalon it is not clear how much of the gray matter adjacent to it is to be assigned to the telencephalon. In cyclostomes an external vertical groove marks the di-telencephalic boundary and an internal groove is present just behind the boundary line (fig. 76). The external groove and internal ridge represent the primitive constriction between the first and second neuromeres. The internal groove represents the widest part or expansion of the second neuromere. The relations of the neuromeric grooves are not so clear in the brains of true fishes. Where they are not present the limits or line of transition between central gray of thalamus and of telencephalon must be determined by working out the fiber connections in each form.

Some evidence has appeared recently (Burckhardt '07, p. 340; Brookover '10) that the nervus terminalis is a mixed nerve, containing in some fishes sympathetic efferent fibers distributed to the blood vessels. These efferent fibers make their exit in a dorsal root (N. terminalis) as the viscero-motor fibers typically do in the spinal region of lower vertebrates. When the nucleus of origin of these fibers is found it will indicate, as a vestige, the position of the most anterior part of the visceral motor column in the brain.

The telencephalic flexure is so thoroughly familiar from the work of embryologists that it requires little comment. The ventral columns taper to a point and end at the chiasma-ridge. This is the anterior end of the brain floor. The dorsal columns end also at this level and dorsal and ventral columns are separated by the sulcus limitans of His which ends in the recessus praeopticus. This sulcus is visible in the brains of embryos and adults of many vertebrates but a full discussion of its relations will be reserved to a later paper. Figs. 78, 82 and 83 serve to illustrate the position of the brain axis which corresponds to the sulcus limitans in the lateral walls. The dorsal columns in the forebrain region begin in the very early embryo to be more voluminous than the ventral columns. This is due to more rapid growth and cell-proliferation 
in anticipation of the formation of the optic vesicles and the large telencephalic centers. The optic vesicles are formed from the dorsal column of the second neuromere (Johnston '05, '06, '09 a, p. 35-38, 104-108, 131,'09 b), and all that corresponds to the cerebral vesicles of mammals from the dorsal column of the first neuromere $(1909 \mathrm{~b})$. After the formation of the optic vesicle which withdraws the material for the retina, the dorsal column of the first neuromere expands to form the great bulk of the telencephalon seen in all vertebrates, whether massive or vesicular, spherical or elongated. In all forms the dorsal seam of the neural tube extends forward and downward around the rostral surface to meet the anterior end of the brain floor at the optic chiasma. This has been clearly stated in a recent paper ('10 c) from which fig. 77 is here reprinted.

The dorsal seam in the telencephalon is divided into two parts, the lamina terminalis and lamina supraneuroporica by the late persistence of the continuity of brain tube and ectoderm at the point known as the neuroporic recess. This recess marks the upper (caudal) border of the anterior neuropore which is open for a considerable time in the embryo. The lower border meets the chiasma. The neuropore closes from below upward and remains open longest at the point of attachment of the pair of telencephalic nerves. This is attested by the relation of the nervus terminalis to the neuroporic recess and also by the close relation of the neuropore to the olfactory placodes during early development. The writer regards the olfactory placodes as essentially the anterior portion of the neural crests. These placodes together with the terminal crest mesectoderm, described in selachian embryos (' $09 \mathrm{~b}$, p.371-378), give rise to the pair of telencephalic nerves. Thisnerve pair is attached to the dorsal border of the brain at about the middle of the telencephalon. The neuropore and especially the neuroporic recess are the expression of the long-persisting continuity of the brain wall with the olfactory placodes. It is in this way that there comes to be developed at the middle of the dorsal seam of the telencephalon a prominent landmark dividing this seam into lamina terminalis and lamina supraneuroporica. The neuroporic recess in no way indicates the anterior end of the brain axis (see 
His contra Kupffer) but indicates the middle of the roof plate of the telencephalon. The point of importance in the present stage of forebrain study is that the portion of the telencephalon which lies below the horizontal level of the neuroporic recess (and above the preoptic recess) is as truly a part of the dorsal column (alar lamina of His) as is the portion which lies above this level. The caudal part of the dorsal column is dorsally placed, the rostral part is ventrally placed, but both are parts of the alar plate of His. These relations are illustrated in figs. 77-82.

In the telencephalon the visceral sensory column holds a position which can scarcely be explained by the facts seen in selachians alone. The full explanation must be reserved until the conditions in cyclostomes are discussed in a later paper. The puzzling thing is that herein the telencephalon the visceral sensory column adjoins the dorsal seam throughout its whole length, whereas in other segments of the brain and cord the somatic sensory column is the most dorsal and adjoins the roof plate. This statement rests upon the conditions in the medulla oblongata which is regarded as the most primitive segment of the neural tube. The visceral sensory column (vagal lobe, gray column of the tractus solitarius, etc.) lies in the wall of the ventricle and is overtopped by the somatic sensory column (acustic and cutaneous centers) (fig. $84 \mathrm{C}$ ). At the lower end of the myelencephalon, however, the visceral sensory columns come together over the ventricle, rising up medial to the cutaneous centers and meeting in a median commissural nucleus (fig. $84 \mathrm{~A}$ ). Not only is this true in all classes of vertebrates, but in cyclostomes the visceral sensory column extends for a long distance along the dorsal border of the medulla oblongata and has the tela chorioidea attached to it. In the spinal cord of all forms we find the visceral sensory column at the base of the dorsal horn, the most dorso-medial part of the gray matter. The truth is that at the level of the commissural nucleus and in the spinal cord the somatic sensory column consists of dorsal gray which has been shifted laterally. It shows a strong tendency to become lateral and superficial, while the visceral sensory column always remains near the ventricle and often rises dorsal to the somatic column. This relation is strik- 
ingly illustrated in the myelencephalon of those fishes in which taste organs are very numerous. In these the vagal or facial lobe or both are greatly hypertrophied and rise up medial to the acustic and cutaneous centers, which are pushed out to the side. I have called attention to this some years ago ('06, p. 279) in explaining the morphology of the nucleus habenulae. A moderate degree of hypertrophy of the visceral sensory column is seen in Amia calva and there is a striking resemblance between a transverse section of themedulla oblongata and one through the nucleus habenulae (fig. 85). The writer regards the medial part of the nucleus habenulae as a part of the visceral sensory column which has risen up to the dorsal border of the brain and has pushed the somatic sensory column (corpus geniculatum) out to the side. It is, then, a common thing in vertebrates for the visceral sensory column, wherever it is strongly developed, to rise to the mediodorsal position, while the somatic sensory column takes a laterosuperficial position.

In the telencephalon the olfactory centers present as marked hypertrophy as is to be found in any part of the brain. If these centers belong to the category of visceral sensory centers, as the writer has held ('05, '06, '09 a), it is to be expected that they will rise to the dorso-medial position, while the somatic sensory centers will be pushed to the lateral surface. This is exactly what we do find. There is a tendency in both myelencephalon and telencephalon toward the eversion of the lateral wall whenever the visceral sensory column is large. This is carried to the extreme in those teleosts which have hypertrophied vagal lobes. The myelencephalon presents an eversion very similar to that of the telencephalon. The hypertrophy and assumption of the medio-dorsal position by the visceral sensory column is one of the earliest and most fundamental of the modifications which the brain tube has undergone in the telencephalic segment. The condition is already well established in cyclostomes, where the primordium hippocampi stands vertically in the lateral wall. The eversion has gone so far in ganoids and teleosts as to secondarily obliterate a large part of the evagination of the lateral lobes. In other classes, including selachians, the evagination has increased and the visceral sensory 
column becomes involved in it. These relations of the somatic and visceral columns will be more fully discussed and illustrated in connection with the brains of cyclostomes, ganoids and teleosts in a later paper.

The evagination of lateral lobes takes place within the olfactory area and under the influence of the olfactory nerve. This is the second effect of hypertrophy in response to the active functioning of the olfactory organ. The increase in the primary receptive station which produced the bulbar formation led to the evagination of part of the olfactory area to give sufficient space. That the evagination took place within the olfactory area is clear from the fact that in cyclostomes and selachians the foramen interventriculare is wholly surrounded by olfactory centers.

In the lowest vertebrates (cyclostomes) the olfactory region presents three specialized areas, the formatio bulbaris, the secondary olfactory area and the primordium hippocampi. The first two are largely involved in the evagination, the third is not. More important than this is the fact that the primordium hippocampi is located above the foramen and adjacent to the lamina supraneuroporica. The essential difference between this and the secondary olfactory area consists in the entrance of the tractus pallii ascending from the hypothalamus. The entrance of taste impressions into this part of the olfactory region led to specialization of histological structure which will be discussed elsewhere. What part of the visceral sensory column in the telencephalon should be thus specialized as an olfacto-gustatory correlation center was determined by space relations simply. The primordium hippocampi was formed from the caudal portion (dorsally placed) of the visceral sensory column because the tractus pallii entered from the caudal direction. These relations will be clear from figs. 69 and 83. Burckhardt's figures of Scymnus (figs. 79, 80,81 ) show that during development the primordium hippocampi shifts forward considerably in relation to the other parts of the forebrain.

Having accounted for the position of the primordial visceral cortex, notice should now be taken of the line of demarcation between it and the other telencephalic structures. I have de- 
scribed above the sulcus limitans medialis and sulcus limitans lateralis which bound the primordium hippocampi in the lateral lobes. It remains to say that these are all parts of one and the same continuous sulcus. Starting at the recessus neuroporicus a sulcus runs around the rostral wall, has the olfactory evagination in its course and continues in the lateral wall of the lateral ventricle to the interventricular foramen.

In Squalus acanthias from the Atlantic coast of the United States the sulcus Monroi is shallow in the telencephalon medium, becomes very deep as it passes caudad between the optic chiasma and the nucleus habenulae, curves lightly ventrad, becomes very shallow and continues beneath the tuberculum posterius into the mammillary recess (fig. 71). Dorsal to this is a groove (fig. 71,a) which extends from the level of the nucleus habenulae caudoventrad to meet the brain floor in a depression behind the tuberculum posterius. Above this is a third groove (fig. 71, $b$ ) which bounds the nucleus habenulae in front and below and continues caudo-ventrad to meet the brain floor a short distance behind $a$. This may be called the sulcus subhabenularis. The two sulci $a$ and $b$ lie nearly parallel and so near together that they cause a common large groove or widening of the ventricle.

In the form which is identified by the collectors at the Naples Station as Acanthais vulgaris the sulci appear in sections as follows: The sulcus Monroi agrees with that of the American Squalus acanthias except that in sections it fades away before it reaches the tuberculum posterius and can not be traced into the hypothalamus. It is, however, directed toward the hypothalamus. Above this is a sulcus $a$ (fig. 72) which evidently corresponds to the sulcus $a$ of the American Squalus. It is directed caudo-ventrad a little above the tuberculum posterius but does not reach the brain floor. It is quite deep in the middle part of its course. The sulcus subhabenularis is short and disappears beneath the stalk of the epiphysis. A short distance caudad appears sulcus $b$ which bounds ventrally the tractus habenulo-peduncularis just after that leaves the nucleus habenulae. The sulcus continues beneath that bundle to disappear just before it reaches the brain floor in the interpeduncular region. Above this is sulcus $c$ (fig. 72). It 
begins along the ventral boundary of the "epiphysial sac" (fig. 38) and continuescaudo-ventrad, bounding the tractus habenulo-peduncularis dorsally. It is a larger and deeper groove than sulcus $b$ and meets the brain floor in the interpeduncular region. The position of these sulci is illustrated by a series of drawings from transverse sections in figs. 37 to 50 and in a diagram made from these sections (fig. 72).

Sterzi gives a figure of the sulci in the diencephalon of Acanthias vulgaris which does not agree with my findings in either of these forms. Sterzi figures a ventral and a dorsal sulcus diencephalicus and between them a sulcus Monroi. From his figure it appears that his sulcus Monroi leads to the dorsal sac caudal to the velum transversum. If so, the sulcus is not the sulcus Monroi. Sterzi's ventral sulcus agrees with the sulcus Monroi as described above but is shorter. His dorsal sulcus seems to be a continuation of the sulcus subhabenularis.

In Scyllium stellare (fig. 73) the sulcus Monroi stops at the level of the epiphysial stalk. The sulcus subhabenularis continues caudad beneath the tractus habenulo-peduncularis to the floor of the mesencephalon. This sulcus is clearly separated from the sulcus Monroi by the velum transversum and a ridge to which the velum is attached (figs. 21-26).

In Scyllium canicula (fig. 74) the sulcus Monroi stops as in Scyllium stellare but a sulcus branches off from it and goes caudad beneath the tractus habenulo-peduncularis to end in the floor of the mesencephalon. This sulcus probably corresponds to the sulcus $b$ in Squalus. The only other sulcus in Scyllium canicula is the subhabenular which extends only as far as the stalk of the epiphysis as in Squalus.

In Scymnus as figured by Burckhardt the sulcus Monroi does not continue into the diencephalon at all (fig. 6). A subhabenular sulcus continues back in the position of sulcus $b$, but is separated by a long space from the sulcus Monroi. A second sulcus in the telencephalon runs from the foramen interventriculare to the recessus praeopticus. This sulcus is very prominent in the embryo of Scymnus (see Burckhardt, fig. 57) and more or less prominent in the embryos of other selachians, amphibians and 
mammals. It persists in adult cyclostomes as well as in Scymnus, but is usually obliterated in the adults of other vertebrates.

In other fishes (Amia, Acipenser, Ameiurus) the sulcus Monroi is short, as in Scyllium. The amphibians which I have studied agree more nearly with Squalus acanthias.

The fact that in the primitive Scymnus the sulcus Monroi does not reach the diencephalon, and its variable relations in those forms in which the sulcus does extend into the diencephalon lead the writer to believe that the sulcus Monroi was primarily confined to the telencephalon. It is to be regarded as a mechanical result of the evagination of lateral lobes of the forebrain. It is not as I first thought a direct continuation of the sulcus limitans hippocampi. Although it leads to the foramen interventriculare the sulcus is extremely broad and shallow for some distance behind the foramen. The sulcus which in embryos, and I believe in primitive forms, is the continuation of the sulcus limitans hippocampi, is that which leads into the recessus praeopticus.

It should be noticed that all the sulci mentioned, except the sulcus Monroi, in the telencephalon and diencephalon are morphologically dorso-ventral in direction. Those in the diencephalon run from the dorsal surface near the nucleus habenulae to the ventral region near the tuberculum posterius. One in Squalus acanthias continues from the sulcus Monroi into the hypothalamus. The same sulcus is found in Necturus, Cryptobranchus, the frog and other amphibians. The sulcus limitans hippocampi in the telencephalon is probablv not a primary continuation of the hypothalamic sulcus, but its own course is strictly dorso-ventral. Its dorsal end is at the recessus neuroporicus, in the middle of the length of the dorsal seam of the telencephalon. In cyclostomes and in selachian, mammalian and human embryos there is a sulcus extending up from the preoptic recess through the foramen interventriculare which is probably the primary continuation of the sulcus limitans hippocampi. I regard the sulcus limitans hippocampi, the hypothalamic sulcus and the subhabenulartuberculum posterius sulcus as the first three neuromeric grooves of the brain tube. That is, these represent the primary expansions of the ventricle in the first three neuromeres. Remnants of two 
such grooves are found in the mesencephalon also and in the myelencephalon they are well known.

The interpretation of these sulci as neuromeric grooves is consistent with the facts of structure in the telencephalon. The existence of the sulcus and zona limitans in the telencephalon shows clearly that a sharp functional distinction exists between the primordium hippocampi on the one hand and the secondary olfactory centers and the somatic centers on the other hand. The cell proliferation which results in the great growth of both areas is not accompanied by migration of cells across the functional boundary line. The secondary olfactory centers develop under the influence chiefly of the olfactory impulses. The primordium hippocampi is greatly influenced by the gustatory impulses coming up from the hypothalamus. I have already indicated that the primordium hippocampi was developed from the caudal part of its column in the telencephalon. Now if the sulcus limitans represents the neuromeric groove, it follows that the caudal half of the visceral sensory column in the first neuromere gave rise to the olfacto-gustatory correlating center while the rostral half remained purely olfactory.

The position of the olfactory ventricle directly in the course of the sulcus limitans hippocampi is also instructive. In connection with the recessus neuroporicus it was stated that the olfactory nerves were attached at about the middle of the telencephalic segment. Under the influence of these nerves was begun the evagination which has produced not only olfactory bulbs but eventually the whole hemispheres. The relation of the olfactory ventricle to the sulcus limitans in selachians seems to indicate that the evagination was at first a further widening of the primary neuromeric expansion within the olfactory region. The caudal part of the olfactory region behind the expanding neuromeric groove became the primordium hippocampi. And in all vertebrates the hippocampal area forms the roof of the ventricle right forward to the primary olfactory area. This condition is destroyed only by the formation of a long olfactory stalk as in some fishes, or by the reduction of the hippocampus in later development as in higher mammials. 
RELATIONS OF GRAY COLUMNS IN DIENCEPHALON AND TELENCEPHALON. As fully described above, the somatic area including the so-called striatum is continuous with the (dorsal) somatic sensory centers in the diencephalon. In the preoptic region the medial olfactory area (i.e. the precommissural body and the preoptic nucleus) comes into contact with the central gray of the thalamus. It does not appear either in selachians or in other fishes that I have studied, that there is a fundamental continuity between these gray masses, and this is not to be expected. The ventral gray of the thalamus extending forward from the nucleus of the III nerve, includes the nucleus of the medial longitudinal fasciculus and the nucleus ventralis thalami. These are "motor" or effective centers whose descending fibers lead to the neurones forming final common paths to the periphery. If these centers and correlation tissue intimately associated with them extend forward to and over the optic chiasma, they form the ventral column in the telencephalon as previously described ('09 b, '10 c). This ventral column meets with the hypertrophied and recurved dorsal column at the preoptic recess (fig. 82). Here the ventral effective and dorsal receptive columns are separated by the rostral end of the sulcus limitans of His.

The primordium hippocampi in selachians and some other fishes shows some signs of continuity with the nucleus habenulae. In cyclostomes the gray matter of the two is broadly contiguous. In selachians the large non-medullated posterior pallial commissure runs through the nucleus habenulae to decussate, and is accompanied through a part of the telencephalon medium by a gray column prolonged from the primordium hippocampi (figs. 13, 32). In ganoids and teleosts this gray column is much larger but in no fishes does it reach the nucleus habenulae as in cyclostomes.

Several factors have operated to separate the hippocampal gray from that of the diencephalon. (1) Most important among these is that the visceral receptive column in the diencephalon is reduced in all known vertebrates. Primary visceral receptive centers are wholly wanting because there is no peripheral nerve. The correlating tissue which represents the visceral receptive column in the diencephalon is known only in the hypothalamus 
and possibly the nucleus habenulae. The hypothalamus is one of the chief stations in the ascending gustatory (and general visceral) pathway. If the nucleus habenulae has been derived, as the writer has held, from the visceral receptive column, it is evident from the facts presented in this paper and by other authors that a large part of the fibers which come to it bring impulses from somatic receptive or correlating centers. The nucleus habenulae is therefore an olfacto-somatic correlating center as Edinger ('08) has suggested. The shifting of the hypothalamus ventrad and of the nucleus habenulae dorsad has helped to break the continuity with the visceral receptive column in the telencephalon. (3) The formation of the optic vesicle and its migration ventrad, although it did not remove any visceral receptive tissue, helped to disturb the primary relations at the di-telencephalic boundary.

In general, then, the telencephalon has a short ventral (motor) column at the chiasma, separated from the dorsal columns by the sulcus limitans of His. As elsewhere in the brain, visceral receptive and somatic receptive columns are present. The somatic receptive column is continuous with that of the diencephalon (p. 29). The visceral receptive column has lost continuity with the corresponding gray of the diencephalon through modifications in the diencephalon itself.

GENERAL MORPHOLOGY OF THE TELENCEPHALIC FIBER TRACTS. Little is to be said of the tracts intrinsic to the telencephalon. The peripheral nerves enter the dorsal columns at about the middle of the segment and secondary tracts spread the impulses through the olfactory centers. The somatic centers receive no peripheral nerve fibers in most vertebrates.

The extrinsic tracts consist of ascending or receptive and of descending or effective pathways. The ascending visceral path is the tractus pallii and, at least in ganoids and teleosts, fibers in the medial forebrain tract. The somatic ascending path consists of optic and general sensory radiations. The descending visceral paths include the tractus olfacto-hypothalamicus, the tractus olfacto-habenularis and the fornix. The somatic descending 
path is provided by the somatic projection tract (so called tractus strio-thalamicus) and the tractus taeniae.

The ascending paths are longitudinal correlating tracts and the course of each is confined to its own column. This is perfectly clear in the case of the optic and general sensory radiations. They pass up from the optic and lemniscus centers in the thalamus directly into the somatic sensory center of the telencephalon. They are directly comparable to fibers which connect adjacent or more distant segments of the dorsal horn in the spinal cord, running in or near the dorsal horn itself. They are directly comparable also to the "direct external arcuate fibers" which run from the nucleus of the dorsal tracts up on the same side through the restiform body to the cerebellum.

The tractus pallii is not in present vertebrates confined to the visceral receptive column because of the interruption of that column. Since the hypothalamus is a visceral sensory center and since the depression of the hypothalamus is shown by the development to be a secondary modification in lower vertebrates, I see no objection to the inclusion of the tractus pallii in the statement that the ascending paths run in their own columns.

The descending paths divide themselves into two sets. The less important are those which make up a great part of the stria medullaris. These go from both visceral and somatic centers to a part of the dorsal columns in the diencephalon. Whether the nucleus habenulae is a part of the visceral or somatic column or includes both, the stria medullaris tracts are longitudinal descending tracts confined to the dorsal columns. They have their counterparts in the tractus tecto-cerebellaris, secondary fibers descending in the visceral lobe of the myelencephalon, etc.

The olfacto-hypothalamic tracts and the fornix go down through the base of the thalamus into the hypothalamus. In doing so they cross the ventral column and I am inclined to believe that the corpora mammillaria represent visceral effective column tissue. The whole question of the morphology of the hypothalamus is still an open problem.

The somatic projection tract clearly connects the dorsal column with the ventral column. In the first part of its course it 
runs nearly in a dorso-ventral direction and crosses the sulcus limitans of His from the dorsal column of the telencephalon to the ventral column in the diencephalon. According to Van Gehuchten and Bochenek part of the fibers can be traced to the myelencephalon. These fibers strongly resemble those of the pyramidal tracts, with which they are very probably homologous. The somatic projection tract belongs in the came category as the tectospinal tract and the vestibulo-spinal tract.

The Pallial PRIMORdia AND THE aNTERIOR PalLIAL COMMIssuRE. The point of special interest is that already in selachians the pallial areas and their commissures present characteristic relations and are as clearly distinguished from the secondary olfactory centers as they are in the lower mammals. In a preliminary communication ('10 c) I have pointed out that the anterior pallial commissure is situated in the lamina supraneuroporica in cyclostomes, selachians, probably in reptiles and certainly in mammalian embryos. This the writer regards as the typical position for the pallial commissure as distinguished from the anterior commissure, which lies in the lamina terminalis. Both belong to the series of dorsal brain commissures, but the pallial commissure is more caudal. The anterior commissure is formed across the closed-up neuropore, the pallial commissure is caudal to the neuropore space. The anterior commissure is formed chiefly of decussating tracts related to the secondary olfactory centers. The pallial commissure is related to correlating centers and contains true commissural fibers of both visceral and somatic pallial areas.

Of the pallial areas it has been noted that at first neither is involved in the evagination of lateral lobes. The cerebral hemispheres begin in vertebrate animals not in order to make room for the great correlating centers which we call cortex, but to accommodate the expanding primary olfactory centers. In cyclo stomes only the primary and secondary olfactory centers are so evaginated. The primordium hippocampi is well advanced in its differentiation but is not at all involved in the evagination. In selachians the evagination has gone much farther and the primordium hippocampi is turned from its vertical position in the 
lateral wall to the position of a roof stretching over the median ventricle and extending forward in the lateral lobe nearly to the olfactory peduncle. In cyclostomes the primordia of the two sides meet in a slight thickening of the lamina supraneuroporica which contains the anterior pallial commissure. In selachians the two primordia have invaded the lamina supraneuroporica to form a very massive gray roof in which the pallial commissureisimbedded. In higher vertebrates this median fusion of the hippocampal formations is recognizable only in early embryos. It was noted above that in essential respects the position of the primordium hippocampi is the same as in all higher vertebrates.

The primordium of the somatic pallium is apparently as highly developed as that of the hippocampus. Its position is not materially affected by the evagination but it extends forward in the lateral wall of the hemisphere a short distance beyond the interventricular foramen. In higher vertebrates the telencephalon medium is gradually involved in the evagination and the somatic area finally comes to form the greater part of the wall of the hemisphere. The steps in this process may best be discussed at a later time but two or three chief factors may be mentioned here. The hippocampal formation is much longer in higher vertebrates than in selachians. This is probably due in part to the fuller development of the unevaginated part which although large in cyclostomes is reduced in selachians. The further evagination of the hemisphere takes place at the expense of the telencephalon medium, and the foramen interventriculare moves caudad along the sulcus Monroi. This brings the primordium hippocampi into the roof and the somatic area into the lateral wall of the hemisphere. Further expansion of the hemisphere first gave rise to a posterior pole into which both hippocampal and somatic pallial areas enter (amphibians, reptiles). In mamals the disproportionate growth of the somatic pallium has pushed the secondary olfactory centers forward and downward to the basal aspect of the hemisphere, the hippocampal formation to the medio-dorsal border. The first modification of the selachian condition leading to this result is the pushing forward of the somatic pallium between the primordium hippocampi and the 
lateral olfactory area. This supposition violates no law of lines of growth or differentiation, since the pushing forward takes place along the lines of the sulcus and zona limitans hippocampi and amounts only to a pushing apart of the hippocampus and lateral olfactory area in order to make room for the growing somatic pallium. The connection between the lateral olfactory nucleus and the hippocampus directly in the posterior pole must be regarded as of late origin in the vertebrate series.

Area superfictalis basalis. Consideration of this has been left to the last as it is the most difficult and at the same time most interesting part of the selachian telencephalon. The area is intimatelyrelated along its medial, lateral and rostral borders with the secondary olfactory nuclei. It sends fibers to the primordium hippocampi, to the nucleus habenulae, and to the hypothalamus. If we look for the homologue of this area in a lower mammal we find a continuous "cortical" area extending from the medial olfactory area to the rhinal fissure. Into its medial border enters the medial olfactory tract and along its lateral border runs the lateral olfactory tract. The cortex of this area is very different in structure from the cortex of other areas. Here in selachians the area basalis agrees in its relations to the medial and lateral olfactory tracts and stands out sharply from the other areas by reason of its cortical structure. It seems to the writer very probable that the area basalis together with the lateral olfactory area corresponds to the tuberculum olfactorium, the area perforata anterior and the pyriform lobe in mammals.

The gray matter through which the lateral olfactory tract runs and in which it ends is usually regarded as the pyriform lobe. In selachians the lateral tract is distributed both to the poorly differentiated lateral olfactory nucleus and to the lateral part of the basal area. It is doubtless this latter which gives rise to the cortex of the pyriform lobe - a cortex of a very different sort from that of the general pallium. The rhinal fissure which bounds the pyriform lobe laterally is doubtless homologous with the sulcus and zona limitans lateralis in selachians. There is this difference, that the rhinal fissure separates the pyriform lobe from the somatic pallium (general cortex), while the zona limi- 
tans in selachians separates the lateral olfactory area from the primordium hippocampi. This difference is explained by the growth of the somatic pallium in higher vertebrates which has led to its pushing forward and wedging itself in between the pyriform lobe and the hippocampal area. In this way the pyriform lobe came to be pushed down to the ventral aspect of the hemisphere. Otherwise, the lateral olfactory nucleus must have been crowded rostrad by the growth of the somatic pallium and there would have been no pyriform lobe formed.

I do not wish to take up here a discussion of the brains of amphibians and higher forms, but will point out only the similarity of the frog brain to the selachian in the matter of the basal area and pyriform lobe. The hemisphere in the frog presents a medial and a lateral sulcus and zona limitans like those of selachians. Below the medial zona limitans is the medial olfactory area filling the septum. Below the lateral zona limitans runs the lateral olfactory tract which meets with the lateral forebrain tract coming up from the thalamus. Between the two is the rounded ventral wall corresponding in position to the basal area of selachians. Reference to fig. 75 will show that there is present in the frog a superficial layer corresponding to the basal area of selachians. This is developed only in the septum and for a very short distance in the ventral wall. Here it holds precisely the same position relative to the nucleus medialis septi as the basal area holds to this nucleus in selachians.

The position of the lateral olfactory tract along the line of the zona limitans lateralis marks the lateral border of the pyriform lobe. The ventral half of the hemisphere-pars subpallialis of Gaupp-corresponds to the part of the selachian hemisphere below the zona limitans medialis and lateralis and corresponds to the area of the mammalian hemisphere reaching from the fissura rhinalis to the area parolfactoria (Brocae).

The roof, above the zona limitans, contains the primordium hippocampi and into this goes a large part of the lateral olfactory tract as in selachians. In the lateral and caudal part of the roof there is also the primordium of the somatic pallium. A part at least of the region into which thalamo-cortical fibres and optic 
radiations enter lies in the lateral wall of the telencephalon medium in the frog as in selachians, but it appears to the writer that a part of the somatic area is evaginated and occupies the lateral part of the roof between the primordium hippocampi and the pyriform lobe. Further discussion of the amphibian forebrain must be left to a later paper.

\section{SUMMARY OF RESULTS}

The following facts have been established in selachians.

1. The boundary between diencephalon and telencephalon is marked by the velum transversum and the caudal border of the chiasma-ridge. The unpaired (better unevaginated) portion rostral to this boundary line heretofore known as the "praethalamus" constitutes a telencephalon medium.

2. The rostral parts of the telencephalic walls are evaginated to form lateral lobes. The cavities of the lateral lobes are lateral ventricles which communicate with the median ventricle by foramina interventricularia. This is the view generally accepted by recent authors.

3. The medial walls of the lateral lobes come into apposition rostral to the lamina terminalis and are secondarily fused. This area of massive fusion is separated from the massive roof by a canal or cleft extending inward from the dorso-rostral surface to meet the recessus neuroporicus at the upper border of the lamina terminalis. In Scyllium this cleft is continued to the ventral surface so that a complete although narrow sagittal fissure separates the area of secondary fusion from the lamina terminalis and the roof.

4. The nervus terminalis typically enters the brain substance near the recessus neuroporicus internus. In some genera it reaches this point by way of the dorsal surface, above the secondary fusion, in others by way of the ventral surface, below the secondary fusion.

5. In the ventricular wall of the telencephalon medium a sulcus Monroi runs caudad from the foramen interventriculare. In some forms this sulcus enters into relation with one or another 
of the sulci in the wall of the diencephalon. In other forms the sulcus Monroi is wholly independent.

6. The recessus neuroporicus marks the division of the roof plate of the telencephalon into lamina terminalis and lamina supraneuroporica.

7. The lamina supraneuroporica is greatly thickened by gray matter forming a massive pallium and is traversed by a large commissure complex. This partly covers the ventricle of the telencephalon medium, the remainder of which is roofed by a tela chorioidea.

8. The following gray masses or functional areas are recognized:

a. Medial olfactory area, including:

1. Rostral wall of lateral lobe.

2. Area of secondary fusion.

3. Precommissural body and nucleus medialis septi corresponding in position to these structures in amphibians, reptiles and mammals.

4. Nucleus praeopticus (?).

b. Lateral olfactory area.

c. Basal superficial area.

d. Pallium.

e. Somatic sensory or correlation area.

9. The area of secondary fusion contains decussating olfactocortical fibers in Acanthias.

10. The massive pallium is everywhere separated from the secondary olfactory areas by a ventricular sulcus and a cell-free zone. The sulcus limitans lateralis is continued caudad as the sulcus Monroi.

11. The precommissural body has a supraforaminal prolongation corresponding to the pars fimbrialis septi (Kappers) in the frog.

12. The area superficialis basalis is closely related to both medial and lateral olfactory areas and is connected by fiber tracts with the olfactory bulb, the primordium hippocampi, the nucleus habenulae and the hypothalamus. 
13. The entrance of secondary and tertiary olfactory fibers and of the tractus pallii from the hypothalamus into the massive roof is confirmed.

14. The pallial commissure complex lies in the lamina supraneuroporica and contains a true pallial commissure.

15. A small tractus cortico-habenularis runs from the pallium through the stria medullaris to the nucleus habenulae as noted by Kappers.

16. A large bundle of fine non-medullated fibers from the pallium runs by way of the stria medullaris and crosses in the commissura superior of Osborn, constituting a posterior pallial commissure.

17. The so-called tractus medianus arises in the massive pallium, descends through the medial wall rostral to the foramen interventriculare and runs to the hypothalamus with the tractus olfacto-hypothalamicus. It thus corresponds in its course to the fornix.

18. The somatic area is a large gray mass in the lateral wall of the telencephalon medium and the lateral lobe. It includes at least a deeper large celled nucleus and a more superficial small celled layer or nucleus.

19. The somatic area receives thalamo-cortical fibers from the center for the lemniscus in the thalamus and optic radiations from the corpus geniculatum laterale.

20. The somatic area is connected with the lateral olfactory area or with the primordium hippocampi by a tract whose polarity is unknown.

21. The somatic areas of the two sides are connected by a true commissure which crosses dorsal to the commissura hippocampi in the lamina supraneuroporica.

22. From the somatic area a tract descends to the ventral part of the thalamus and perhaps to lower brain segments. This tract arises at least in part from the large celled nucleus.

23. The somatic area has relations to the anterior commissure, the meaning of which is not fully understood.

24. The tractus thalamo-corticalis and optic radiations con- 
stitute a lateral forebrain bundle not heretofore recognized in selachians.

25. The stria medullaris in selachians is composed of at least six distinct kinds of fibers. These are summarized on p. 34 .

The facts above summarized have led to the following theoretical conclusions or hypotheses bearing upon the evolution of the cerebral hemispheres.

26. If the area of secondary fusion in anura is the same as that in selachians, it must be a part of the medial olfactory area (secondary) and not the olfactory bulb (primary) as usually stated.

27. The position of the olfactory centers in the telencephalon adjacent to the roof plate of His is what is to be expected if these centers represent a hypertrophied visceral sensory column of the brain.

28. The position of the somatic area on the lateral surface corresponds to that of the somatic sensory column in those segments of the brain in which the visceral sensory column is hypertrophied.

29. The evagination of lateral lobes primarily takes place wholly within the olfactory area and carries out the bulbar formation and part of the olfactory area.

30. In fish-like vertebrates only a small part of what corresponds to the future cerebral cortex is involved in the evagination. The lateral lobes of fishes are therefore not equivalent to the mammalian hemispheres. The evagination of the hemispheres becomes complete only gradually in the vertebrate series.

31. The sulcus limitans hippocampi is a prominent feature in selachians and amphibians. It is essentially a vertical transverse sulcus in the course of which the evagination of the lateral ventricle takes place. The continuation of this in the telencephalon medium primarily ends in the preoptic recess.

32. The sulcus Monroi in selachians separates the primordium hippocampi from the central gray ental to the somatic area in the telencephalon medium, and is variable in its caudal extent and in its relations to diencephalic sulci. In higher vertebrates where the telencephalon medium has been largely used up in the evagi- 
nation of lateral lobes the sulcus Monroi is perhaps a late product of mechanical conditions of slight importance for morphological purposes.

33. There is no evidence that any part of the telencephalon beyond the immediate region of the optic chiasma is derived from the ventral columns of the neural tube (basal plate of His).

34. All the olfactory centers have probably been derived from the visceral sensory column of the telencephalon; the primary and secondary centers from the rostral part, the primordium hippocampi from the caudal part of this column.

35. The pyriform lobe is represented in selachians by the lateral olfactory area together with a part of the basal superficial area.

36. The somatic area is believed to represent the primitive somatic sensory column of the telencephalon.

37. The afferent and efferent tracts of the somatic area are comparable with those of the somatic or general pallium of mammals.

38. The somatic area lies between the pyriform lobe and the caudal part of the primordium hippocampi. When the telencephalon medium is involved in the evagination of the hemisphere the relative position of these functional areas is maintained. The grow th of the somatic cortex in higher vertebrates results in pushing the pyriform lobe and primordium hippocampi to the margins of the hemisphere.

39. The commissure of the somatic areas in the lamina supraneuroporica resembles in every way the corpus callosum, with which the writer believes it to be homologous.

40. The somatic cortex is at least as highly specialized in fishes as the visceral cortex. The terms archipallium (Elliot Smith) and neopallium (Edinger) are therefore not appropriate.

41. The beginnings of localization in the general pallium are perhaps to be seen in the separation of the optic radiations from the general sensory radiations and in the origin of the somatic projection tract chiefly from the large celled nucleus.

42. The motive for the development of the general pallium is found in the need of correlation of cutaneous, muscular and optic 
sense impressions. The chief reason for the development of the generalpallium in the telencephalon rather than in other segments is found in the freedom of the telencephalon from primary somatic sensory centers and nerves (see paper on correlation mechanisms in Anat. Record, vol. 4).

\section{BIBLIOGRAPHY}

Bochenex, A. 1899 Die Nervenbahnen des Vorderhirnes von Salamandra maculosa. Bull. Internat. Akad. Sei. Krakovie.

Вотаzzi. 1894-95 Il cervello anteriore dei Selacei. Ricerche Labor. di Anat. d. Reale Univ. di Roma, etc., Fasc. 3-4, vol. 4.

Brookover, Chas 1910. The olfactory nerve, the nervus terminalis and the preoptic sympathetic system in Amia Calva L., Jour. Comp. Neur. Psych., vol. 20.

Burckhardt, Rudolf. 1907 Das Zentral-Nervensystem der Selachier. I. Teil: Einleitung und Scymnus lichia. Abhdl. der Kais. Leop. Carol. Deutsch. Akad. Naturf., Bd. 73, p. 29, Halle.

Cators, E. H. $190 \mathrm{~L}$ Recherches sur l'histologie et l'anatomie microscopique de l'encéphale chez les poissons. Bull. scientif. de la France et de la Belgique, Tome 36 , pp. 81-83.

EDINGER 1888 Untersuchungen über die vergleichende Anatomie des Gehirns I. Das Vorderhirn. Abhdlg. Senckenberg Naturf. Ges., Bd. 15.

1896 Vorlesungen, p. 146.

1908 Vorlesungen, vol. 2, 7 Aufl., 255, 267-269, 299.

Goldstein, KURT. 1905 Untersuchungen über das Vorderhirn und Zwischenhirn einiger Knochenfische. Archiv f. mikr. Anat., Bd. 66.

GaUPP 1897 Anatomie des Frosches, 2. Abth.

Haller, B. 1898 Vom Bau des Wirbelthiergehirns. I. Theil, Salmo und Scyllium. Morph. Jahrb., Bd. 26, p. 579, 617.

Herrick, C. Judson. 1910 Jour. Comp. Neur. Psych., vol 20.

HIs, W. 1893 Ueber das frontale Ende des Gehirnrohres. Arch. Anat. u. Entw .

Houser, G. L. 1901 The neurones and supporting elements of the brain of a selachian. Jour. Comp. Neur., vol. 11, p. 153.

Johnston, J. B. 1901 The brain of Acipenser. Zool. Jahrb., Anat., Bd. 15, pp. $112,212$.

1902 The brain of Petromyzon. Jour. Comp. Neur., vol. 12. 1905. The morphology of the veterbrate head, etc., Jour. Comp. Neur. Psych., vol. 15, pp. 233-242. 
1906 Nervous system of vertebrates. Philadelphia, Blakiston. 1909 a. The central nervous system of vertebrates, Ergebn. u. Fortschr. der Zoologie, Bd. 2, pp. 35-38, 104-108, 131. With citation of literature.

$1909 \mathrm{~b}$ The morphology of the forebrain vesicle in vertebrates. Jour. Comp. Neur. Psych., vol 19.

$1910 \mathrm{~b}$ The problem of the correlating mechanisms. Anat. Rec., vol. 4.

$1910 \mathrm{c}$ The evolution of the cerebral cortex. Anat. Rec., vol 4. $1910 \mathrm{~d}$ A note on the forebrain of Chimaera, Anat. Anz., vol. 36.

Kappers, C. U. ArIEns. 1906 The structure of the teleostean and selachian brain. Jour. Comp. Neur. Psych., vol. 16, pp. 15, 17, pl. 10 and 13.

Kappers Und Thednissen. 1907 Zur vergleichenden Anatomie des Vorderhirnes der Vertebraten. Anat. Anz., Bd. 30, p. 502.

1908 Die $\cdot$ Phylogenese des Rhinencephalons, des Corpus striatum und der Vorderhirnkommissuren. Folio Neuro-Biologica, Bd. 1, pp. 198-200.

v. KUPFFER, C. 1893 Studien zur vergleichenden, Entwickelungsgeschichte des Kopfes der Kranioten. I. Die Enwickelung des Kopfes von Acipenser sturio. München u. Leipzig,

LocY, W. A. 1905 On a newly recognized nerve connected with the forebrain of selachians. Anat. Anz., vol. 26.

Snessarew, P. 1908 Ueber die Nervenfasern des Rhinencephalon beim Frosche. Jour. f. Psychol. u. Neurol., Bd. 13.

Sterzi, G. $1909 \mathrm{Il}$ sistema nervoso centrale dei vertebrati. Vol. 2, Pisci Lib. 1, Selachi, Pt. 1, Anatomia, pp. 577, 801, Padova.

Van Gendchten 1894 Contribution à l'étude du système nerveuse des Téléostéens. La Cellule, T. 10.

1897 Le ganglion basale, la commissure posthabénulaire, le faisceau longitudinal postérieur, et les cellules médullaires dorsalis de neuraxe de Salamandra. Verhandl. Anat. Ges., p. 120. 


\title{
EXPLANATION OF FIGURES
}

\author{
ABRREVIATIONS
}

$a .$, the first of three sulci dorso-caudal to the sulcus Monroi in the diencephalon

a.c.b., area superficialis basalis

a.olf.lat., lateral olfactory area

$b$., the second diencephalic sulcus dorsocaudal to the sulcus Monroi

$c$. , the third diencephalie sulcus dorsocaudal to the sulcus Monroi

c.g.l., corpus geniculatum laterale

c.a. or c. ant., commissura anterior

c.c., cerebellar crest

c.call., corpus callosum

c.hipp., commissura hippocampi

ch.op., optic chiasma

c.mam., corpus mammillare

com.sup., commissura superior (Osborn)

com. pal. ant., commissura pallii anterior

com. pal. post., commissura pallii posterior

c. post., commissura posterior

dec. pop. decussatio postoptica

dec. $t r$. olf. lat., decussation of lateral olfactory tract

dec.tr.olf.-hab., decussation of tractus olfacto-habenularis

dec.tr.pall., decussation of the tractus pallii in postoptic region

fasc.com., fasciculus cummunis

$f . i$., foramen interventriculare

fiss.sag., fissura sagittalis

f.l.m., fasciculus longitudinalis medialis

g.hab., nucleus habenulae

hypoth., hypothalamus

lat.fb.bdl., lateral forebrain bundle

lat.olf.area, or

lat.olf.nuc., lateral olfactory nucleus

lat.ven., lateral ventricle

$l . s .$, lamina supraneuroporica

l.t., lamina terminalis

med.fb.bdl., medial forebrain bundle

med.olf.nuc., medial olfactory nucleus or area n.prof., profundus division of trigeminal nerve

$n . s p .$, spinal nerve

n.t., nervus terminalis

nuc.hab., nucleus habenulae

nuc.lem., nucleus of the lemniscus in thalamus

nuc.med.sep., nucleus medialis septi

olf.ped., olfactory peduncle

olf.som., olfacto-somatic correlation tract

op.rad., optic radiations

p.c.b., precommissural body

plx.ch., plexus chorioideus

prim. hipp., primordium hippocampi

rec. neur., recessus neuroporicus

r.n.e., recessus neuroporicus externus

$r . n . i .$, recessus neuroporicus internus

$r . p .$, recessus praeopticus

r.po., recessus postopticus

sac. $d$, dorsal sac

s.f. p.c.b., supraforaminal part of precommissural body

s.lim.His., sulcus limitans of $\mathrm{His}$

s.lim.l., sulcus limitans hippocampi lateralis

s.lim.med., sulcus limitans hippocampi medialis

s.M., sulcus Monroi

som.area. somatic area

som.proj., somatic projection tract

s.s., somatic sensory column

$s . s-h .$, sulcus subhabenularis

str.med., stria medullaris

taen.for., taenia fornicis

t.p., tuberculum posterius

tr.cort-hab., tractus cortico-habenularis

tr.hab-ped., tractus habenulo-peduncularis

tr.hab-thal., tractus habenulo-thalamicus

tr.olf.lat., tractus olfactorius lateralis

tr.olf.med., tractus olfactorius medialis 
tr.olf-cort.m.c., tractus olfacto-corticalis medialis cruciatus

tr.olf-cort. $m$-d., tractus olfacto-corticalis medio-dorsalis

tr.olf-cort,sep., tractus olfacto-corticalis septi

tr.olf-hab.lat., tractus olfacto-habenularis lateralis

tr.olf-hab.post., tractus olfacto-habenularis posterior

tr.olf.hyp., tractus olfacto-hypothalamicus

tr.op., tractus opticus

tr.pall.cr., tractus pallii cruciatus tr.pall.r., tractus pallii rectus

tr.sac-thal., tractus sacco-thalamicus

tr.sep-hab., tractus septo-habenularis

tr.taen., tractus taeniae

tr.thal.-cort., tractus thalamo-corticalis

tub.post., tuberculum posterius

$v . m$. , visceral motor column

v.s., visceral sensory column

v.tr., velum transversum

zona lim.l., zona limitans lateralis zona lim.m., zona limitans medialis

$i, i i, i i i, i v, v, v i$, neuromeres 

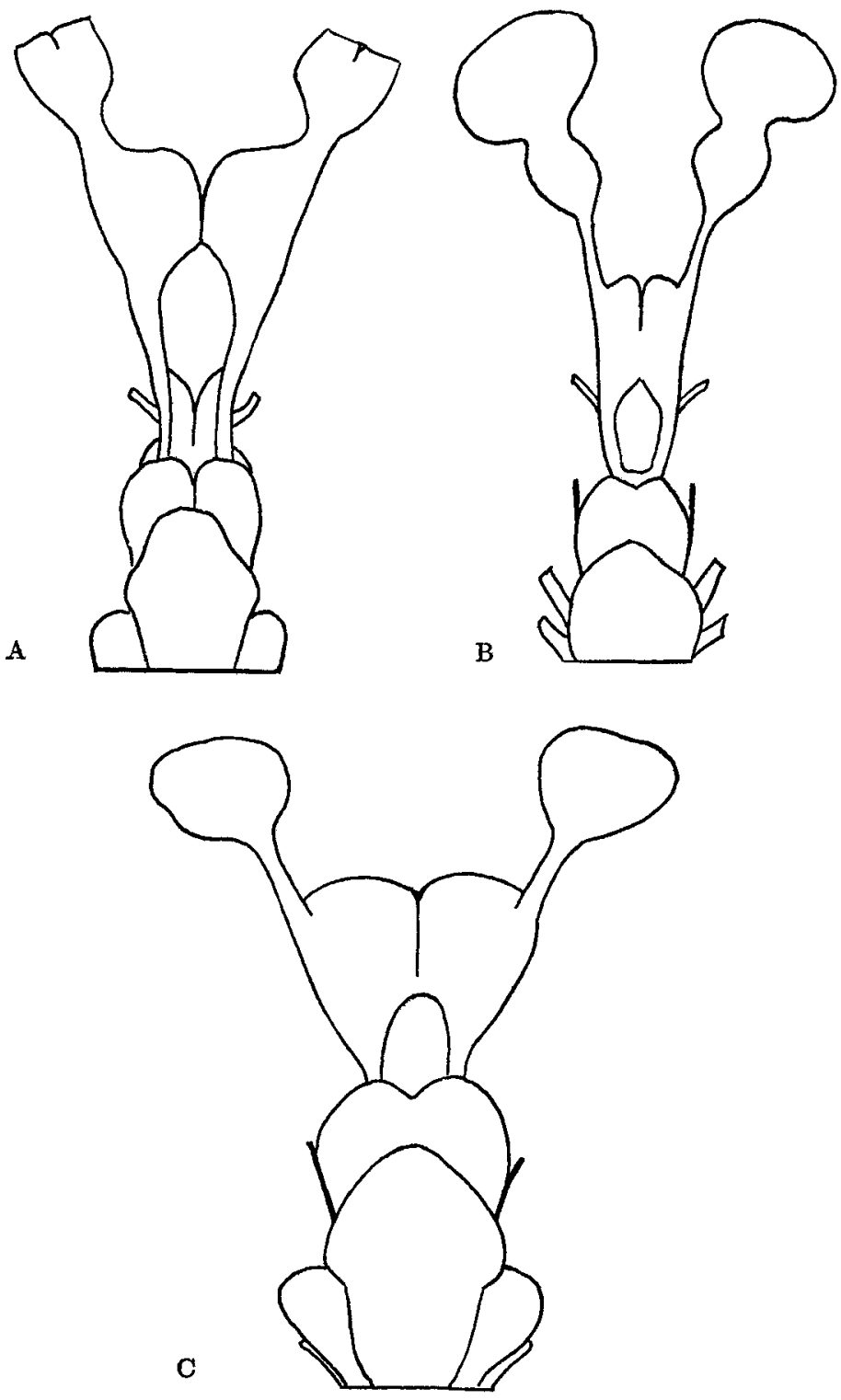

Fig. 1 Outlines of the anterior part of the brains of three selachians as seen from above, to show the progressive fusion of the lateral lobes, $A$, Scymnus; $B$, Heptanchus; $C$, Acanthias. The nervus terminalis is not drawn. 

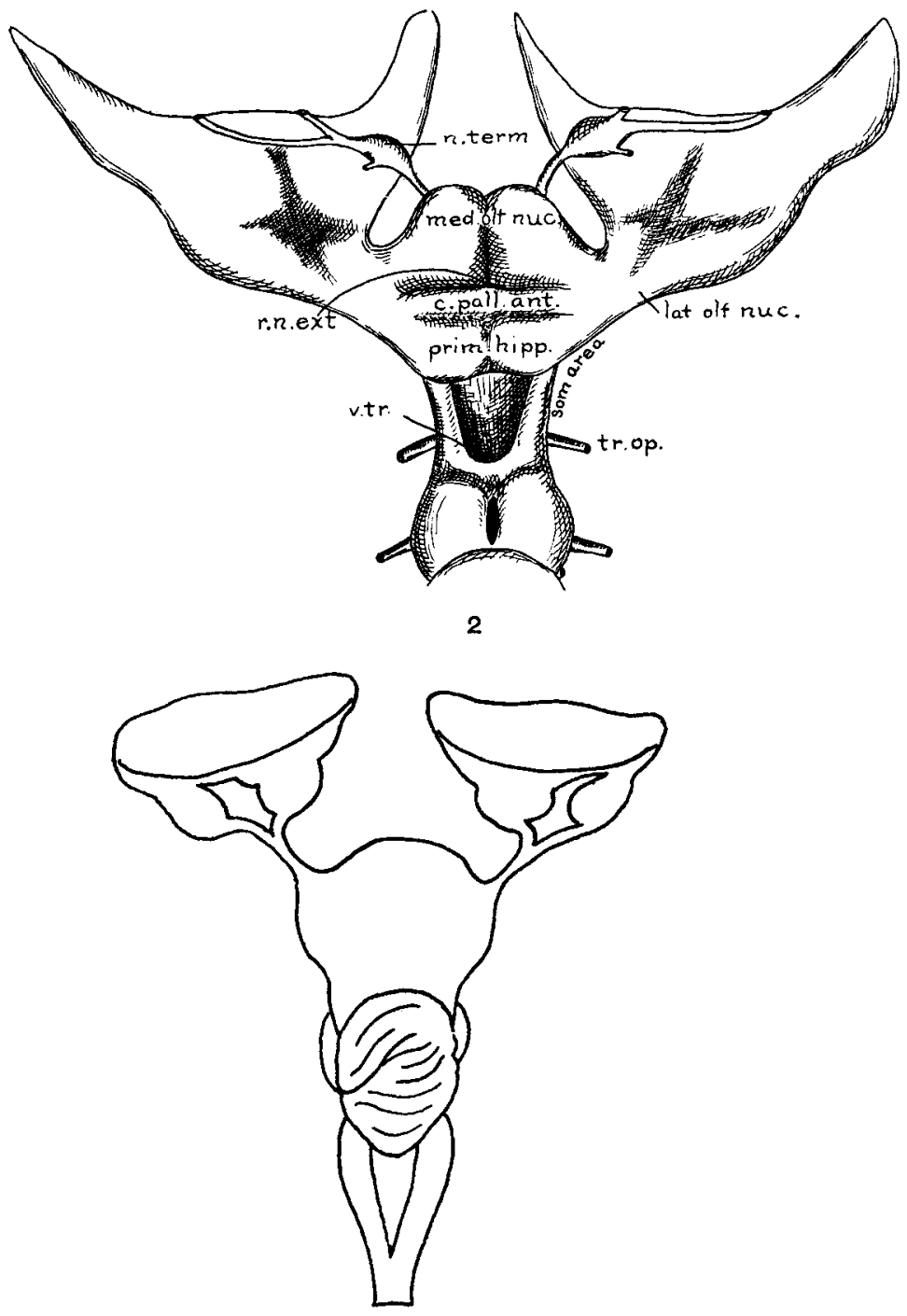

3

Fig. 2 Scyllium stellare, anterior part of the brain seen from above, to show further fusion of the lateral lobes due to the hypertrophy of the medial olfactory area. The line v.tr. marks the point of attachment of the velum transversum.

Fig. 3 Scoliodon, anterior part of brain for comparison with figs. 1 and 2 . The fusion of the lobes is apparently complete. 


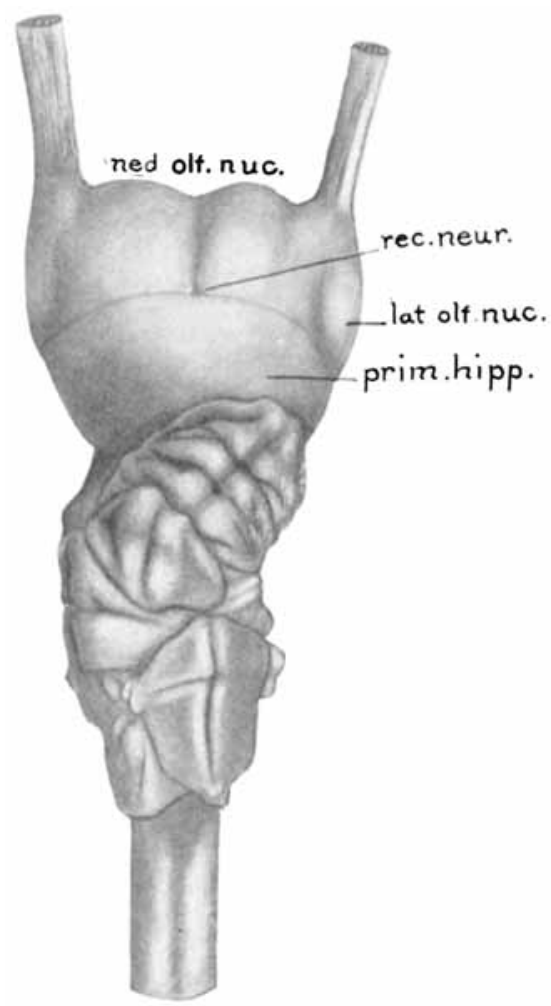

Fig. 4 Myliobatis brain seen from above. All parts of the central olfactory apparatus are very large. The external neuroporic recess is carried far back on the dorsal surface. The large primordium hippocampi is overlapped by the much elongated and convoluted cerebellum. The diencephalon and mesencephalon are completely hidden in dorsal view. 

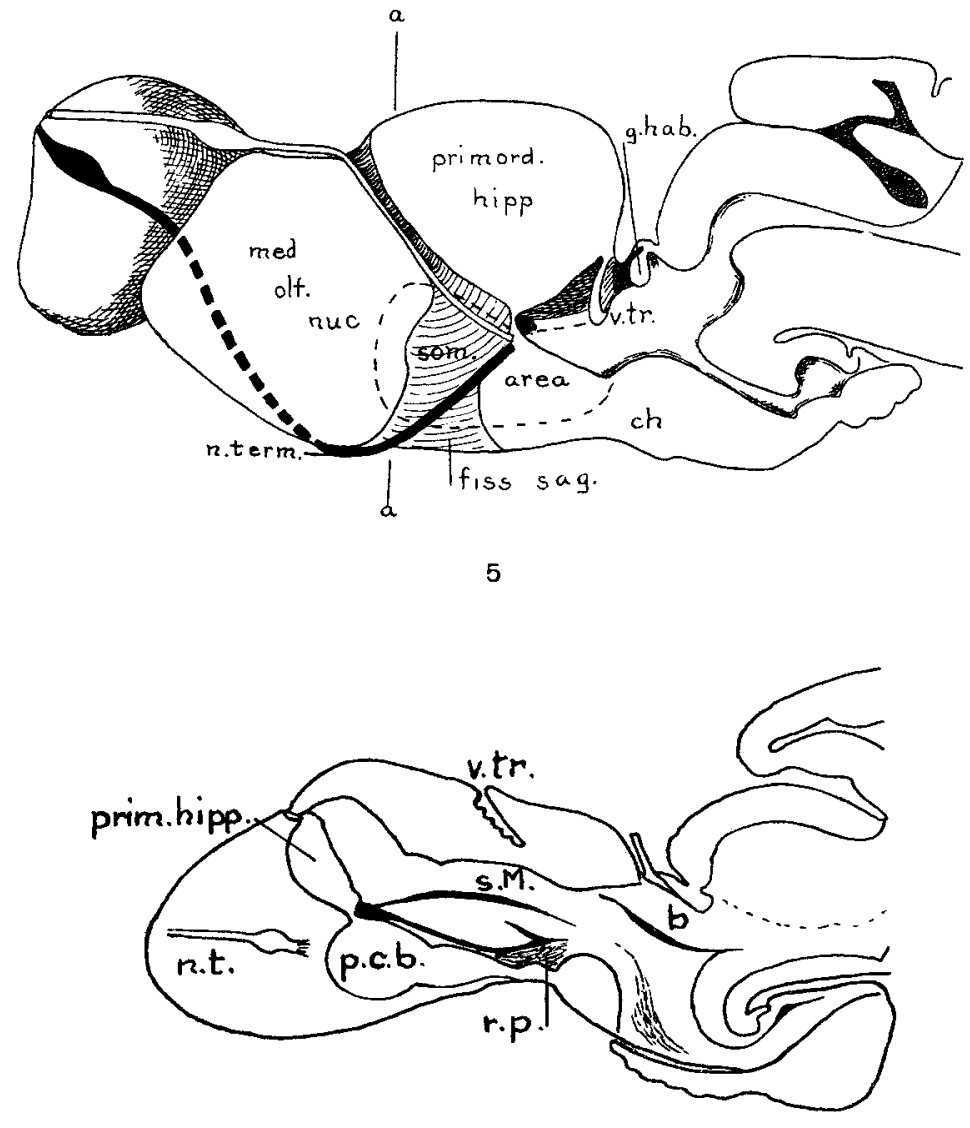

6

Fig. 5 Scyllium stellare, sketch of right half of the anterior part of brain. The course of the nervus terminalis in Scyllium is shown in black. In light outlines is drawn the dorsal course of the nerve as seen in Hexanchus, Acanthias, and others. In Scyllium the external neuroporic canal is extended through to open on the ventral surface, thus forming a complete sagittal fissure. The area of secondary fusion lettered med.olf.nuc. in this figure is to be compared with the so-called fusion of the olfactory bulbs in the frog. The thickened lamina terminalis just caudal to the sagittal fissure corresponds to the precommissural body of the frog. The elongation of the frog's brain takes place in the area represented here by the sagittal fissure.

Fig. 6 Scymnus lichia, outline of right half of anterior part of brain after Burckhardt's figure 21. The telencephalon medium is much longer than in Scyllium, the primordium hippocampi smaller and there is no secondary fusion. The nervus terminalis is added from Burckhardt's fig. 18. 

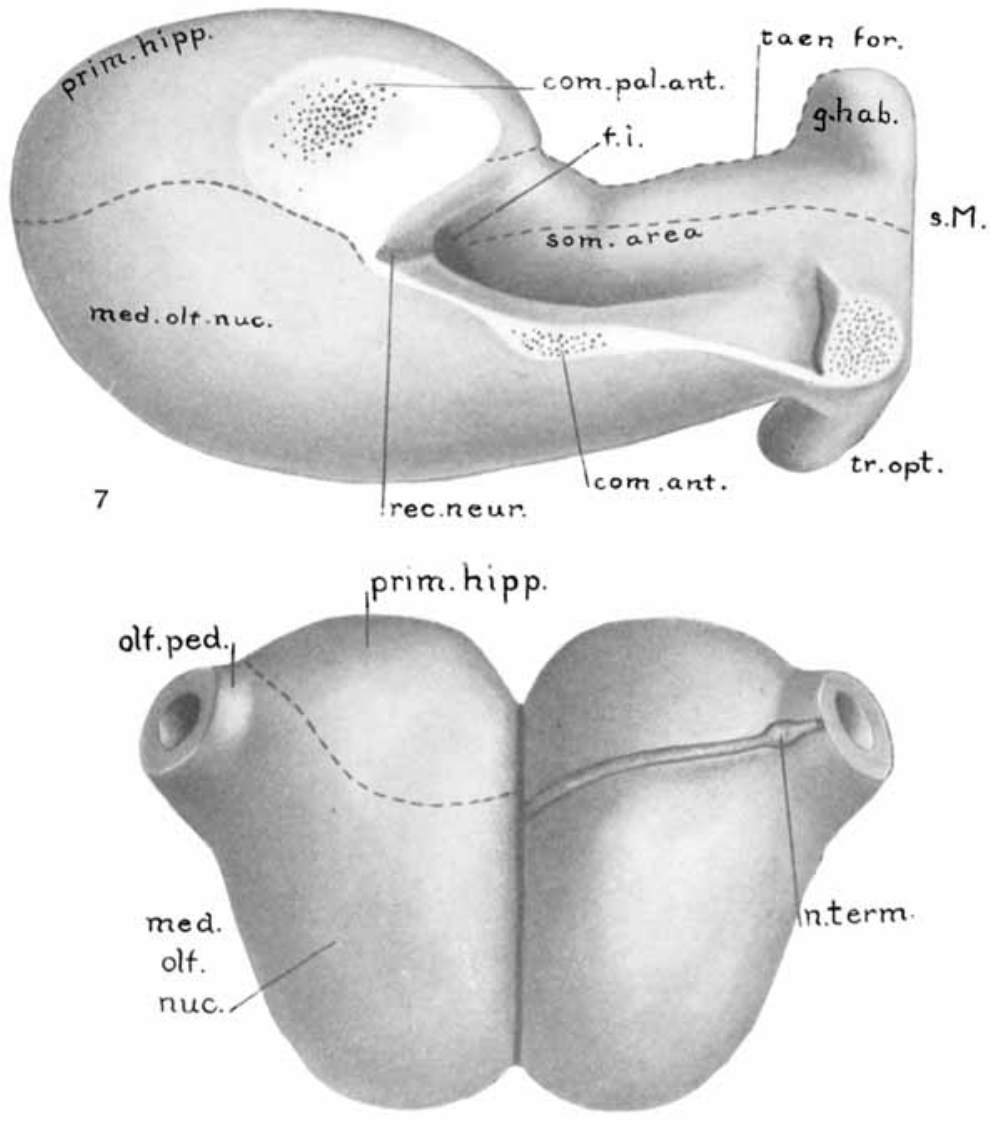

8

Fig. 7 Drawing of a clay model made to represent the right half of the telencephalon of a selachian in a condition more primitive than that of Scymnus. The olfactory centers are supposed to be considerably enlarged without producing secondary fusion of the lateral lobes. The primitive sulcus connecting the interventricular foramen with the preoptic recess is shown as in Scymnus. The sulcus Monroi is indicated only by a dotted line. As compared with cyclostomes, the primordium hippocampi is reduced in the telencephalon medium. Its pallial portion, although not greatly enlarged, overhangs the median ventricle more than in adult Scymnus, somewhat as it does in embryos of Scymnus and Acanthias. The lamina terminalis is only very slightly thickened by the invasion of the precommissural body. The somatic area, although lettered on this surface, lies wholly on the lateral surface.

Fig. 8 Drawing of the same model as seen from in front, to show the extent of the primordium hippocampi and the relations of the nervus terminalis. 

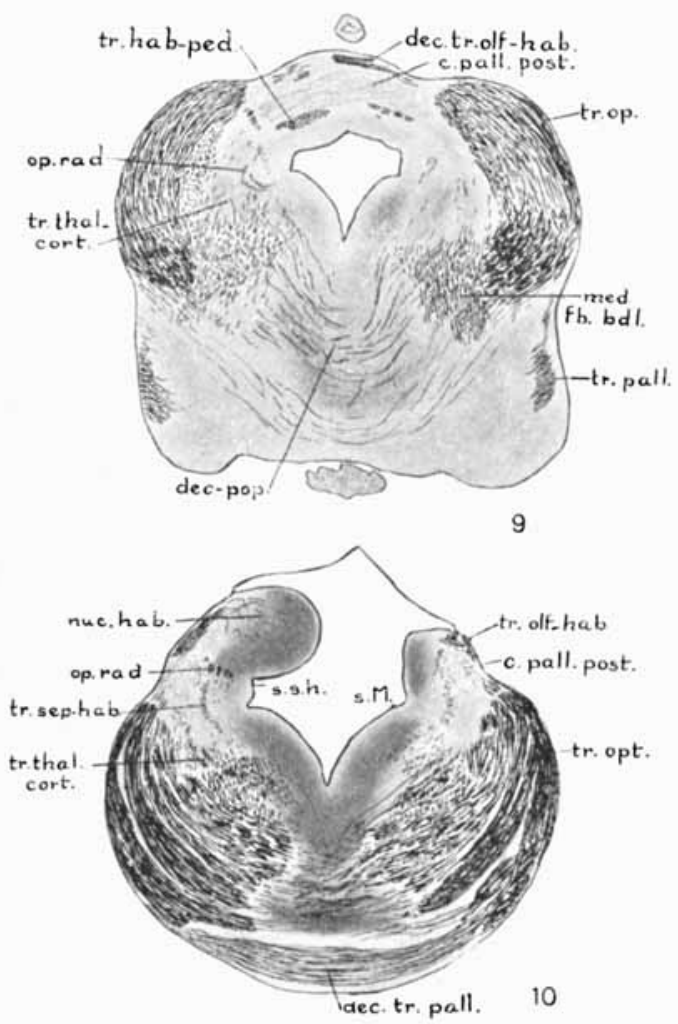

Figs. 9 to 20 Scyllium canicula, transverse sections to show the relations of fiber tracts and gray masses in the telencephalon. In all these figures the depth of shading indicates the relative number and density of cell bodies in various regions All the main features of the sections were outlined by means of the Edinger drawing apparatus and the details were filled in from the microscope.

Fig. 9 Section through the superior commissure (Osborn) and the post-optic decussations. The medial forebrain bundle is beginning to bend down into the hypothalamus. The optic radiations and thalamo-cortical fibers are both quite diffuse here. The superior commissure is very large and the greater part of its thickness is taken up by the fine non-medullated fibers of the posterior pallial commissure. The medullated portion may contain in addition to the olfacto-habenular fibers, all the other components of the stria medullaris as well.

Fig. 10 Section through the rostral part of the nucleus habenulae and of the postoptic decussations,including the decussation of the tractus pallii. The thalamocortical fibers and optic radiations are more compact than in fig. 9. The tractus septo-habenularis is cut just as it goes dorsad to join the stria medullaris. 


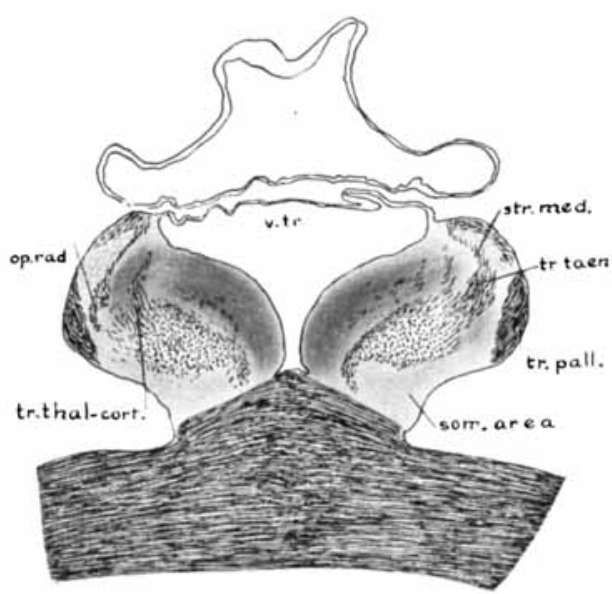

11

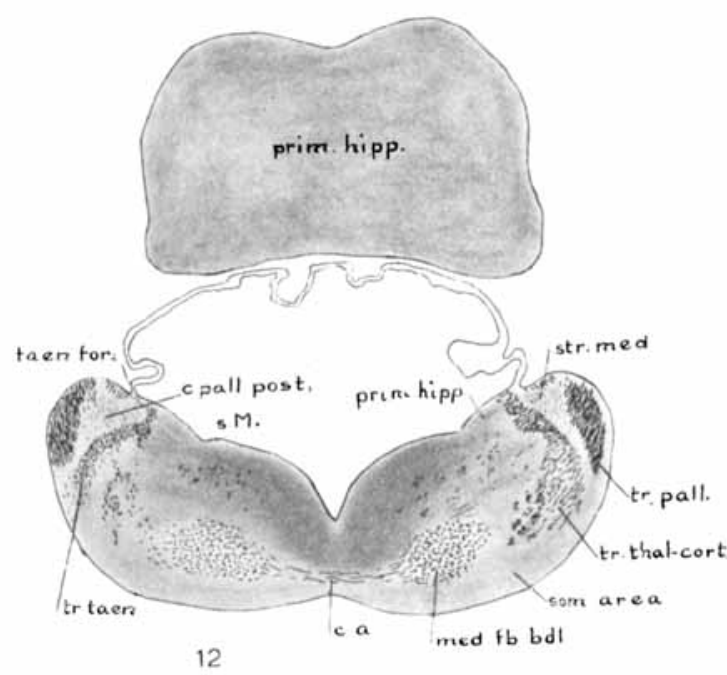

Fig. 11 Section through the velum transversum and the rostral part of optic chiasma. The section cuts the telencephalon medium alone. In this region the somatic area is traversed by the tractus pallii which rises rapidly above that area and runs forward along the border of the primordium hippocampi (see diagrams beyond). At this level the optic radiations and tractus taeniae are interwoven (see fig. 30).

Fig. 12 Section taken just rostral to the preoptic recess, through the caudal part of the anterior commissure and primordium hippocampi. The fibers of the tractus taeniae are intermingling with the thalamo-cortical fibers so that they can not be represented separately in a small drawing. Under the microscope the two sets of fibers have different directions and in sagittal sections both these and the optic radiations can be distinguished (see figs. 29-31). 

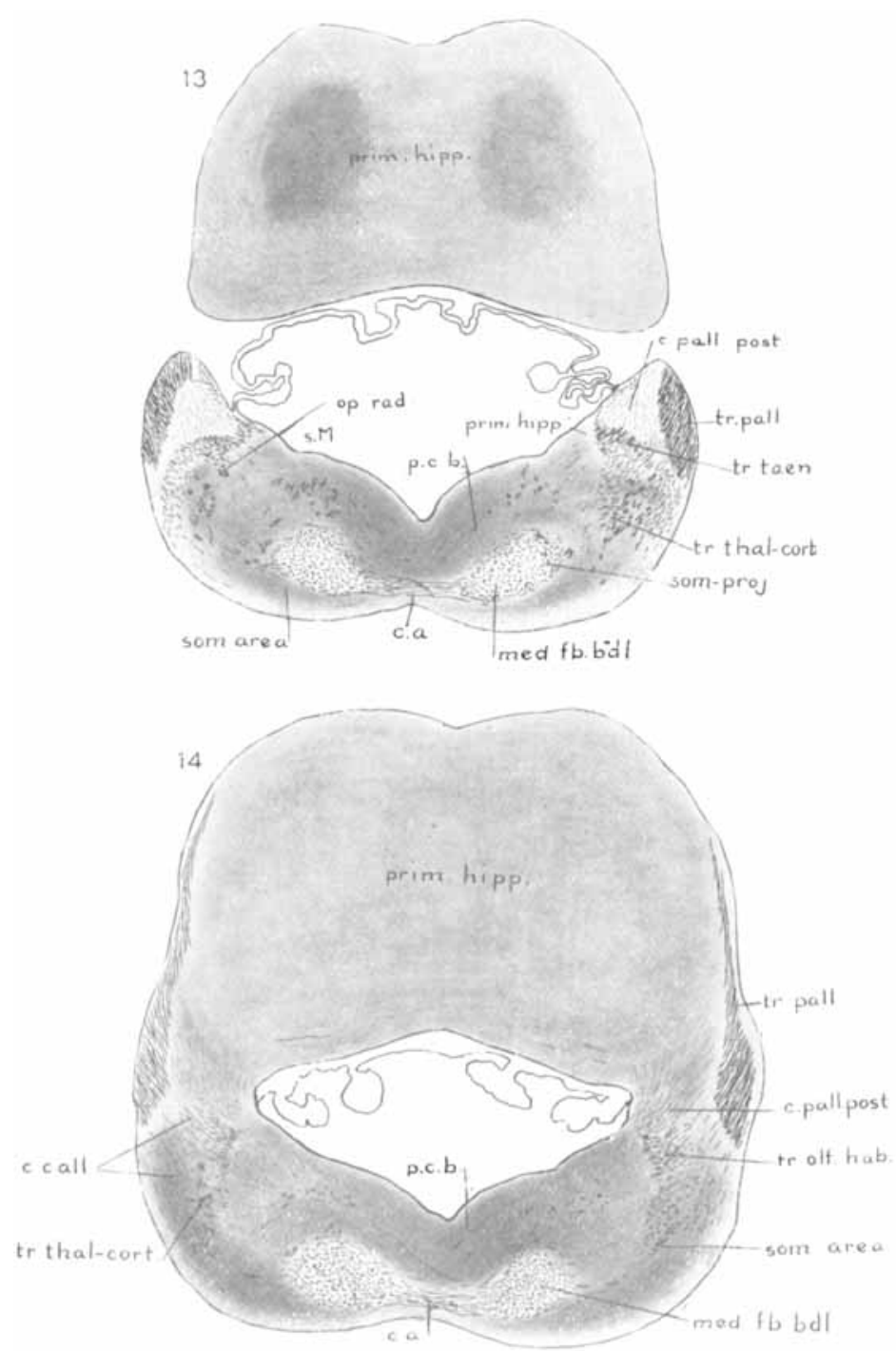

Fig. 13 Section a short distance rostral to fig. 12. The tractus pallii and the posterior pallial commissure rise up in a sort of peduncle of the primordium hippocampi. Adjoining the ventricle between these tracts and the sulcus Monroi is a moderately dense grey mass which constitutes a caudal prolongation of the primordium hippocampi. This body is cut in sagittal section in fig. 32 . In figs. 12 and 13 the distinctness of the medial and lateral forebrain bundles is striking.

Fig. 14 Section through the primordium hippocampi, anterior commissure and the caudal border of the foramen interventriculare. The somatic area is here at its 


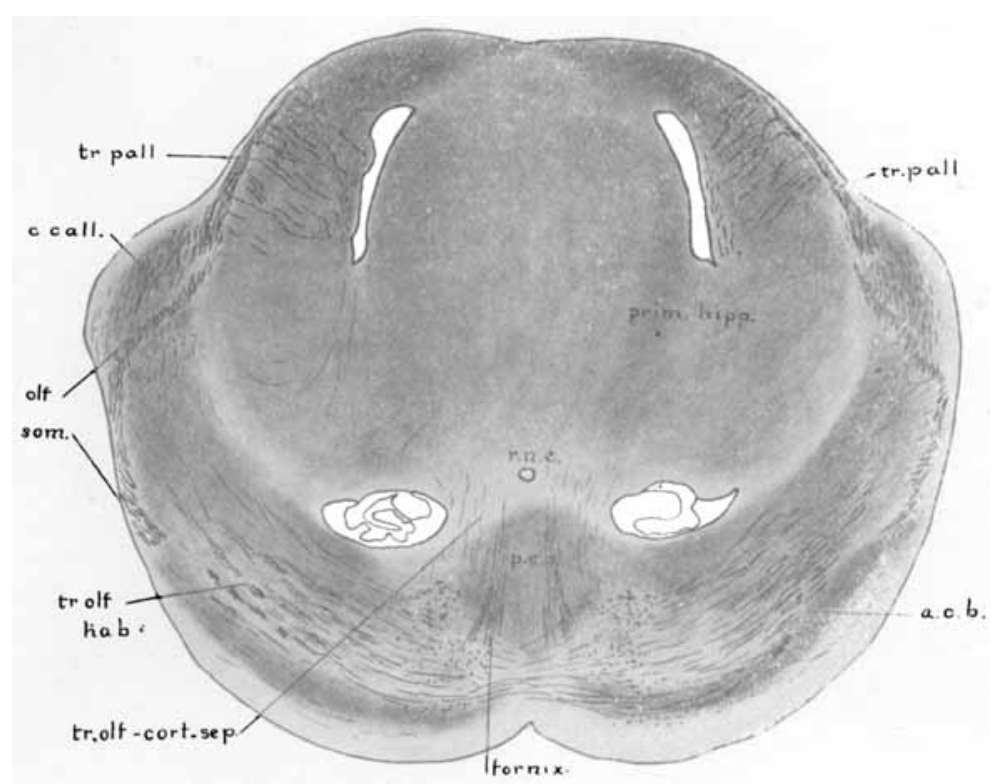

largest size, but just rostral to this gives way to the lateral olfactory area. The ascending somatic fibers have mostly disappeared. The tractus pallii and posterior pallial commissure go up into the primordium hippocampi. In the lateral part of the somatic area the fibers of the corpus callosum begin to be recognizable.

Fig. 15 Section rostral to foramen and cutting the dorsal polongations of the lateral ventricles (see sagittal sections beyond). The tractus pallii gives off fibers which penetrate the primordium hippocampi. Lateral to this a ridge represents the base of the olfactory peduncle. In this the corpus callosum follows the tractus pallii. Its fibers are finer and more numerous than appear in this figure. Below the corpus callosum the olfacto-somatic correlation tract forms a broad band most of which disappears between this and the section drawn in fig. 16. The zona limitans is very prominent at this level. The dense precommissural body is traversed by the pillars of the fornix which here join the medial forebrain tract (compare fig. 34). The area superficialis basalis has appeared in place of the somatic area. 


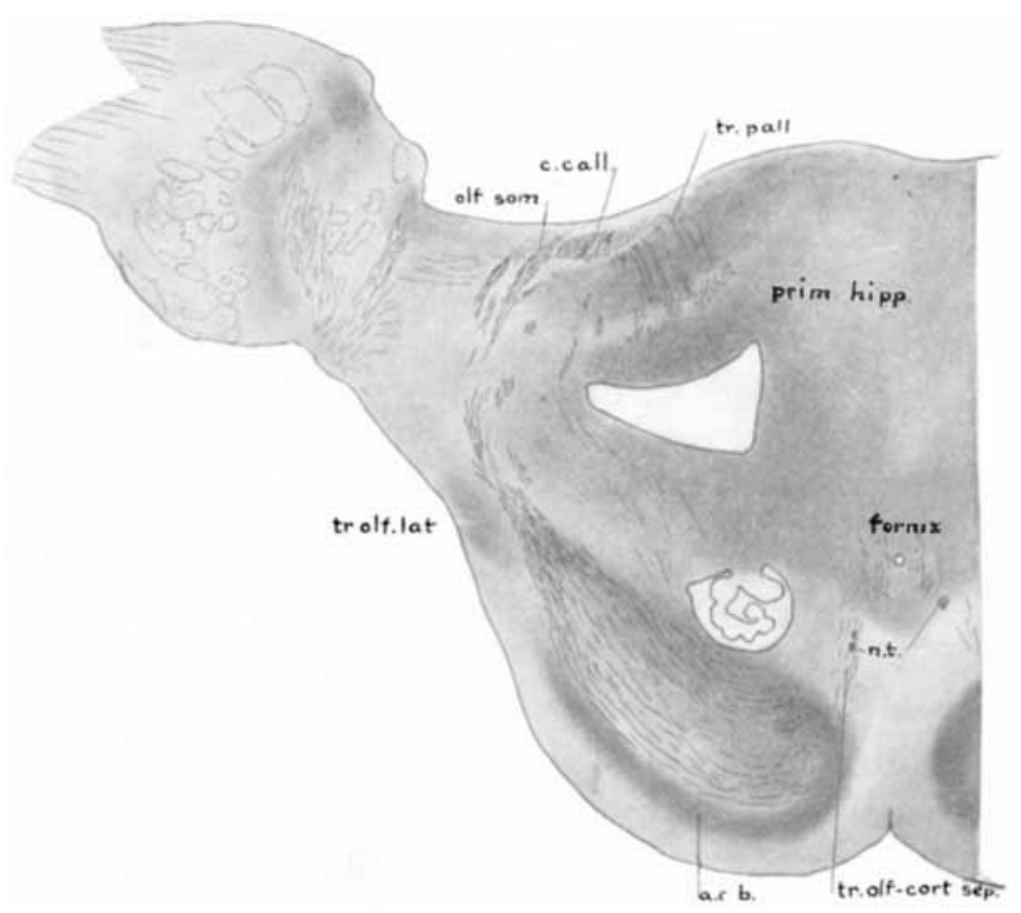

Fig. 16 Section through the eaudal part of the olfactory bulb and peduncle. The most rostral fibers of the trastus pallii are seen here. The olfacto-somatic tract has mostly ended in that part of the lateral olfactory area which lies in dorsal wall of the peduncle. The lower part of the olfactory area is covered by the basal lamina. The tractus olfacto-corticalis septi is lightly medullated in this specimen. It is distinct from the fornix. 


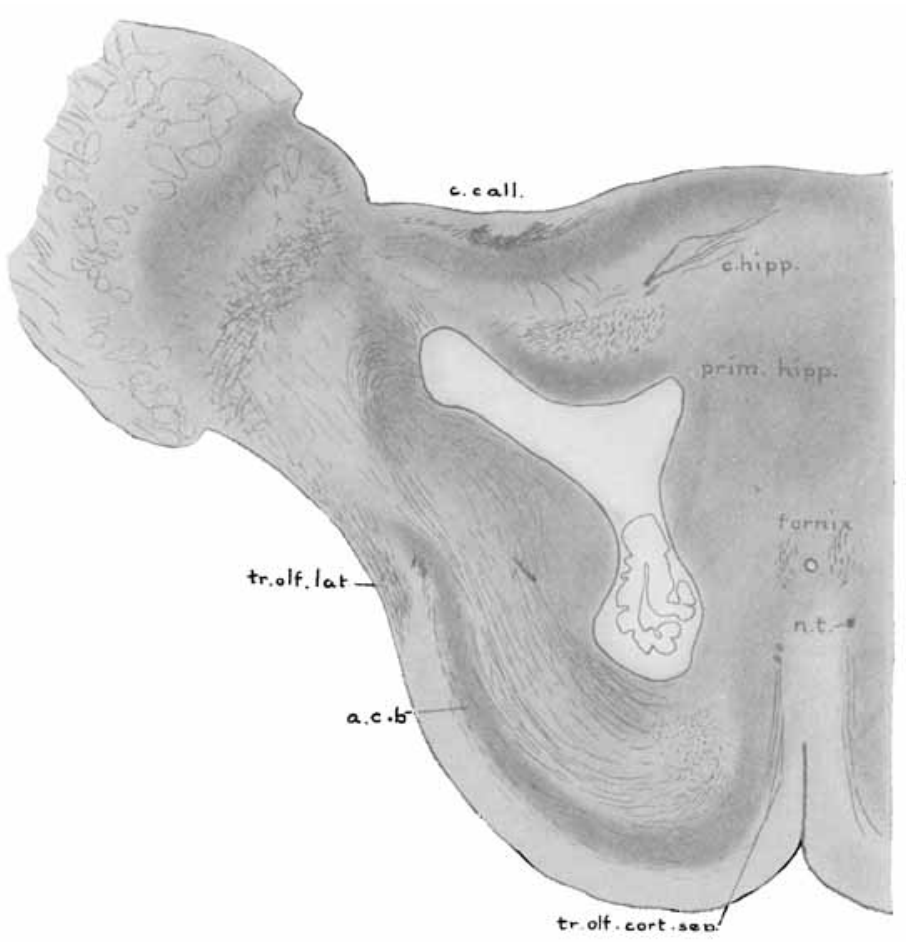

Fig. 17 Section through the olfactory peduncle just behind its ventricle. The hippocampal commissure begins to appear. It arises from the region in which the tractus pallii ends. The corpus callosum bends toward the median line. Note the lateral olfactory tract on the outer surface of lateral olfactory area and the basal area. 


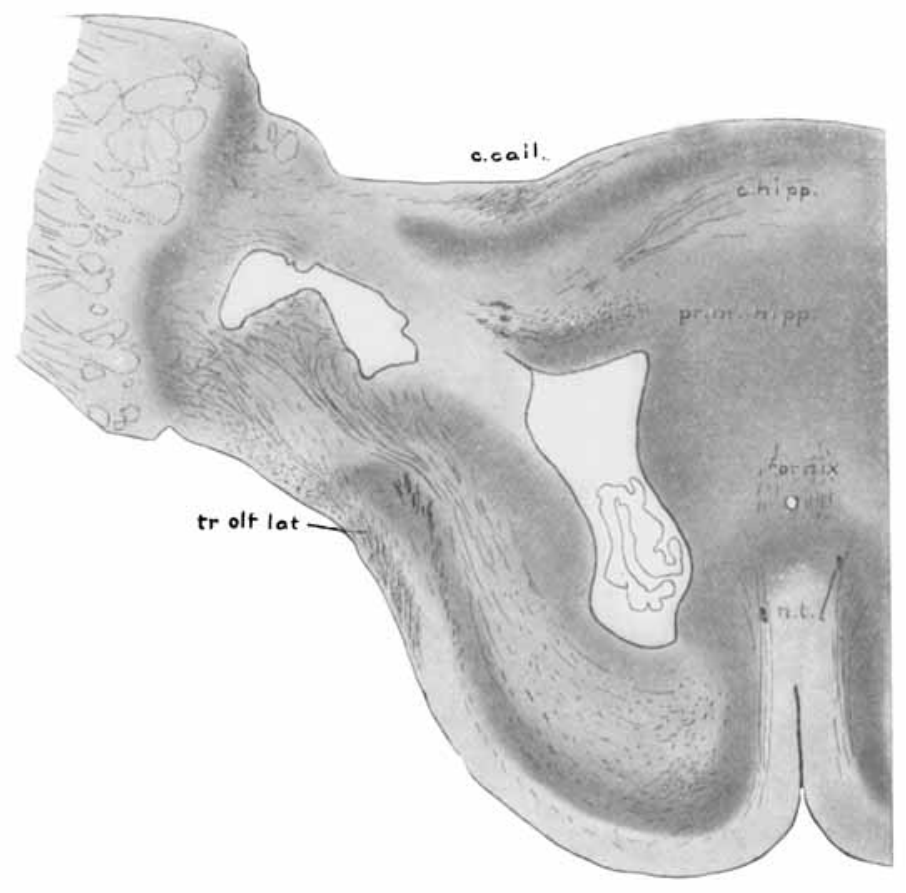

Fig. 18 Section through the olfactory peduncle and its ventricle. The limits of the primordium hippocampi are indicated by the zona limitans medialis, the light area in which the fornix is seen, and by the position of the corpus callosum in this section. Over the olf actory peduncle the gray of the primordium hippocampi is continuous with that of the lateral olfactory area. In the septum the nucleus medialis forms a slight ridge projecting in to the lateral ventricle. It is noticeable that this nucleus surrounds the external neuroporic recess between the fornix columns. The basal area is practically continuous with the nucleus medialis. 


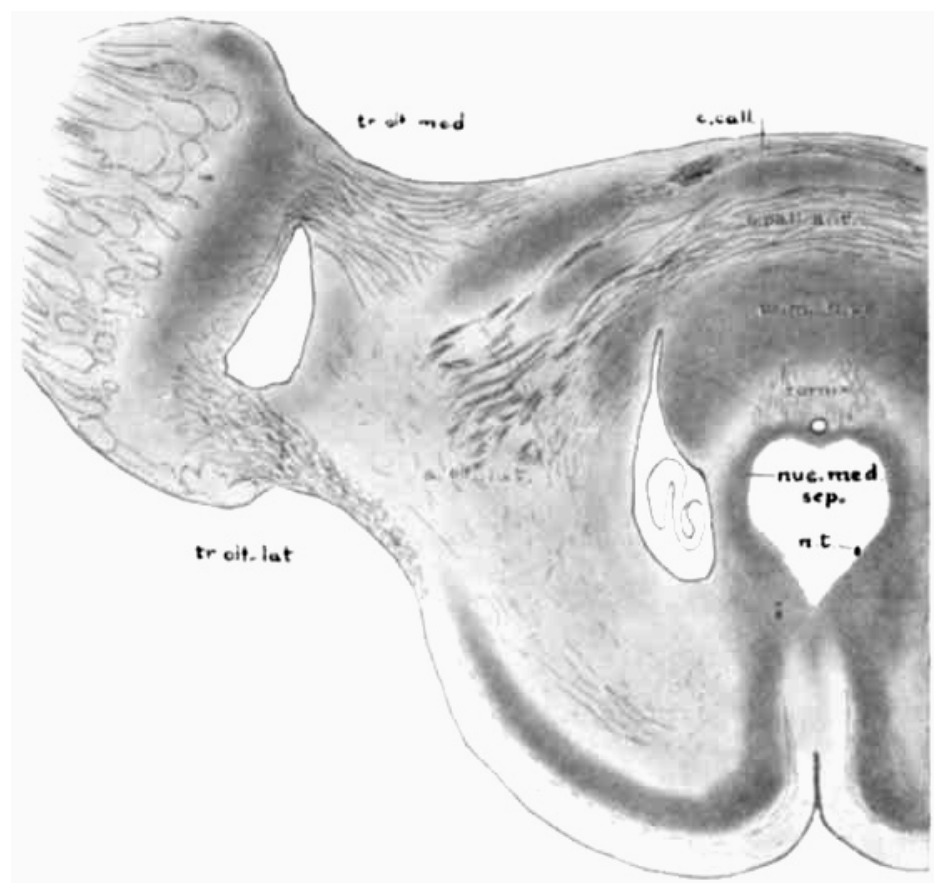

Fig. 19 Section through the anterior pallial commissure. Note that the corpus callosum is separated from the hippocampal commissure by a mass of cells. The hippocampal commissure now receives large bundles of fibers from the lateral olfactory area. (This is the "epistriatum" of Kappers). These fibers are coarser and more heavily medullated than the true commissural fibers. Although the ventricle is small in Scyllium on account of the thick walls, the two ridges projecting from the medial wall into the lateral ventricle are prominent here and in fig. 20. They are formed by the primordium hippocampi and the nucleus medialis septias in Acanthias and the frog and are separated by a distinet sulcus and zona limitans. 


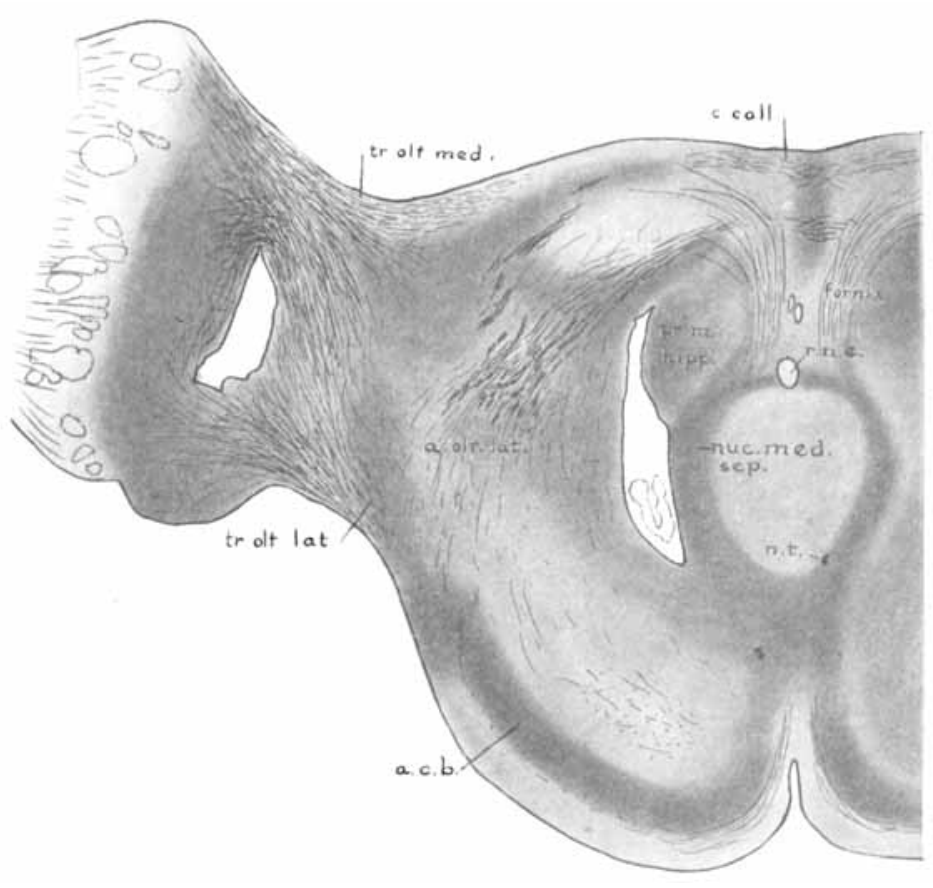

Fig. 20 Section through the anterior part of the olfactory bulb and peduncle. The lateral ends of the tertiary olfactory bundles of the pallial commissure are still present, and the section cuts the rostral border of the corpus callosum. The fornix fibers are collecting from the two sides and descending in the zona limitans.

Figs. 21 to 26 Transverse sections of the brain of Scyllium stellare to show the course and relations of the sulcus Monroi. The outlines and the chief fiber tracts were drawn with the aid of the Edinger apparatus. Fig. 21 is at the anterior border of the velum transversum and optic chiasma. Fig. 26 cuts the rostral surface of the tectum and the ventricle of the hypothalamus on one side. Between the level of fig. 21 and the foramen interventriculare the sulcus Monroi is very shallow and broad. In fig. 22 when the nucleus habenulae appears, the subhabenular sulcus (b) is separated from the sulcus Monroi by a ridge in which runs the stria medullaris 


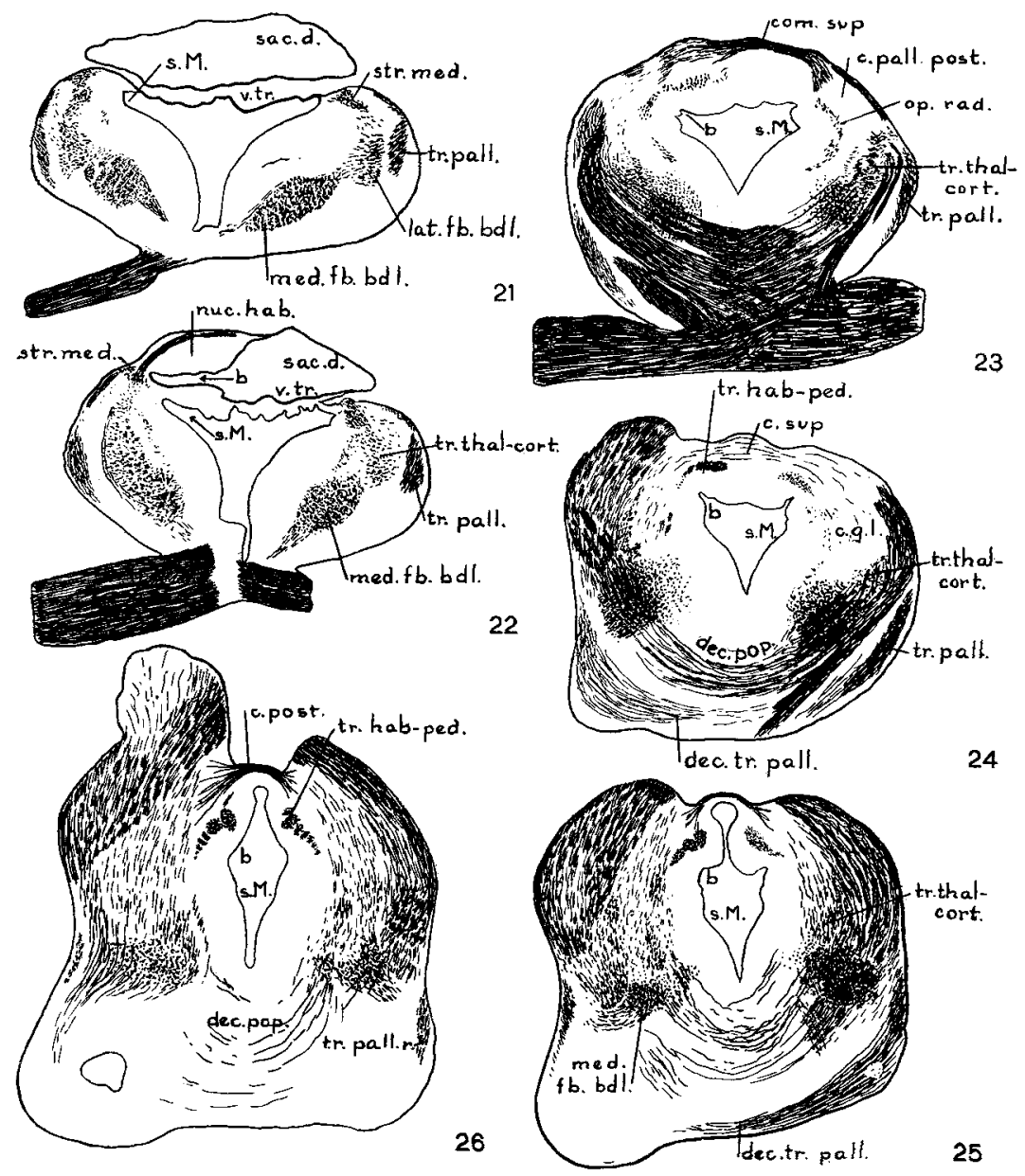

and to which the velum transversum is attached. This sulcus $b$ therefore opens into the dorsal sac above and runs caudo-ventrad from that. This is true of other forms also, but is more striking in Scyllium stellare because the attachment of the velum transversum extends farther caudad in this form. The sulcus Monroi fades away in figs. 25 and 26 beneath the rostral border of the posterior commissure The sulcus $b$ continues almost to the brain floor in the interpeduncular region. The disposition of these sulci is shown in a diagram in fig. 73.

The fiber tracts present essentially the same appearance as in the sections of Scyllium canicula shown in previous figures. The thalamo-cortical fibers and optic radiations are somewhat more distinct in S. stellare, as fig. 23 shows. 

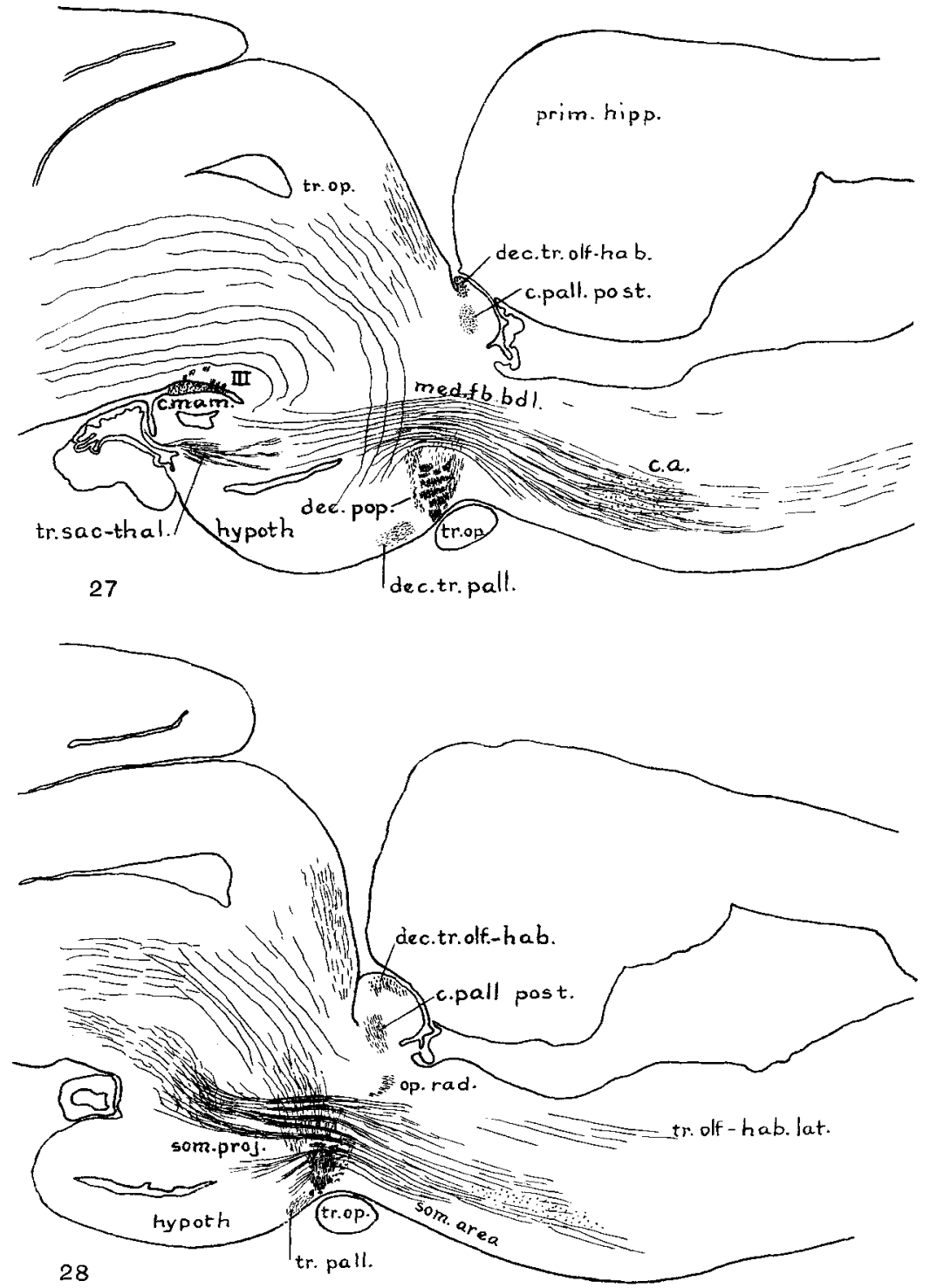

Figs. 27 to 31 Sections from a sagittal series of the brain of Scyllium stellare, to illustrate the fiber tracts related to the telencephalon medium. Drawn under the Edinger apparatus.

Fig. 27 Section lengthwise of the medial forebrain bundle. The bundle enlarges greatly at the anterior commissure, passes caudad over the optic chiasma and bends down into the hypothalamus. A large part of it reaches the corpus mammillare.

Fig. 28 Section through the lateral part of the medial forebrain bundle. A part of the bundle pierces the optic tract and bends down into the hypothalamus. The larger part in this section passes caudad at the level of the tuberculum posterius and is intermingled with fibers which run on caudad through the brain base. This is the somatic projection tract. Above this appear in this section the optic radiations. 

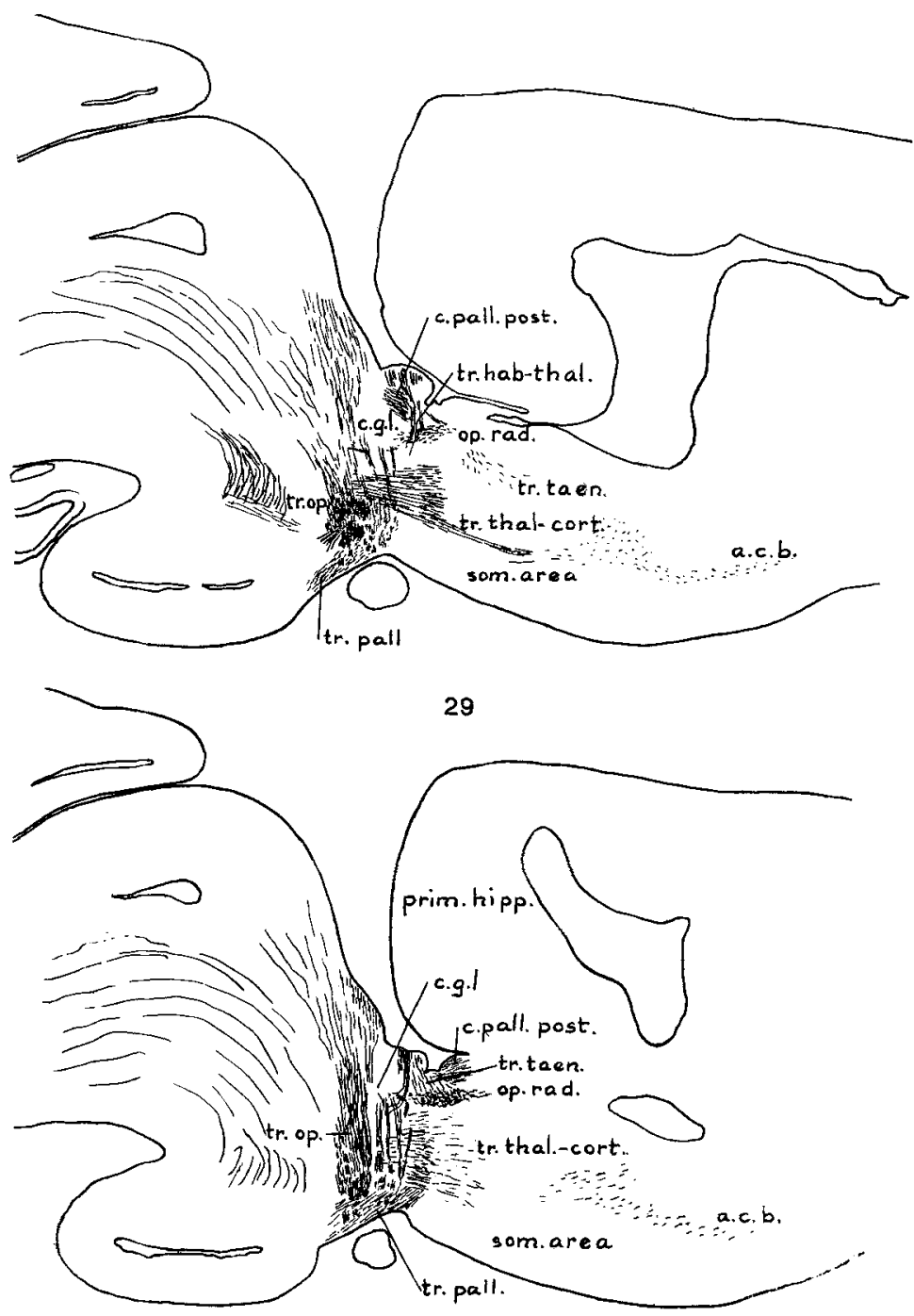

30

Fig. 29 Section lengthwise of the thalamo-cortical tract (lateral forebrain bundle). In this section are seen several small bundles of the optic tract entering the lateral geniculate body, the optic radiations going forward from it, and several components of the stria medullaris. The thalamo-cortical tract pierces the innermost bundles of the optic tract and is cut obliquely as it turns laterad into the somatic area. Farther rostrad the fibers which arise in the basal area are cut across as they run toward the anterior commissure. In this and fig. 30 the tractus pallii passes forward beneath the optic tract.

Fig. 30 A few sections lateral to fig. 29. Optic tract fibers enter the lateral geniculate body and some fibers from the nucleus habenulae have the same ending. The optic radiations passing forward from the geniculatum are interlaced with the tractus taeniae. The posterior pallial commissure occupies a small ridge, the caudal portion of the primordium hippocampi (compare fig. 32). 

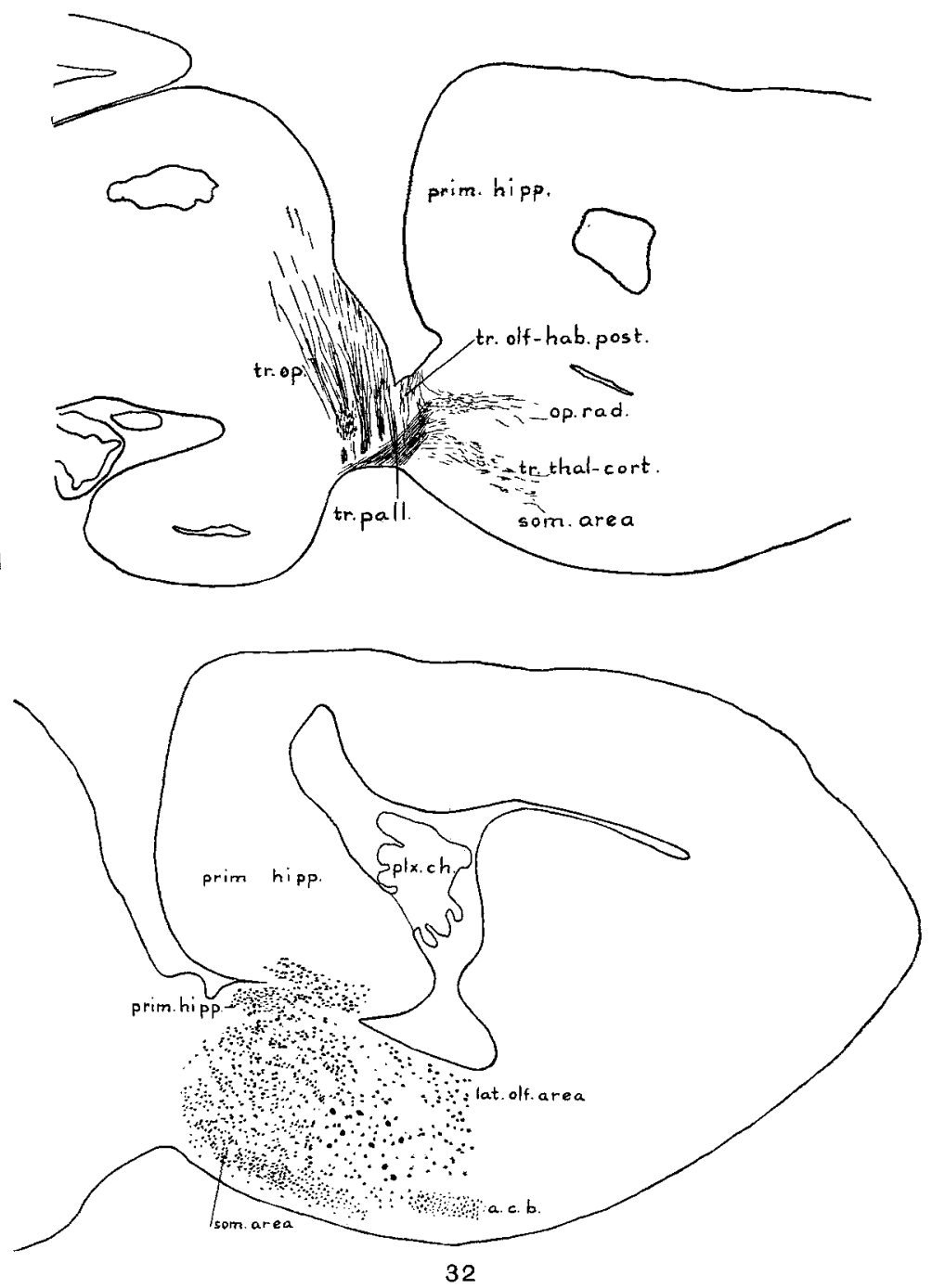

Fig. 31 A section far lateral showing the tractus pallii going up over thelateral surface of the telencephalon medium. The optic radiations and thalamo-cortical tract go forward nearly parallel, the optic radiations farther dorsally. The section shows fibers of the stria medullaris coming up from the preoptic recess ( $t r$. olf. hab. post.).

Fig. 32 Scyllium stellare, parasagittal section taken between the levels shown in figs. 29 and 30 . The cell bodies of the somatic area and the borders of adjacent areas are drawn under the Edinger apparatus. The somatic area has a superficial 


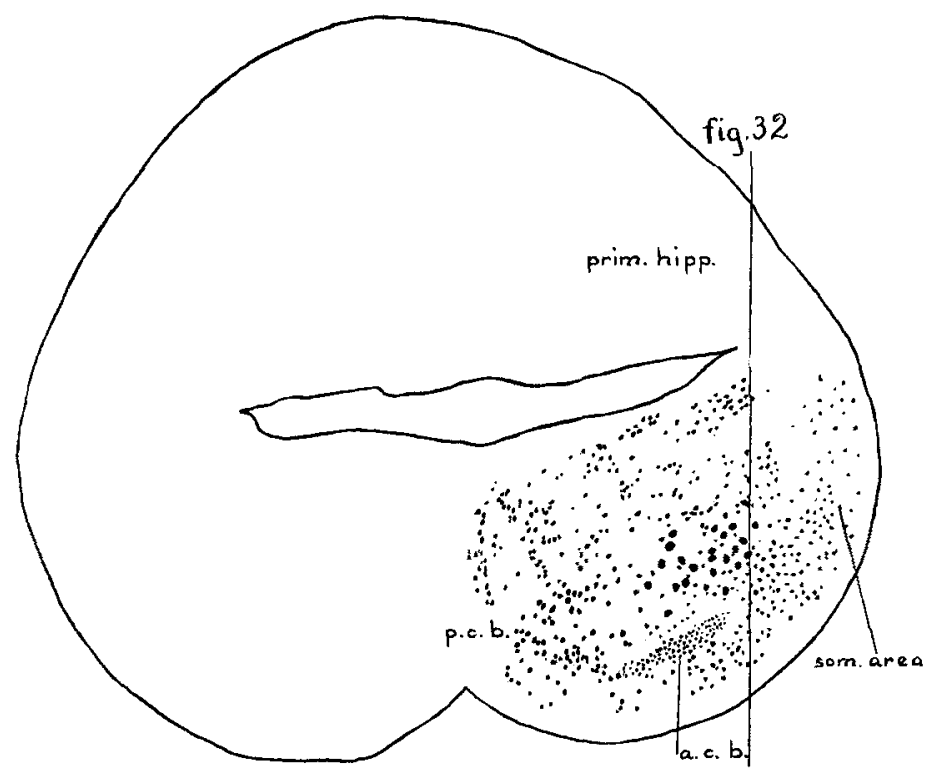

dense layer of cells. This is nearer the suface than the basal lamina and is separated from the latter by a distinct gap occupied by fibers of the medial forebrain bundle. The large-celled nucleus is in the rostral part of the somatic area. The cells in the caudal rudimentary part of the primordium hippocampi are drawn as well as a few in the main part. In the caudal portion the cells are in part imbedded among the fibers of the posterior pallial commissure.

Fig. 33 Scyllium canicula, transverse section through the caudal border of the foramen interventriculare to show the distribution of cell bodies. Compare with fig. 32. The caudal border of the basal lamina appears within the cortical layer of the somatic area. A short distance rostrad from this both the large-celled nucleus and cortical layer of the somatic area disappear. 


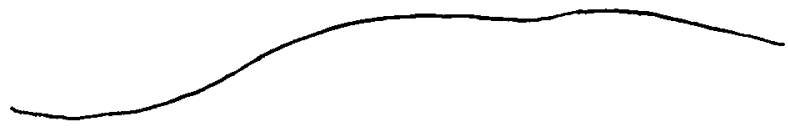

prim. hipp.

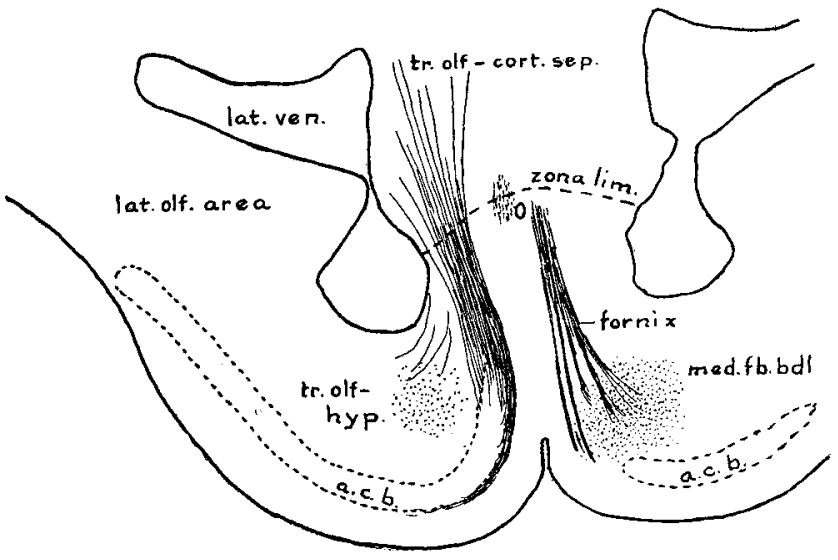

Fig. 34 Seyllium canicula, a drawing combined from several transverse sections to show the relatons of the fornix and the tractus olfacto-corticalis septi. On the left side the tractus olfacto-corticalis septi is reconstructed from a number of sections rostral to those in which the fornix columns join the medial forebrain bundle. In those sections the fornix is cut obliquely at the level of the zona limitans. On the right side the fornix column is reconstructed from more caudal sections. The two tracts are not intermingled and the fornix joins the basal bundle near the caudal border of the basal area ("nucleus taeniae" of Kappers). 


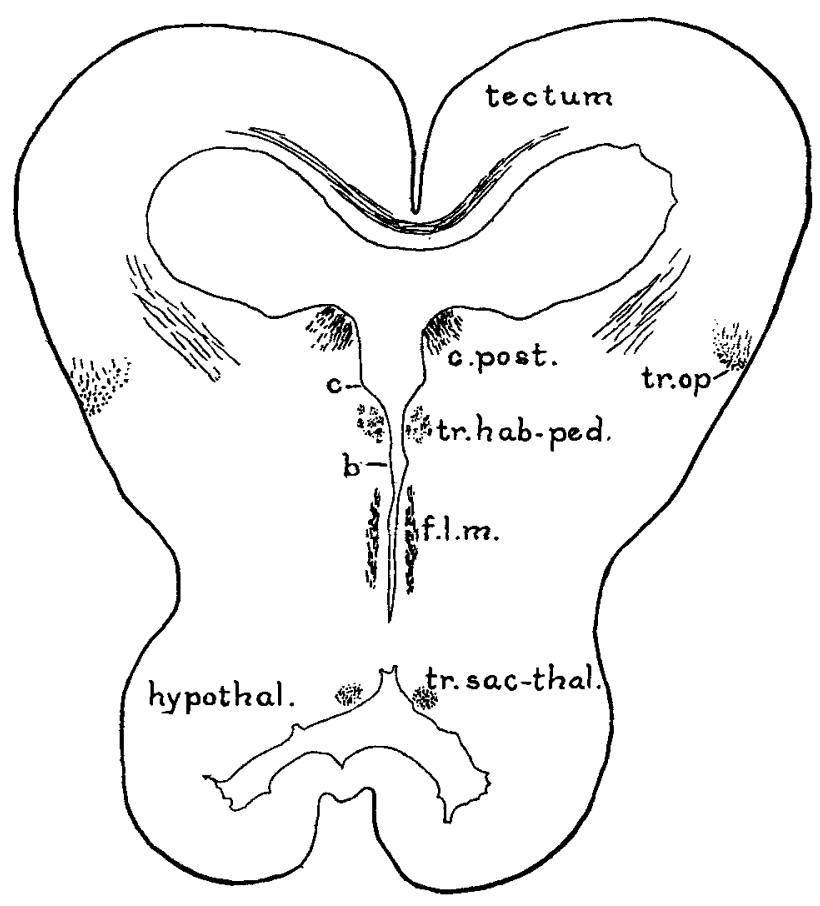

Figs. 35 to 64 A series of transverse sections of the brain of Acanthias to show the general relations of sulci and fiber tracts. All are drawn at the same magnification under the Edinger apparatus.

Fig. 35 Section through the tuberculum posterius showing the sulci $b$ and $c$ bounding the tractus habenulo-peduneularis. 


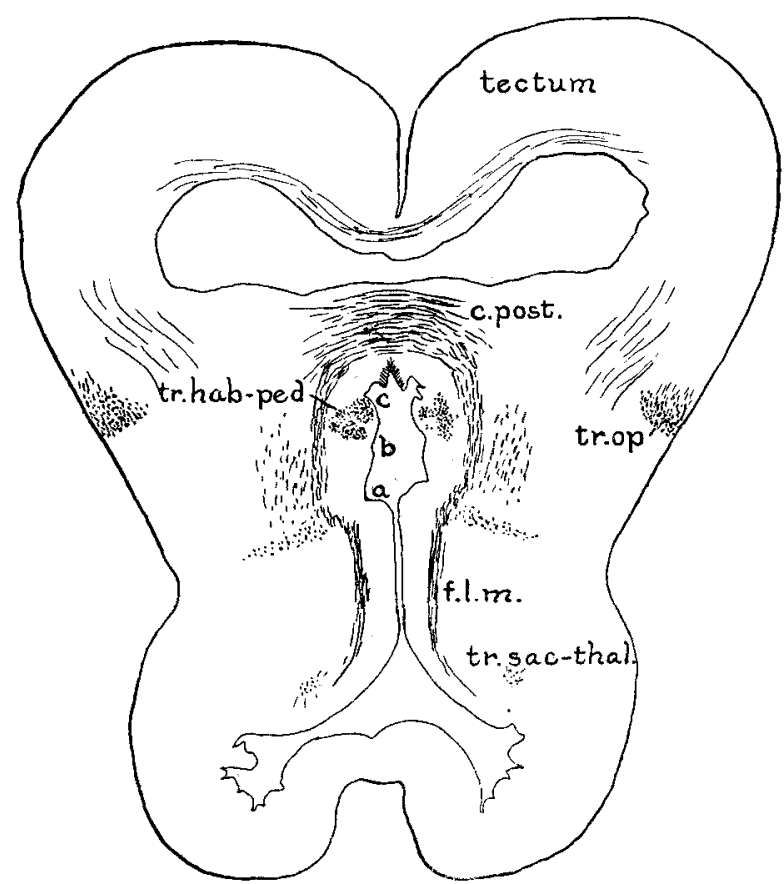

Fig. 36 Section through the posterior commissure and the nucleus of the medial longitudinal fasciculus. The sulcus $a$ appears as a deep groove. 


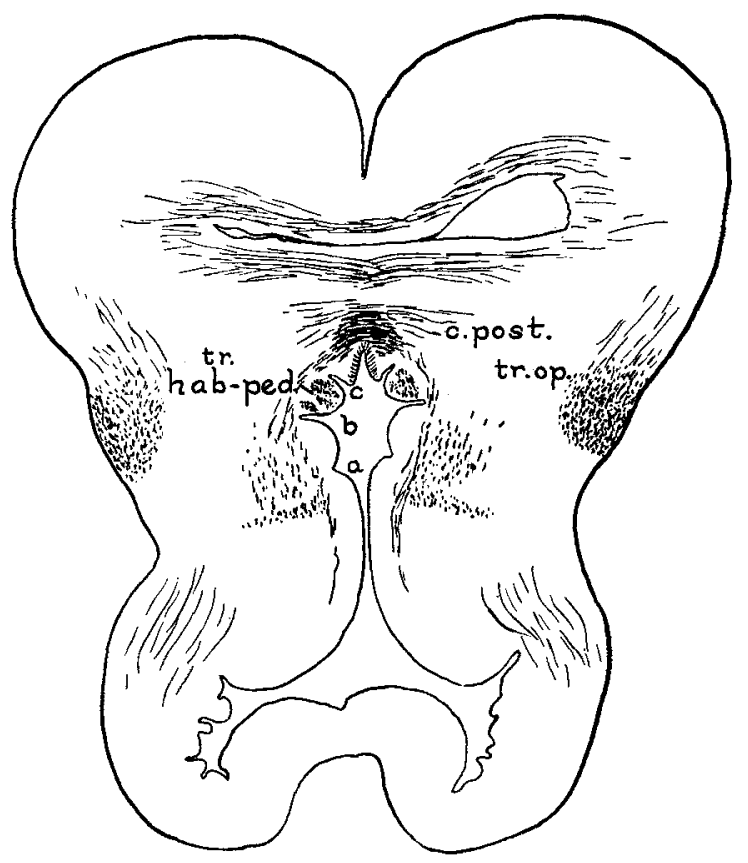

Fig. 37 Section through the posterior commissure farther forward. The sulci $a, b$ and $c$ are all deep. 


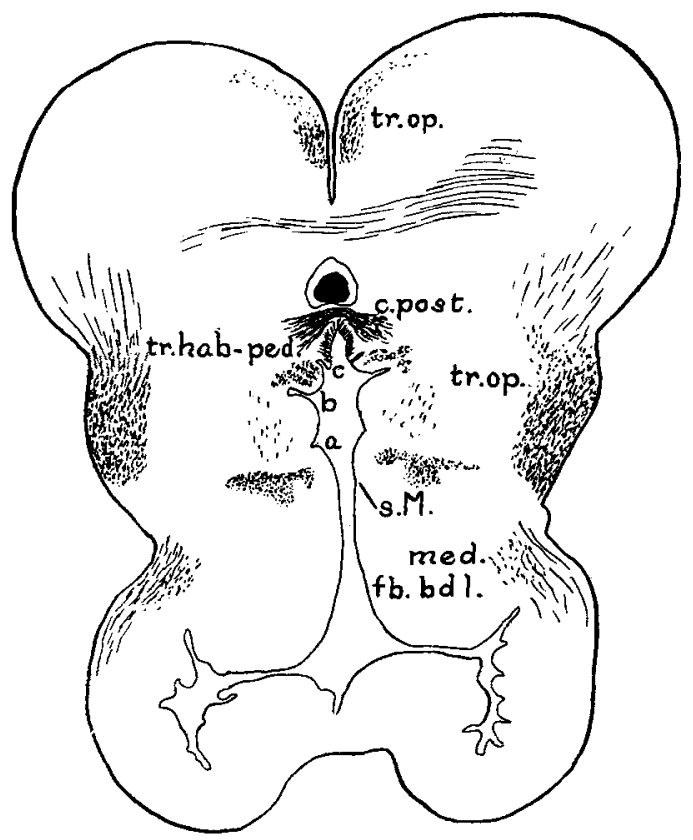

Fig. 38 Section through the rostral border of the posterior commissure. It shows the beginning of sulcus $c$ and the last trace of the sulcus Monroi. 


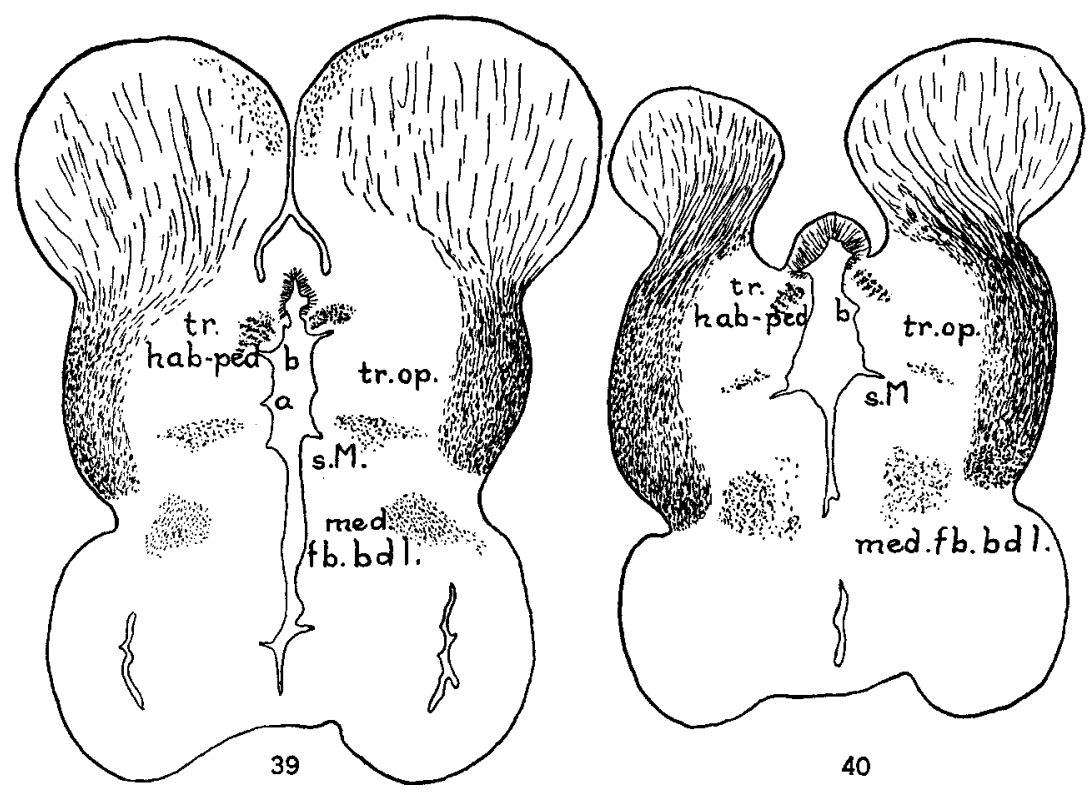

Fig. 39 Section through the "epiphysial sac" at its caudal border.

Fig. 40 Section through the "epiphysial sac" farther forward. The sulcus Monroi has deepened, sulcus $a$ has disappeared and sulcus $b$ nearly so. 

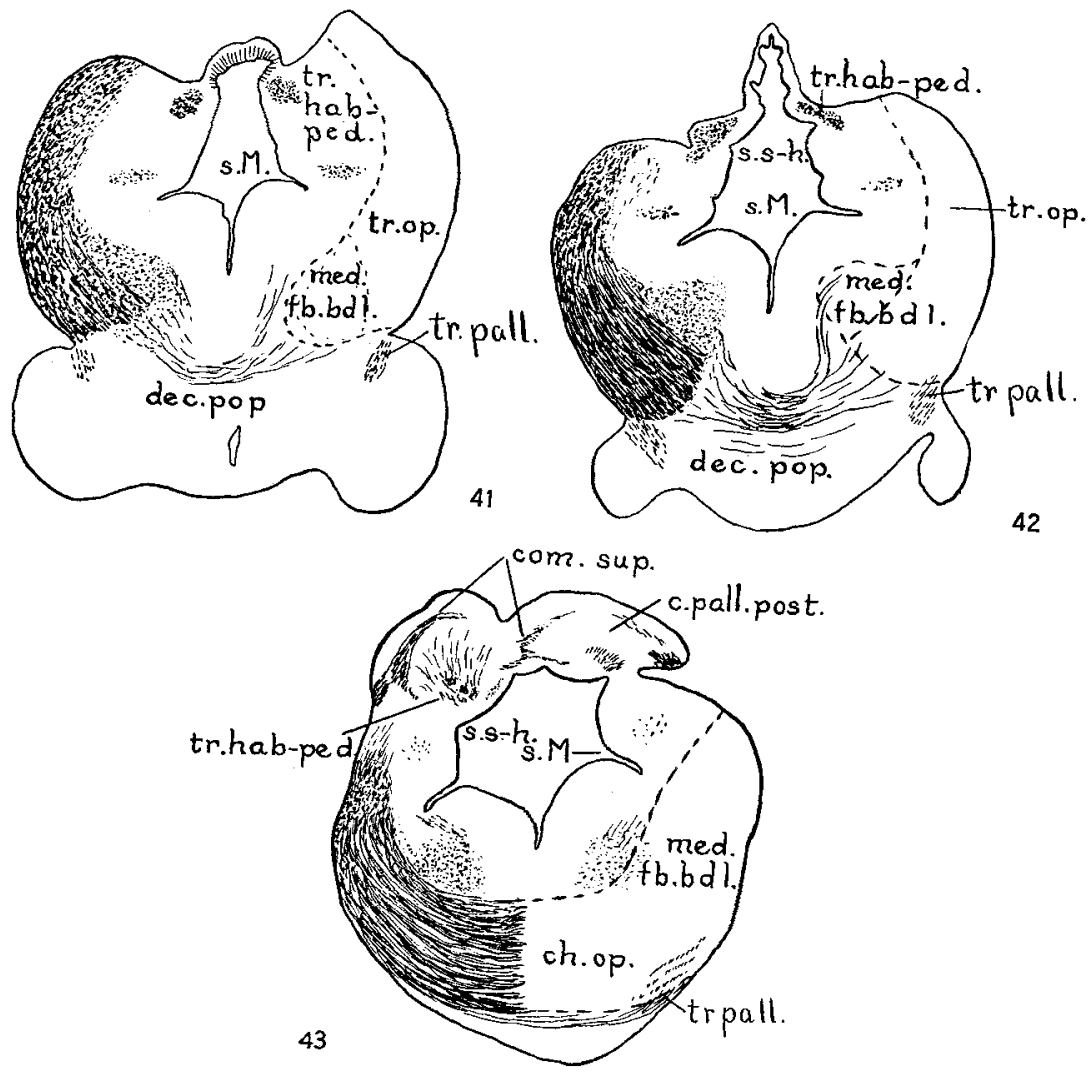

Fig. 41 Section through the base of epiphysis. The suleus Monroi is the only one present.

Fig. 42 Section through the epiphysis. The sulcus-subhabenularis appears.

Fig. 43 Section through the superior commissure (Osborn). The rostral border of the descussation of the tractus pallii is cut; the decussation lies between this and fig. 42 . 

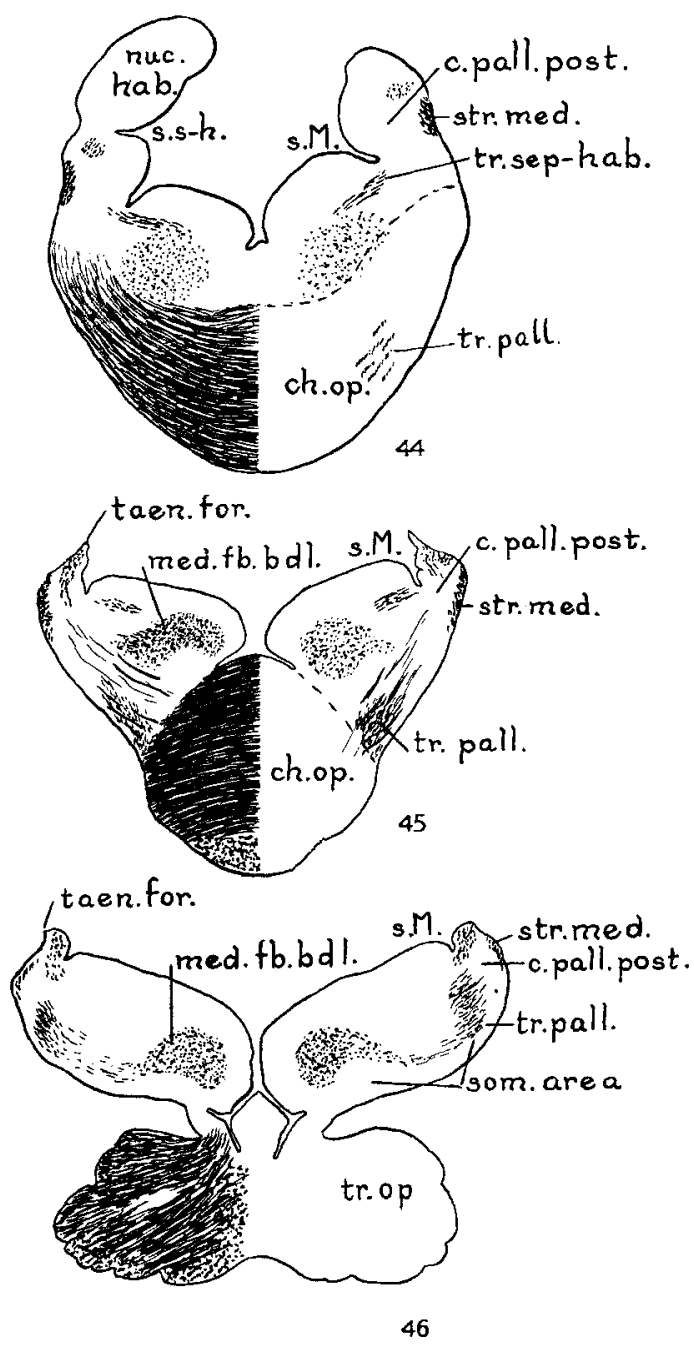

Fig. 44 Section through the rostral border of the nucleus-habenulae. Note the tractus septo-habenularis.

Fig. 45 Section through the rostral border of the optic chiasma. The tractus palli is interlaced with optic tract fibers.

Fig. 46 Section through the preoptic recess. 


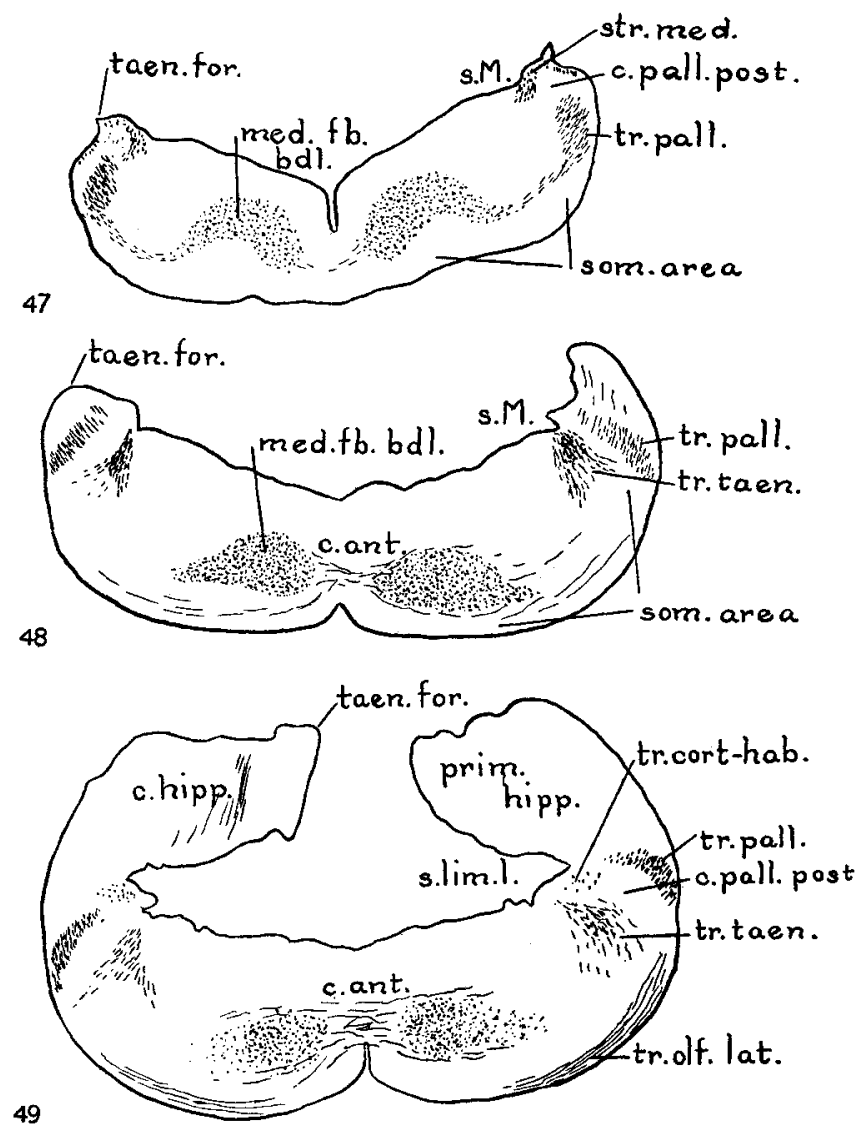

Fig. 47 Section through the narrow part of the telencephalon medium.

Fig. 48 Section through the caudal border of the anterior commissure.

Fig. 49 Section through the caudal border of the primordium hippocampi. On the outer surface of the somatic area appears the loop of the decussating lateral olfactory tract. Compare fig. 68. 


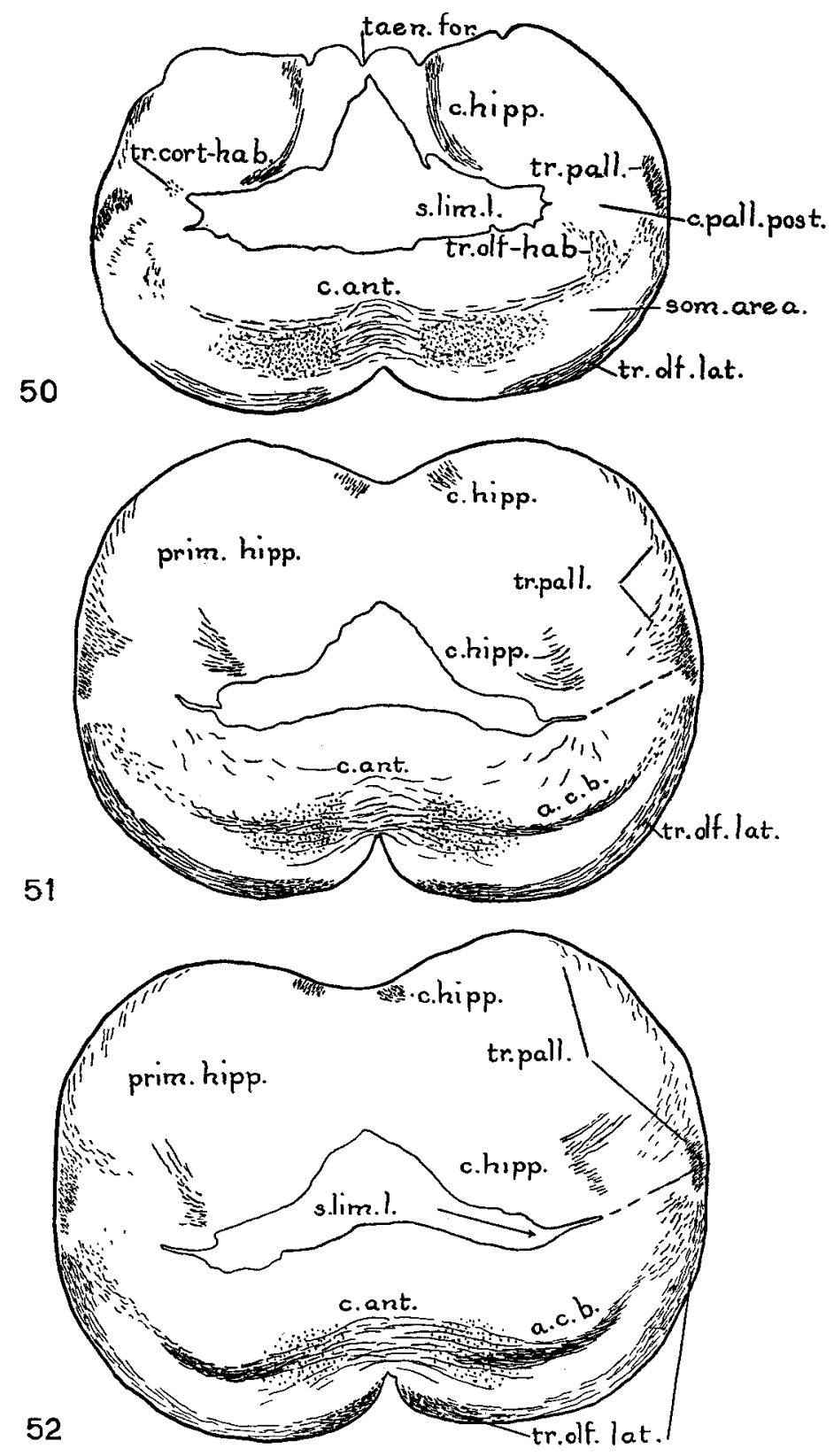

Fig. 50 Section through the caudal part of the primordium hippocampi. Note the loop of the commissura hippocampi. Compare fig. 68.

Fig. 51 Section through the rostral part of the anterior commissure and cutting the caudal border of the basal lamina.

Fig. 52 Section through the rostral border of the anterior commissure. Note in this and fig. 51 the layer of medullated fibers from the basal lamina entering the median forebrain bundle and the anterior commissure. 


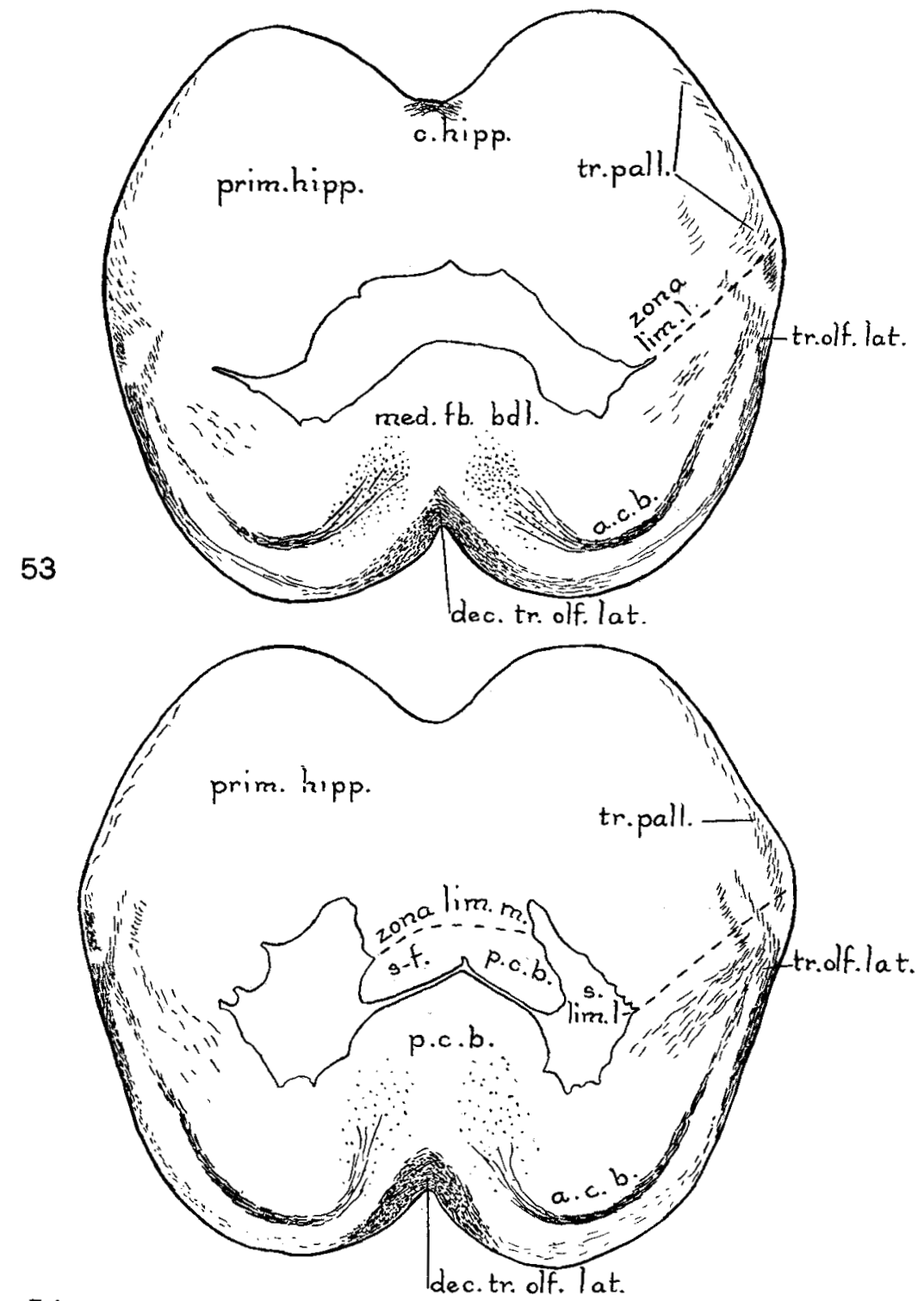

54

Fig. 53 Section through the decussation of the lateral olfactory tract. A definite zona limitans lateralis is present; it is marked by a broken line in figs. 51 to 55 .

Fig. 54 Section through the base of the recessus neuroporicus which is very long in Acanthias. Note in this and fig. 55 the supraforaminal precommissural body bounded above by the sulcus limitans medialis. 

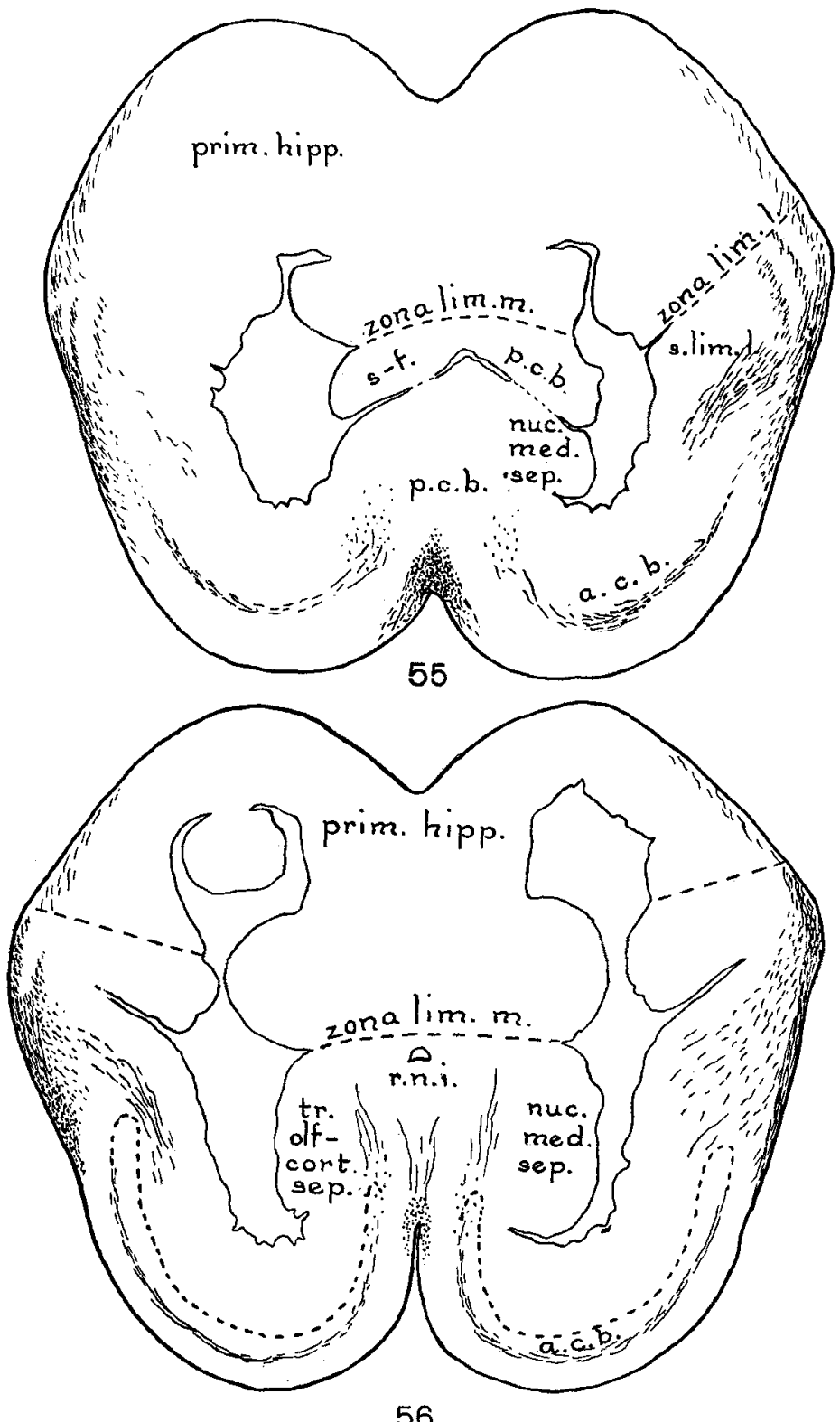

Fig. 55 Section through base of recessus neuroporicus internus. The precommissural body shows clearly a nucleus medialis septi at either side projecting into the lateral ventricle.

Fig. 56 Section near the base of the olfactory peduncle. The sulcus limitans lateralis in this and the next three figures extends laterad to enter the olfactory ventricle. The structure indicates that the lateral olfactory nucleus extends up over the base of the peduncle and the limit of the primordium hippocampi is indicated by the broken line. Compare fig. 75 . 


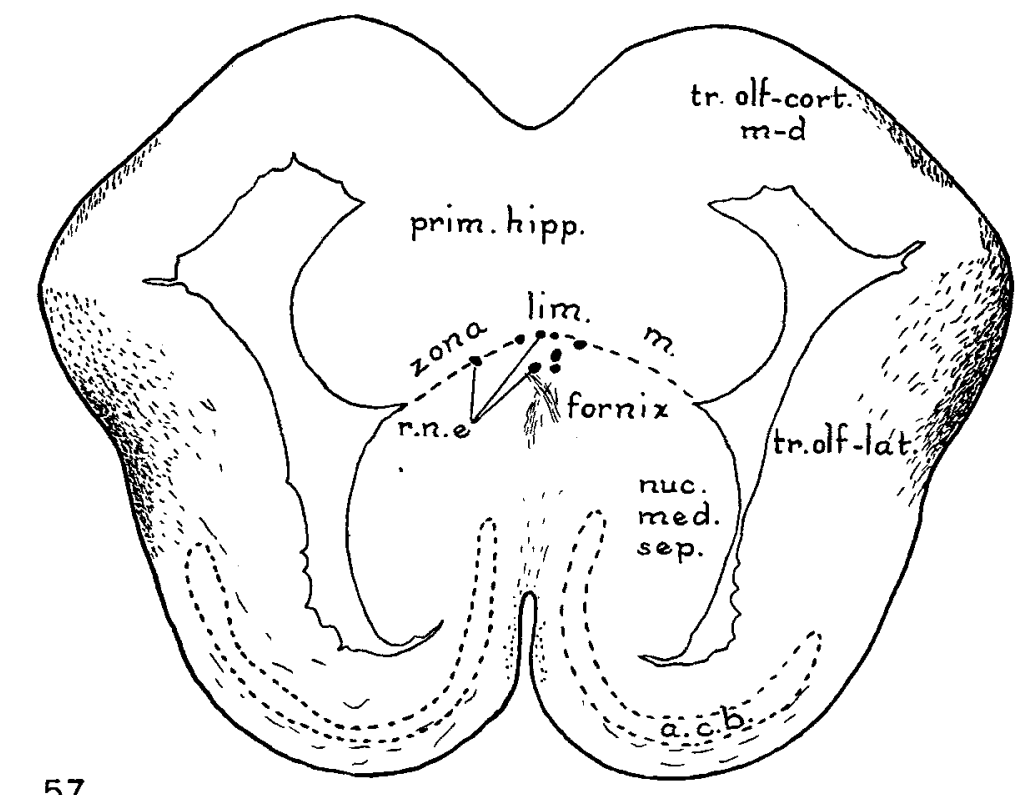

57

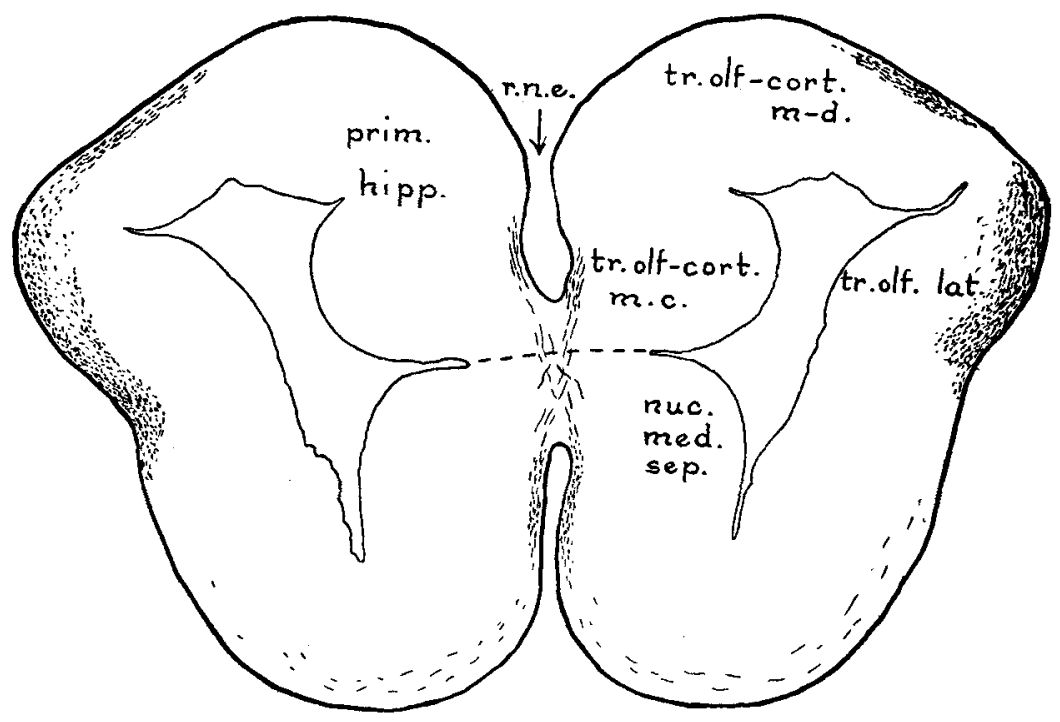

58

Fig. 57 Section just in front of the recessus neuroporicus internus. The tractus olfacto-corticalis medio-dorsalis seems to mark the border of the primordium hippocampi.

Fig. 58 Section through the recessus neuroporicus externus where it opens to to the dorsal surface. Note the striking resemblance in these figures to the sections of the frog's brain. 

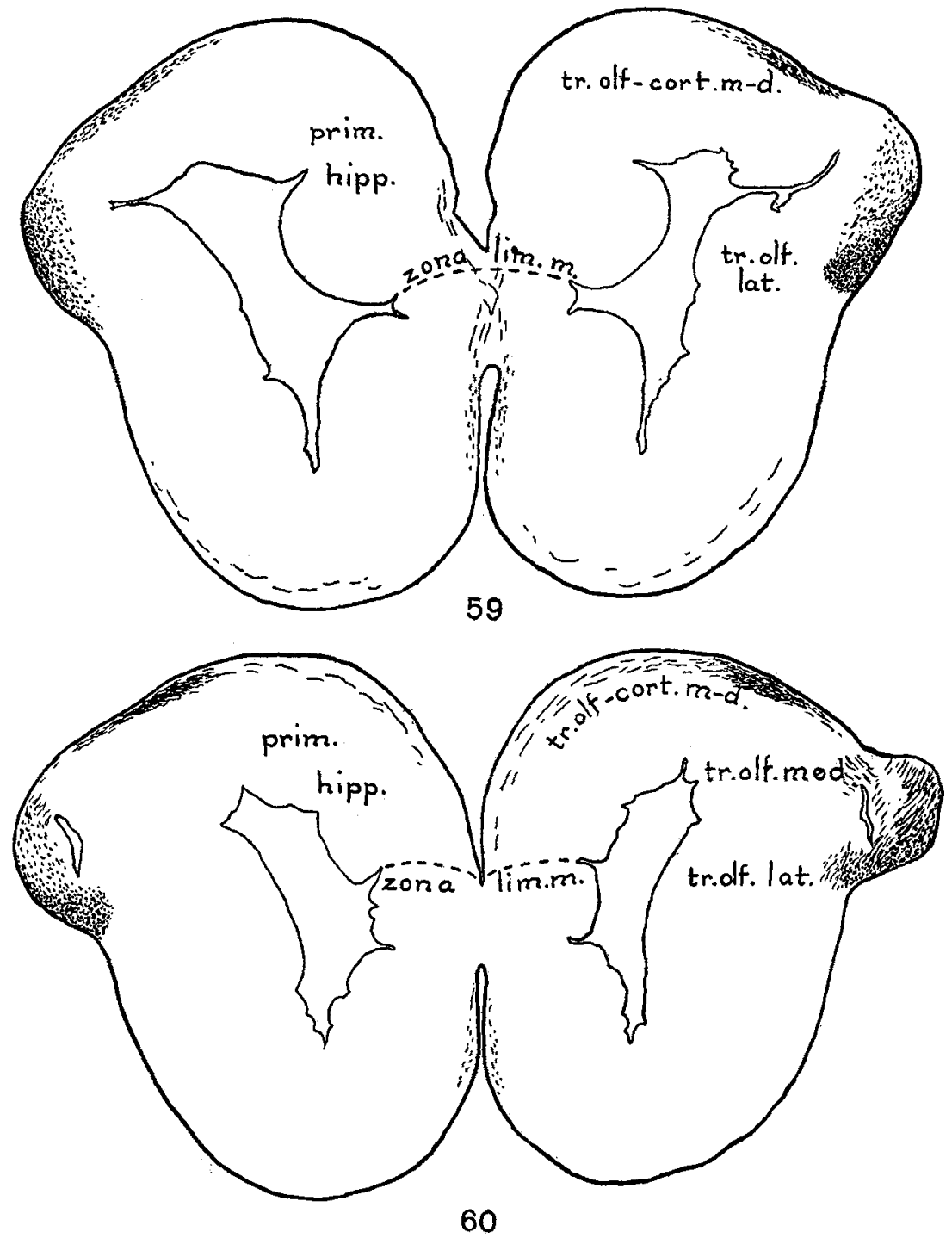

Fig. 59 to 64 Sections from the base of the olfactory peduncle forward. A new sulcus appears in the medial wall of the ventricle and from here forward the medial nucleus is in two parts. The dorsal part grows larger while the primordium hippocampi grows smaller until in fig. 63 the primordium disappears. Note the medial olfactory tract and the tractus olfacto-corticalis medio-dorsalis in these figures. 

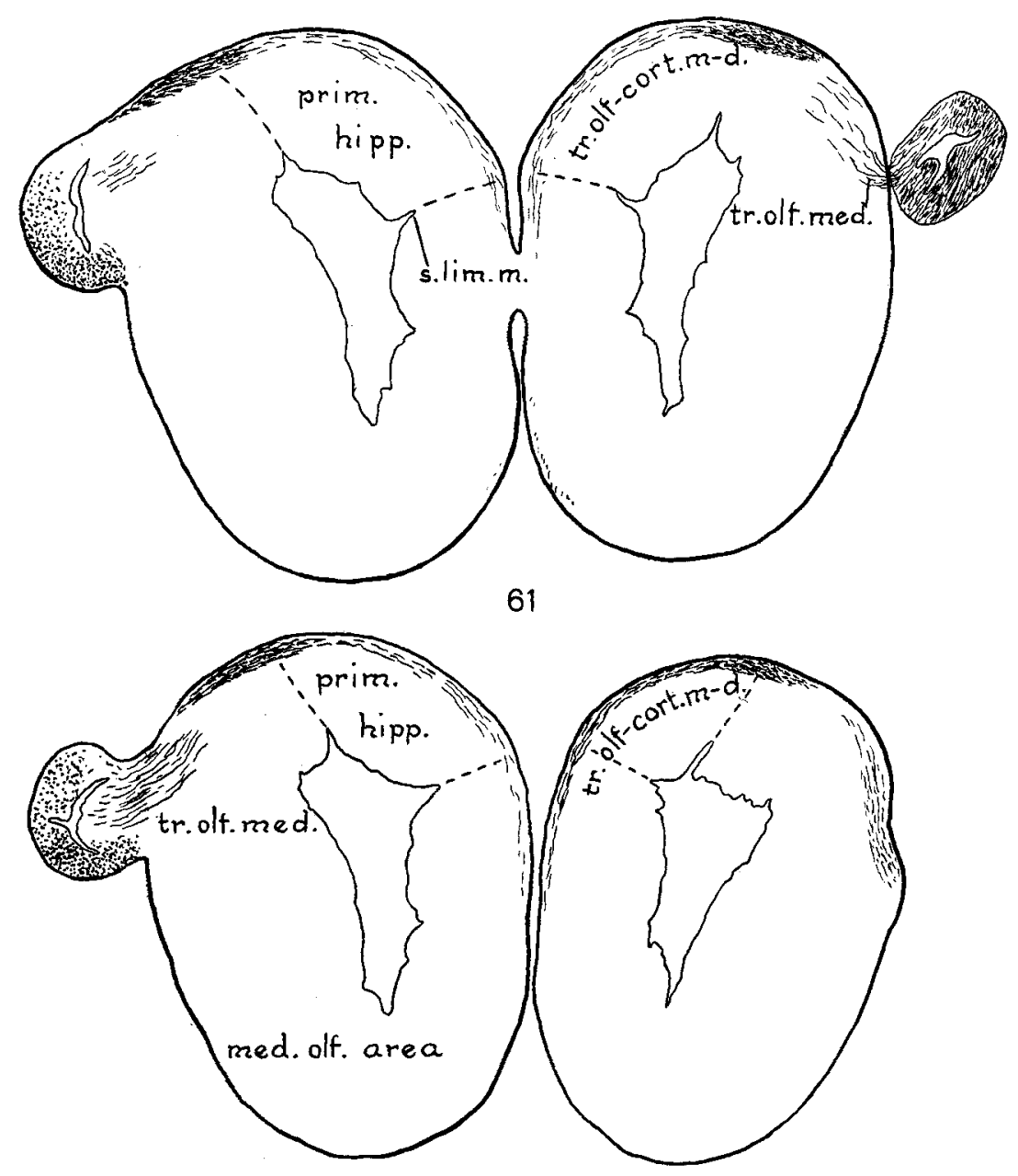

62 


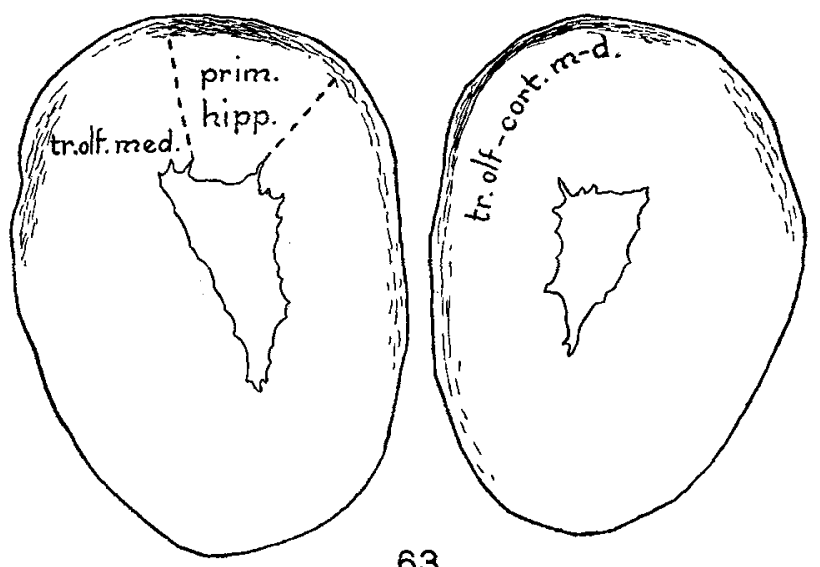

63

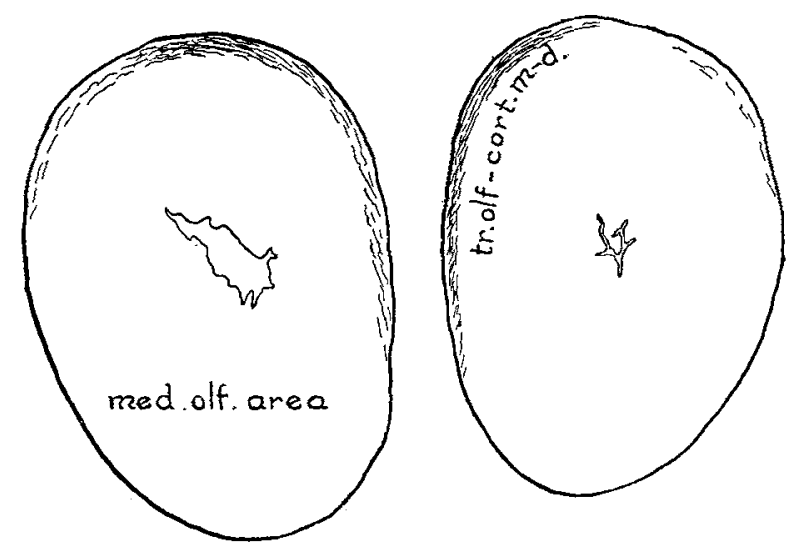

64

THE JOURAAL OF COMPaRATIVE NEUROLOGY Vol. 21 , No 1 . 


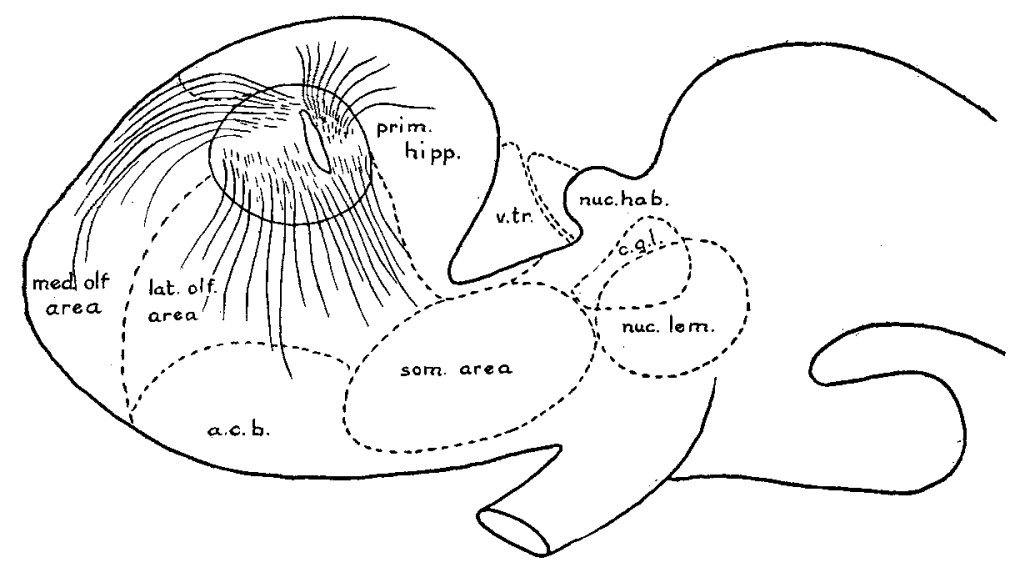

65

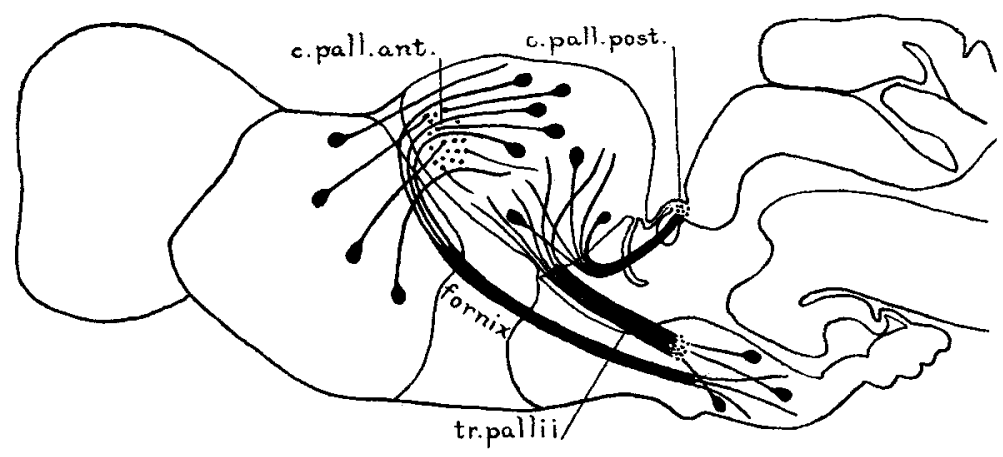

66

Fig. 65 Scyllium, outline sketch of the forebrain from the left side to show the functional areas and the distribution the olfactory tract. The olfactory peduncle is cut through near its base and the bulb removed. The position of the velum transversum is indicated by broken lines.

Fig. 66 Scyllium, diagram of the fiber tracts connected with the primordium hippocampi, projected on the median plane. 


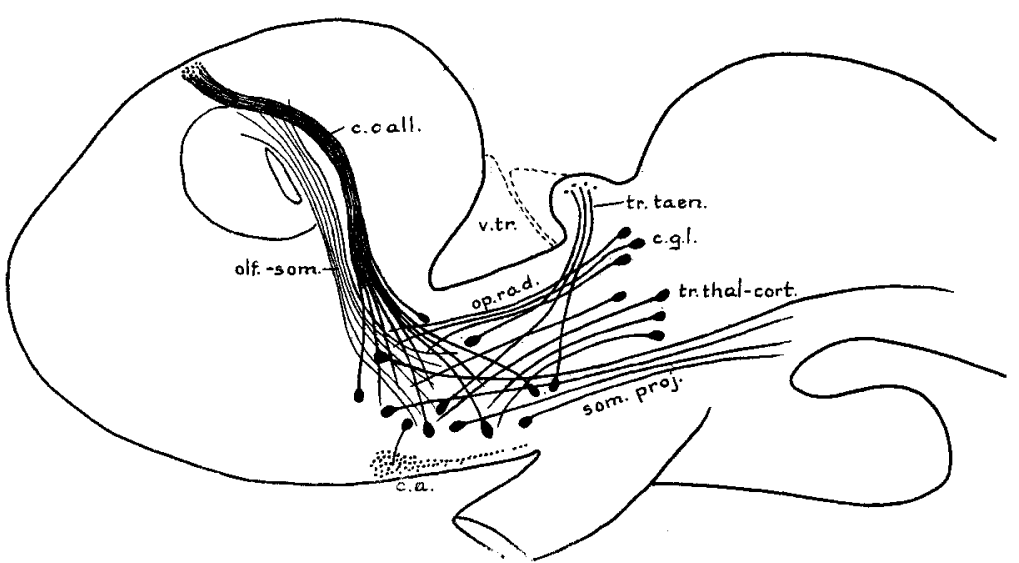

67

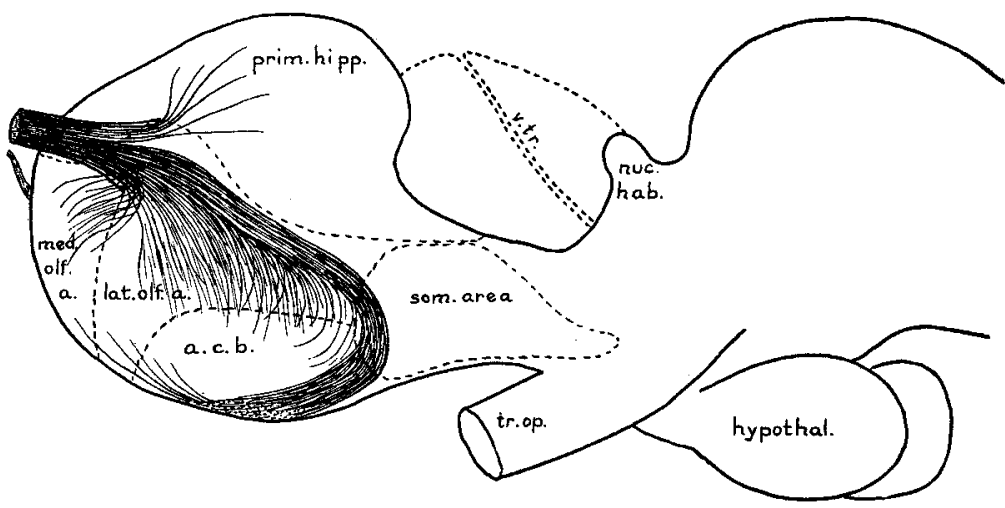

68

Fig. 67 Scyllium, diagram of the fiber tracts connected with the somatic area as seen from the lateral surface.

Fig. 68 Acanthias, outline sketch of the forebrain from the left side to show the outlines of the functional areas and the distribution of the olfactory tract. 


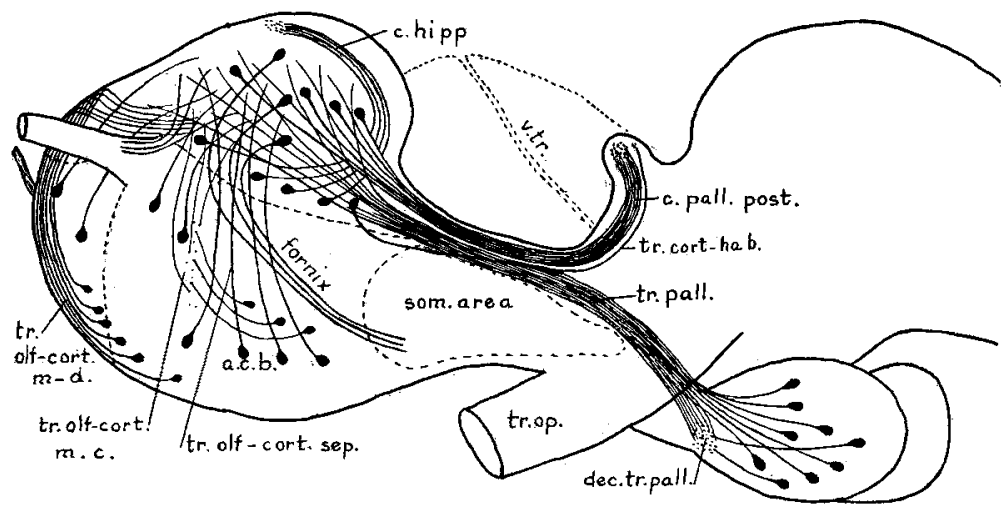

69

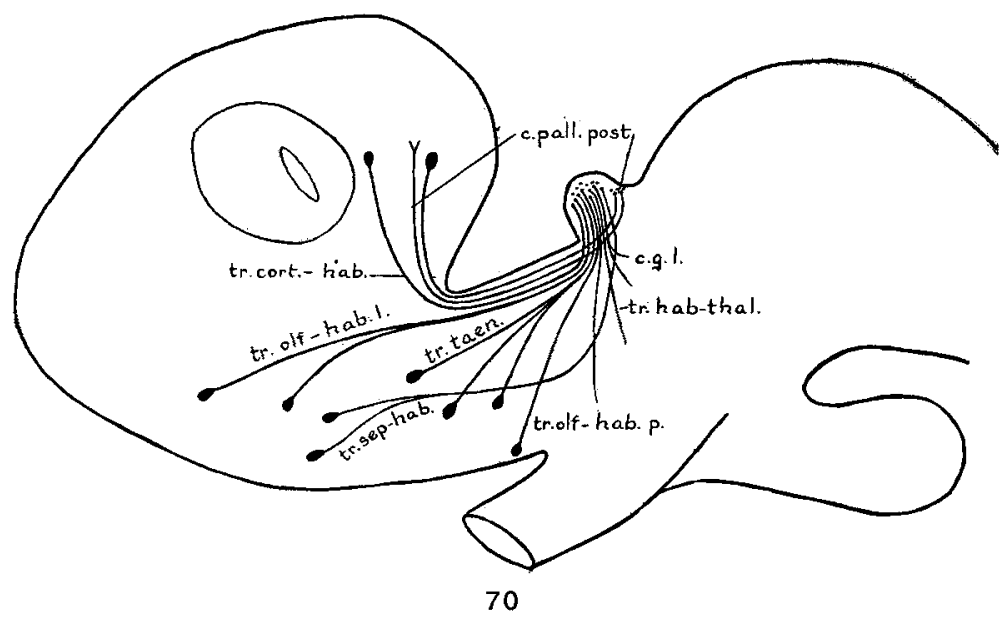

Fig. 69 Acanthias, diagram of the fiber tracts connected with the primordium hippocampi shown in a left Iateral view of the forebrain. It was not intended to represent the tractus pallii as in greater part uncrossed. It is probably in greater part crossed. The fibers arising in a.c.b. constitute the tractus olfacto-corticalis septi. Note the presence of the tractus olfacto-corticalis medialis cruciatus and tractus olfacto-corticalis medio-dorsalis which have not been seen in Scyllium. On the other hand, the hippocampal commissure seems to be much smaller in Aeanthias.

Fig. 70 Diagram of the several components of the stria medullaris based on Scyllium. There are present: commissura pallii posterior, tractus cortico-habenularis, tractus olfacto-habenularis lateralis, tractus septo-habenularis, tractus olfacto-habenularis posterior, tractus taeniae, tractus habenulo-thalamicus. The last includes a number of bundles which require further analysis. Some of them enter the lateral geniculate body, others go farther ventrad. 

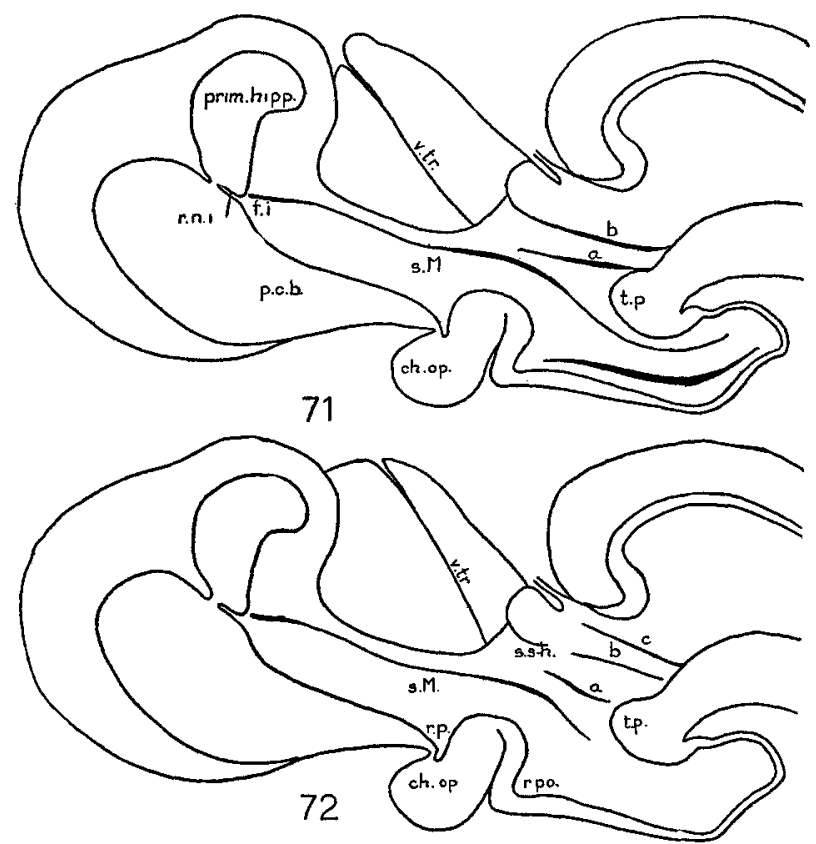

Fig. 71 Sketch of ventricular sulci in Squalus acanthias of the Atlantic Coast. Drawn from the bisected brain.

Fig. 72 Reconstruction of the ventricular sulci in the brain of Acanthias vularis from the Naples Station, taken from serial sections (figs. 35-64). 


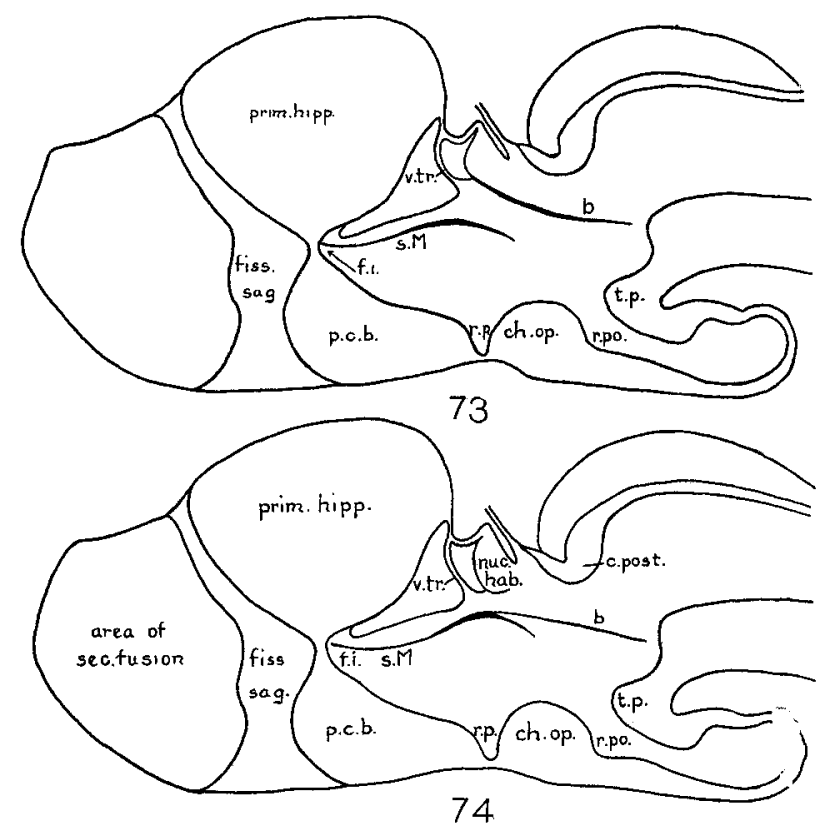

Fig. 73 Reconstruction of the ventricular sulci in the brain of Scyllium stellare from serial sections.

Fig. 74 Reconstruction of the ventricular sulci in the brain of Scyllium can cula from serial sections. 


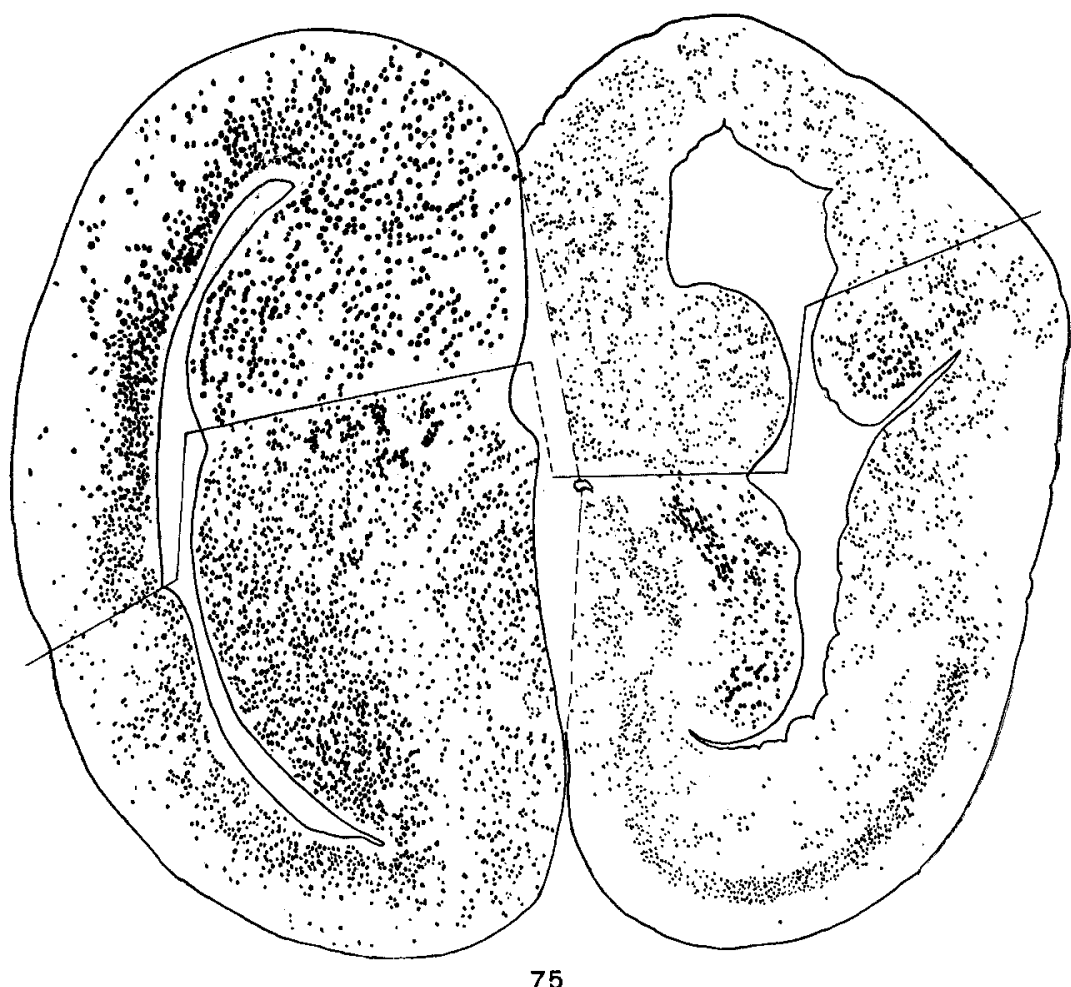

Fig. 75 A figure for the comparison of the brain of Acanthias with that of the frog. On the right is drawn the right half of the section from which fig. 56 was drawn. On the left is drawn the left half of a section through the hemispheres of the frog. The Acanthias section is magnified 30 diameters, the frog section 110 diameters. Under the Edinger apparatus the cell bodies are drawn. The drawing of the frog section is accurate and complete. In Acanthias probably some cells are omitted as the stain was less favorable. The grouping of cells is faithfully represented. In the following points the two sections agree very closely; sulcus and zona limitans medialis, the projection of the primordium hippocampi into the lateral ventricle, the nucleus medialis septi, the area superficialis basalis. In this section of Acanthias the zona limitans lateralis is displaced or obliterated by the lateral olfactory area growing up around the olfactory ventricle. The limit of the hippocampal primordium is probably represented by the line drawn above the sulcus which leads to the olfactory ventricle. Caudal from this level this sulcus is clearly the sulcus limitans lateralis and the zona limitans lateralis lies opposite the sulcus as in the frog. In the frog the primordium hippocampi probably does not extend down in the lateral wall to the zona limitans lateralis. Some part of this wall above the zona limitans is probably occupied by the primordium of the somatic cortex. The cells in this part of the wall are smaller and present a somewhat different arrangement from that in the medio-dorsal wall which is undoubted hippocampal primordium. 

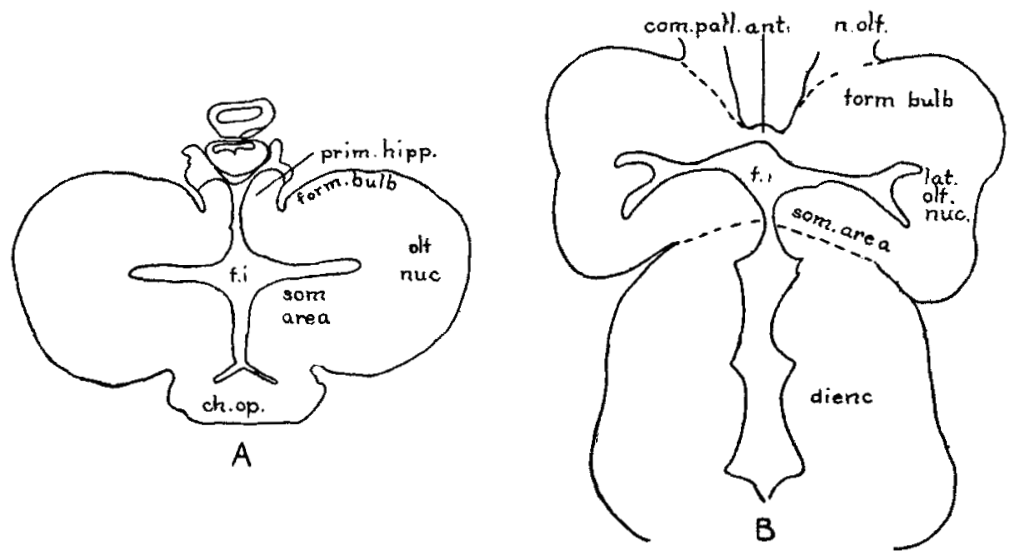

76

Fig. 76 Petromyzon dorsatus, late ammocoetes. $A$, transverse section of telencephalon; $B$, horizontal section, both through the foramen interventriculare. The broken line beneath the letters som. area in $B$ marks approximately the di-telencephalic boundary. The ventricular sulcus caudal to this is probably the expansion of the first diencephalic neuromere and is not a mark of the di-telencephalic boundary as Sterzi considers it. 

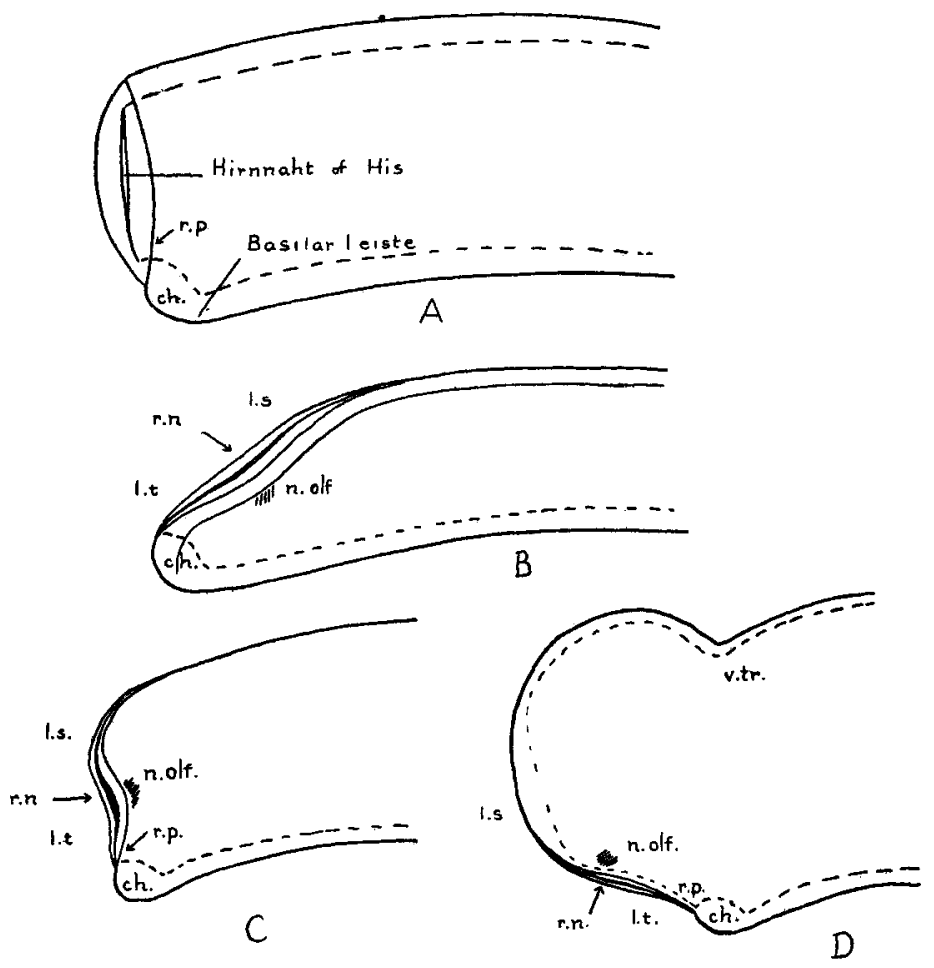

Fig. 77 Schemata to illustrate the morphology of the lamina terminalis. In $A$ is repreented the view of His and most authors, that the lamina terminalis is in reality the closing membrane of a neural tube whose dorsal and ventral seams are of equal length. In $B, C$ and $D$ is illustrated the writer's view that the lamina terminalis is nothing more or less than the rostral part of the roof plate. 

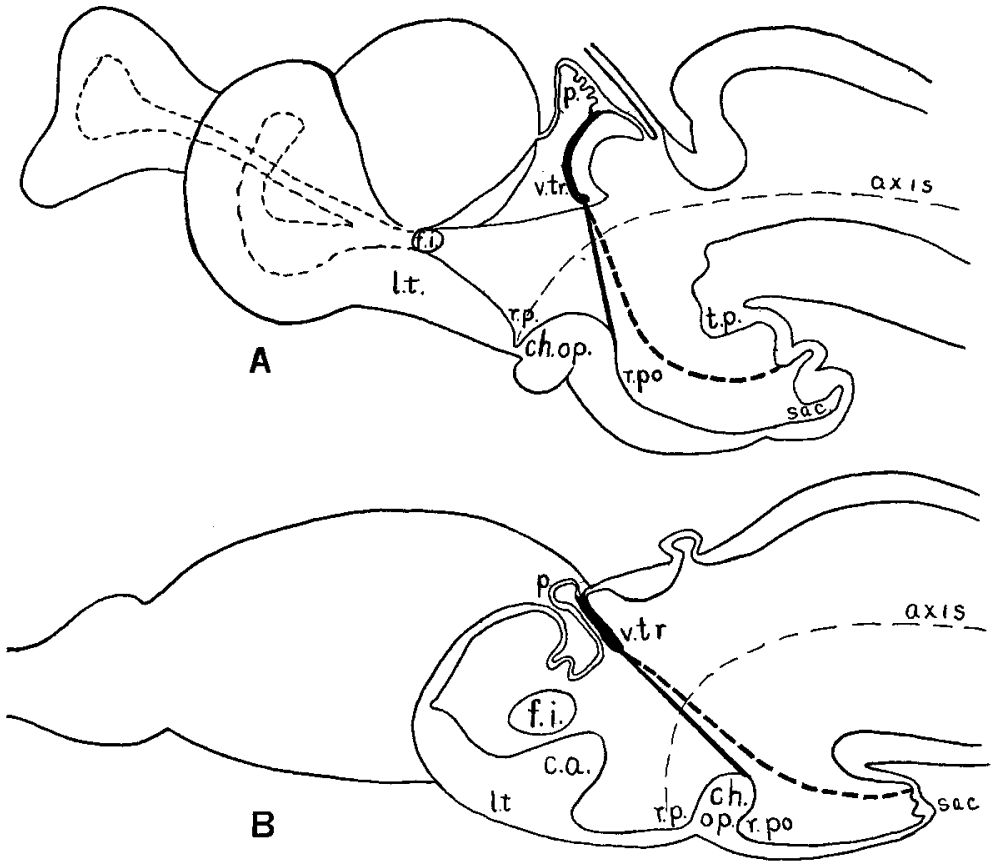

Fig. 78 Sketches to illustrate the boundary between the diencephalon and telencephalon and the position of the sulcus limitans of His. The heavy continuous line indicates the di-telencephalic boundary, the heavy broken line the boundary as defined by His. The light broken line indicates the sulcus limitans and the brain axis. It curves somewhat too far dorsad in the diencephalon. $A$, selachian; $B$, amphibian. 


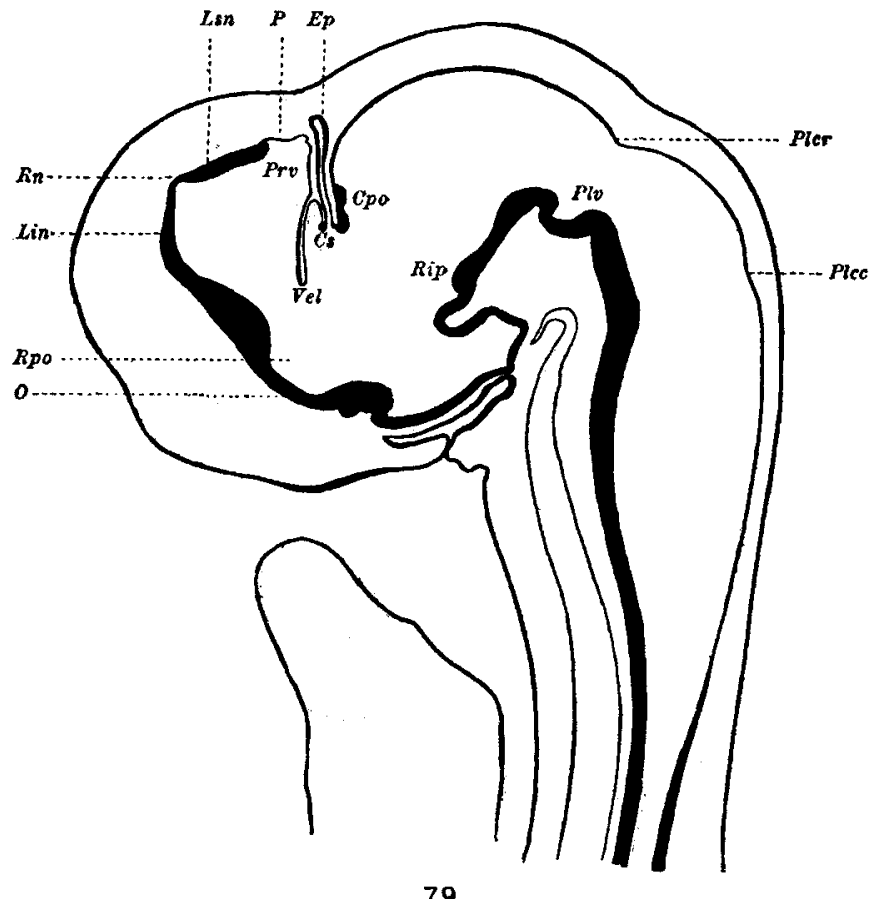

Fig. 79 Median sagittal section of the brain of an embryo of Scymnus, $4.2 \mathrm{~cm}$. in length. From Burckhardt. Note the position of the lamina supraneuroporica over the median ventricle. $L s n$, lamina supraneuroporica; $L i n$, lamina terminalis; $R p o$, recessus praeopticus. 


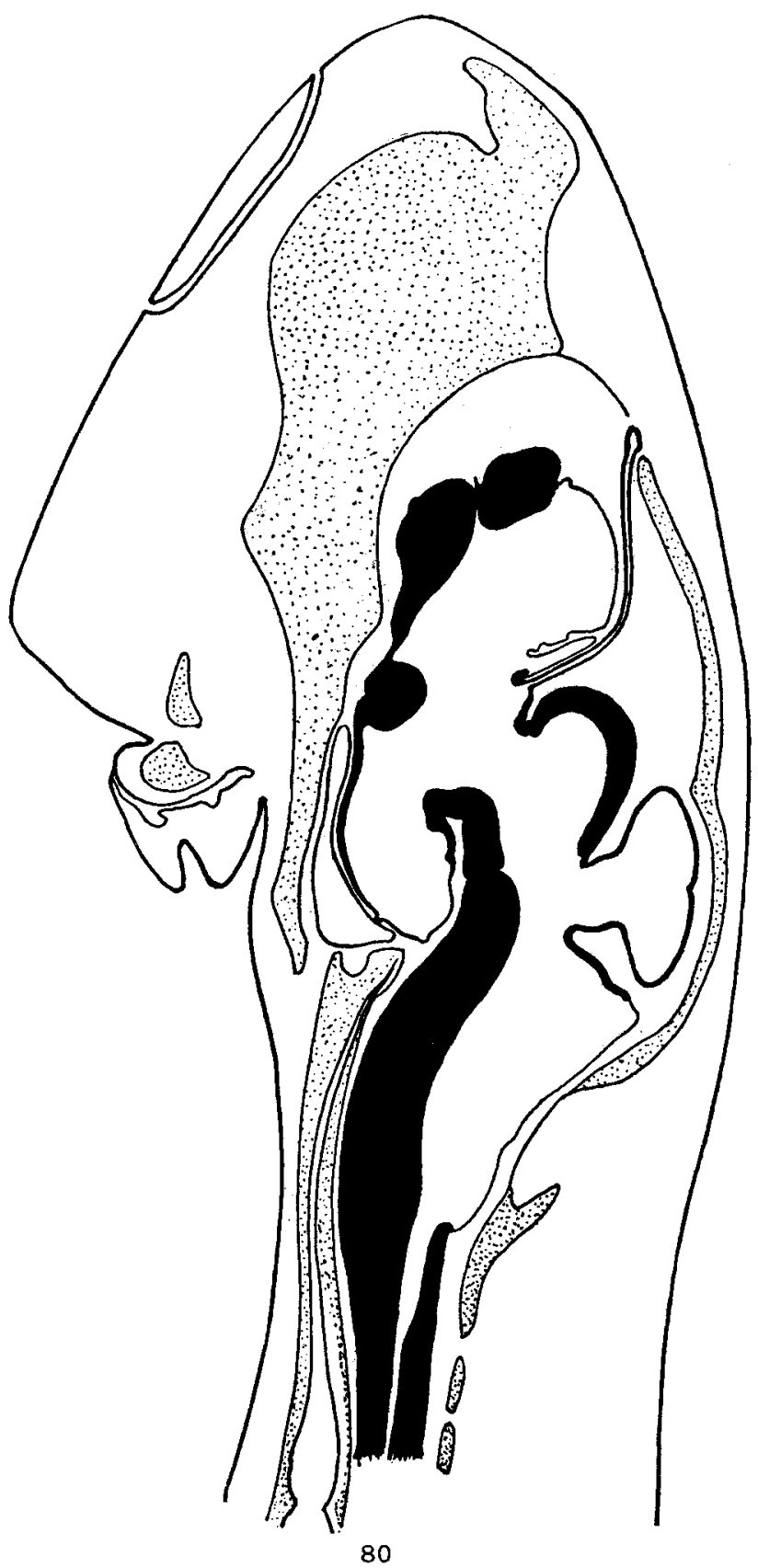

Fig. 80 Median sagittal section of the brain of an embryo of Scymnus $18 \mathrm{~cm}$.in length. From Burckhardt. Note the shifting forward of the lamina supraneuroporica. This means a moving forward of the primordium hippocampi which has gone still farther in the adult brain. 


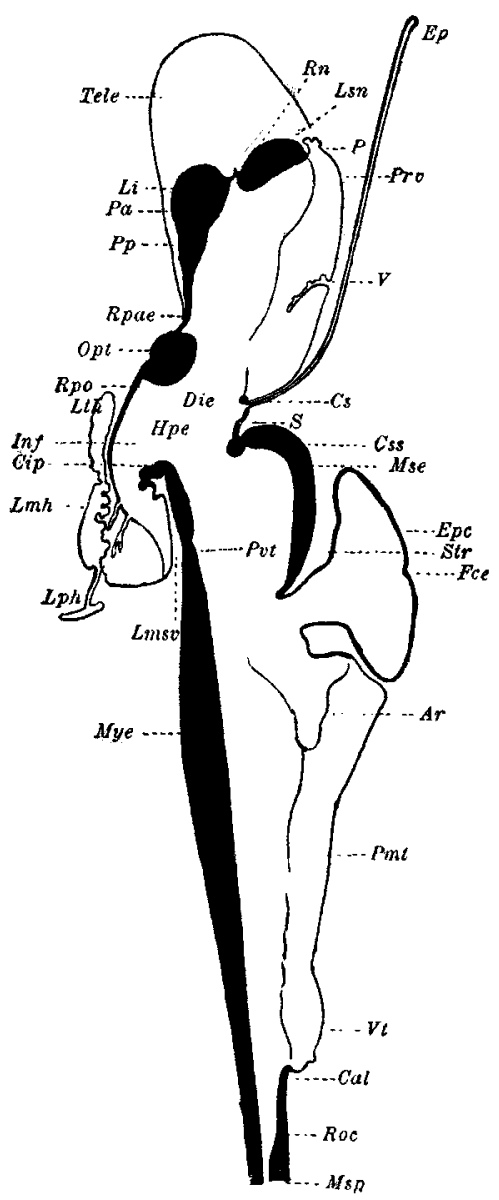

Fig. 81 Median sagittal section of the brain of an adult Scymnus. From Burckhardt. $C s$, commissura superior; $P a$, precommissural body; $R p a e$, recessus praeopticus; $V$, velum transversum. 
Fig. 82 Hypothetical primitive vertebrate. Sketch of a model of the right half of the anterior part of the brain. This model was demonstrated at the meeting of the Association of Anatomists at Boston in December, 1909. The primitive neuromeric grooves are supposed to be preserved (i, ii, iii, etc). The depression of the hypothalamus has not proceeded as far as in most vertebrates. Its deepest part is the saccus vasculosus which is already recognizable in Amphioxus. The dorsal part of the diencephalon shows the evagination of the eye and of one epiphysis. The second epiphysis which is supposed to be related to the tectum mesencephali is not shown. The eye is represented as a vesicle with wide stalk, directed dorsolaterally beneath the integument. The relation of the optic evagination to the first neuromeric groove of the diencephalon has been demonstrated in a previous paper. The groove ends below in the recessus postopticus. From the recessus praeopticus a groove leads to the foramen interventriculare. This is supposed to be continued around the wall of the lateral ventricle to the recessus neuroporicus. This is the first neuromeric groove and in selachians and amphibians forms the sulcus limitans hippocampi.

The sulcus limitans of His continues forward through the diencephalon and ends in the recessus praeopticus.

The telencephalon is not elongated, the telencephalon medium is broad dorsoventrally as in cyclostomes. The sulcus limitans of His separates the dorsal and ventral columns. The dorsal columns are very much the larger and the characteristic flexure and bulging dorsally is pronounced. The expansion of the dorsal region is due chiefly to the hypertrophy of the visceral sensory column (see text, p. 40) and this has already assumed the position which it occupies in all vertebrates adjacent to the taenia. The evagination of the lateral lobe has taken place in the first neuromeric groove and within the visceral column (olfactory area). The evagination provides for the expansion of the bulbar formation and the secondary olfactory areas. There is left in the wall of the median ventricale a large part of the visceral sensory column which curves about the interventricular foramen in the form of a letter $U$. The dorsal limb of this $U$ is the original caudal part of the column and becomes the hippocampal formation under the influence of the ascending tractus pallii. The ventral limb (lettered p.c.b.) forms the medial olfactory area and ends at the preoptic recess.

Behind the interventricular foramen the primordium hippocampi is sepatated from the somatic sensory column by a slight groove, the sulcus Monroi. The somatic area has reached its apparently anomalous position by the hypertrophy and rising up of the visceral column which has turned the somatic column out to the lateral surface.

Over the optic chiasma is an area representing the ventral columns which is larger in this model than in most existing vertebrates.

The chief changes by which the mammalian hemispheres are developed from this condition are two. The further evagination of the lateral lobes carries out nearly all the telencephalon except the ventral column adjacent to the optic chiasma. The somatic area grows enormously from amphibians onward and becomes the dominant part of the hemisphere. 


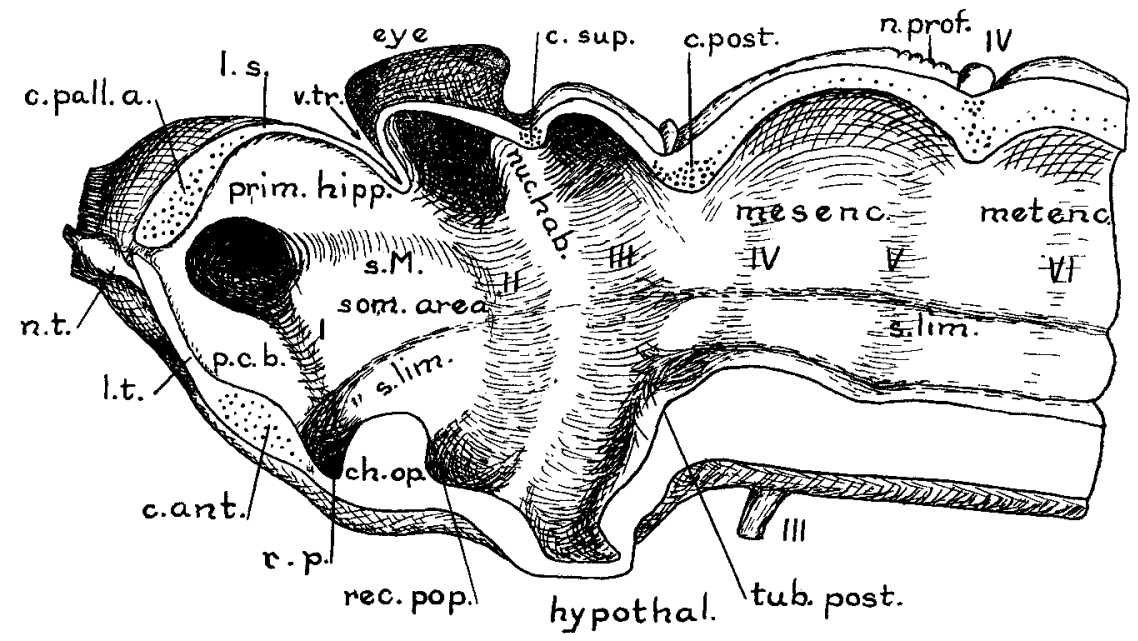

82

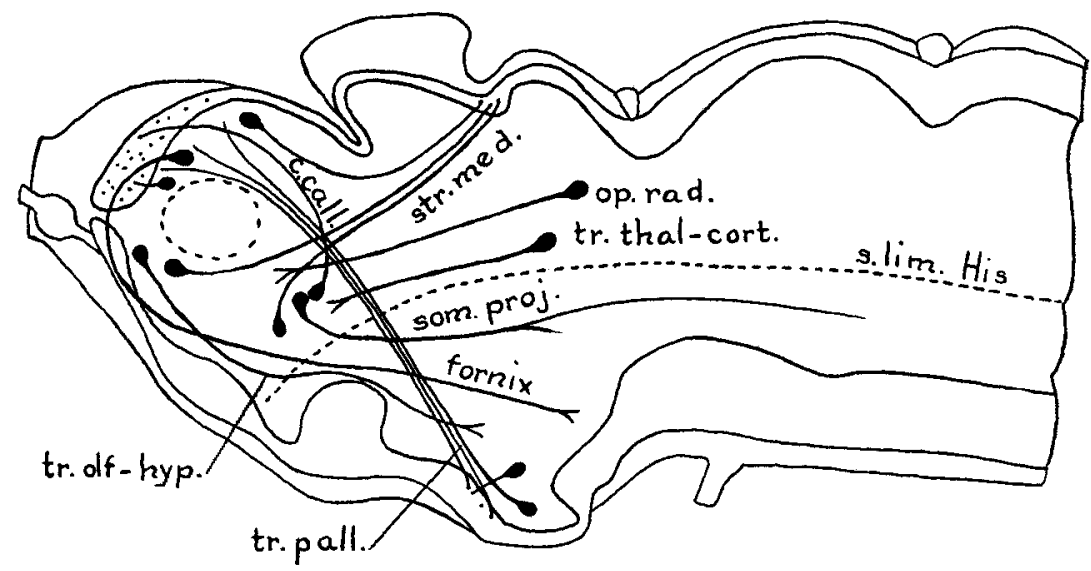

83

Fig 83 Diagram of the chief tracts of the telencephalon drawn into the outline of the above model. This makes clear that the general sensory and optic radiations and the stria medullaris are confined to the dorsal columns. The somatic projection tract and the fornix descend from the dorsal columns into the ventral columns. The relations of the tractus pallii and the olfacto-hypothalamic tracts in this regard are somewhat in doubt owing to the uncertain state of knowledge regarding the hypothalamus. 

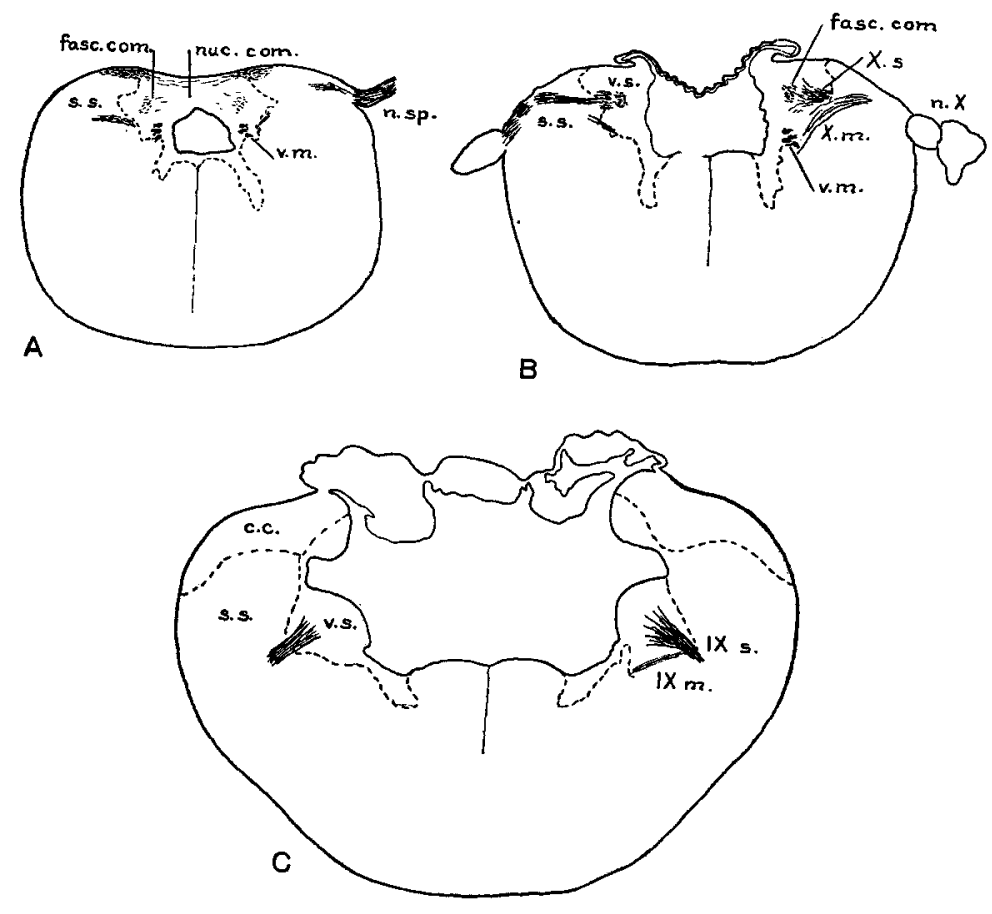

84

Fig. 84 Three transverse sections of the medulla oblongata of Scyllium canicula to show the relations of visceral and somatic sensory columns. $A$, through the commissura infima; $B$, through the caudal rootlets of the vagus; $C$, through the root of the glossopharyngeus. In $A$ and $B$ the visceral column rises to the dorsal surface and in $B$ it has the tela choroidea attached to it. Compare sections of the forebrain in figs. 13 and 47 . In $C$ the somatic sensory column is larger and overtops the visceral column. 

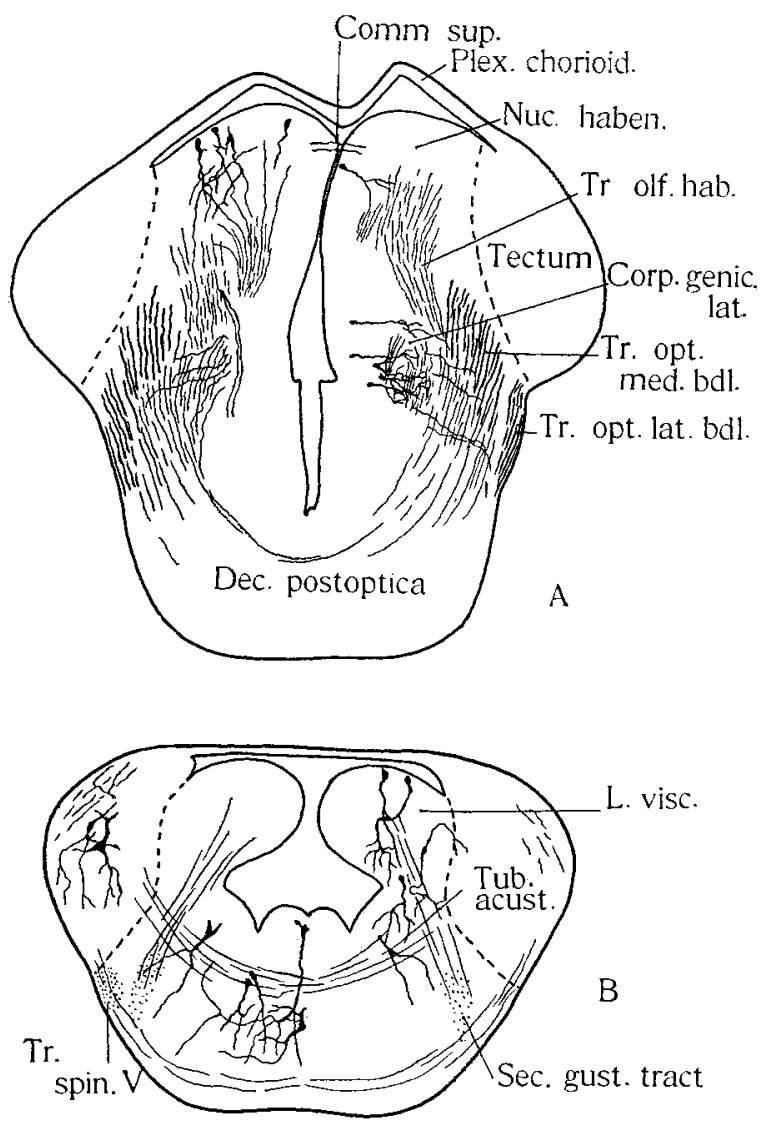

Fig. 85 Transverse sections through the brain of Amia at the level of the nucleus habenulae and of the facial lobe. The sections illustrate how the nucleus habenulae has risen to the dorsal position and pushed the somatic sensory centers laterally as the visceral sensory column in the medulla has done. From Johnston 1906.

THE JOURNAL OF COMPARATIVE NEUROLOGT, VOL, 21, No. 1 , 